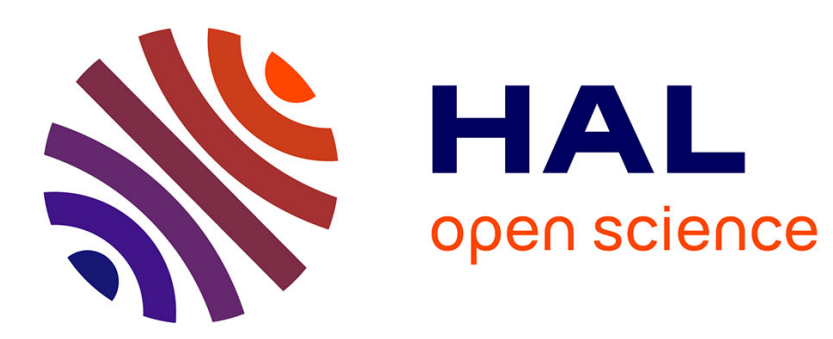

\title{
A critical review of the ultrastructure, mechanics and modelling of flax fibres and their defects
}

Emmanuelle Richely, Alain Bourmaud, Vincent Placet, Sofiane Guessasma, Johnny Beaugrand

\section{- To cite this version:}

Emmanuelle Richely, Alain Bourmaud, Vincent Placet, Sofiane Guessasma, Johnny Beaugrand. A critical review of the ultrastructure, mechanics and modelling of flax fibres and their defects. Progress in Materials Science, 2021, 124, pp.100851 (31). 10.1016/j.pmatsci.2021.100851 . hal-03427027

\section{HAL Id: hal-03427027 \\ https://hal.science/hal-03427027}

Submitted on 12 Nov 2021

HAL is a multi-disciplinary open access archive for the deposit and dissemination of scientific research documents, whether they are published or not. The documents may come from teaching and research institutions in France or abroad, or from public or private research centers.
L'archive ouverte pluridisciplinaire HAL, est destinée au dépôt et à la diffusion de documents scientifiques de niveau recherche, publiés ou non, émanant des établissements d'enseignement et de recherche français ou étrangers, des laboratoires publics ou privés. 


\section{Journal Pre-proofs}

A critical review of the ultrastructure, mechanics and modelling of flax fibres and their defects

Emmanuelle Richely, Alain Bourmaud, Vincent Placet, Sofiane Guessasma, Johnny Beaugrand

PII: S0079-6425(21)00075-X

DOI: https://doi.org/10.1016/j.pmatsci.2021.100851

Reference: JPMS 100851

To appear in:

Progress in Materials Science

Received Date:

20 July 2020

Revised Date:

12 July 2021

Accepted Date:

13 July 2021

Please cite this article as: Richely, E., Bourmaud, A., Placet, V., Guessasma, S., Beaugrand, J., A critical review of the ultrastructure, mechanics and modelling of flax fibres and their defects, Progress in Materials Science (2021), doi: https://doi.org/10.1016/j.pmatsci.2021.100851

This is a PDF file of an article that has undergone enhancements after acceptance, such as the addition of a cover page and metadata, and formatting for readability, but it is not yet the definitive version of record. This version will undergo additional copyediting, typesetting and review before it is published in its final form, but we are providing this version to give early visibility of the article. Please note that, during the production process, errors may be discovered which could affect the content, and all legal disclaimers that apply to the journal pertain.

(C) 2021 Published by Elsevier Ltd. 


\section{A critical review of the ultrastructure, mechanics and modelling of flax fibres and their defects}

Emmanuelle Richely ${ }^{1}$, Alain Bourmaud ${ }^{2}$, Vincent Placet ${ }^{3}$, Sofiane Guessasma ${ }^{1}$, Johnny Beaugrand $^{1 *}$

1. INRAE, UR1268 BIA Biopolymères Interactions Assemblages, Nantes, France

2. University of South Brittany, IRDL FRE CNRS 3744, Lorient, France

3. FEMTO-ST Institute, Department of Applied Mechanics, Besançon, France

* Corresponding author: johnny.beaugrand@inrae.fr +33 (0)2 40675277

\section{Abstract}

Prompted by environmental legislation and citizens' awareness induced by global warming effects, the market for plant-fibre reinforced composites has been growing steadily for the past $10-20$ years, as observed by the substantial increase in academic and industrial research developments. However, the transition to larger production still requires several uncertainties to be overcome. Among these uncertainties, defects in plant fibres are known to decrease the mechanical properties at the composite scale. It is therefore of interest to better understand the defects nature, origin and consequences at the fibre scale to monitor the use of plant fibres as reinforcement. In recent decades, finite element modelling has emerged in various scientific fields as an interesting tool that complements experimental characterization. Finite element modelling is even more critical for small and intricate elements such as plant fibres where standard mechanical tests require substantial adjustments and investments due to their complex ultrastructure compared to synthetic materials. The main objective of this review is to provide a novel overview of defects found in plant fibres and their influence on the mechanical properties of plant fibres based on experimental and modelling work. Through a top-down and multi-scale approach, we first describe the 
flax fibre ultrastructure with a focus on defects. Then, advanced testing methods and emerging numerical approaches that capture the complex mechanical behaviour of plants, especially flax fibres, are addressed.

Keywords: Natural fibres, dislocations, mechanical properties, computational modelling, biocomposites; multiscale

\section{Introduction}

In the present context of the growing demand for sustainable resources, plant fibre reinforcement has gained increasing visibility and hold on the market in recent years. Reliable documentation on the market volumes is scarce; however, the European Confederation of Flax and Hemp (CELC) and JEC group report of 2018 [1] highlighted that natural fibre composites represented 92000 tonnes in Europe in 2012, namely 15\% of the total European market volume when combined with wood plastic composites. Among plant fibres, flax appears as a predominant choice, with over $51 \%$ of the total fibre mass used for European automotive applications in 2012 (for a total of 29500 tonnes, excluding wood and cotton). The environmental advantages compared to glass fibres have already been indicated by life cycle analysis [2]. However, the use of plant fibres at a larger scale as an alternative is undermined by several factors that will be highlighted throughout this critical review, such as the difficulty of predicting the quality and thus mechanical performance of the plant fibres.

The botanical definition of plant fibres is as follows: elongated sclerenchyma cells of vascular plants organized into bundles [3]. The common definition encompasses more than the botanical definition since it usually describes all types of cells as long, generally thick-walled, with tapered extremities, durable and having 'high' tensile strength [3]. 
Moreover, plant fibres are traditionally classified by origin: animal, mineral or vegetal

[4]. The latter biogenic fibre elements are the most commonly used fibres in the industry of biocomposites, and among them, sub-categories differentiate the origin of the fibre based on the plant, as illustrated in Figure 1. There is also another technical classification featuring short (mainly wood) and long (mainly annual plants) fibre elements.

Among plant fibres that are of interest in the biocomposite industry, flax and hemp present interesting similarities with well-described wood fibres [5], whose research has been driven by older industrial interests [6] and their abundance on earth [7]. It is therefore of interest to call upon the knowledge acquired in last decades on these plant fibres to better investigate the behaviour of flax.

The natural character of plant fibres introduces variabilities at different levels, raising the challenging necessity to better understand their structure-property-relationship. Consequently, the need for a precise structural, biochemical or mechanical description of plant fibres has led to the development of tailored testing devices in various fields. In particular, the development of Synchrotron sources for numerous characterization techniques has permitted to push the limits of investigation beyond the laboratory scale and reach finer scales of observation. However, research gaps, including the development of innovative coupling techniques enabling in situ mechanical testing for instance and a better understanding of the composition and interactions between the biopolymers inherent to the fibre structure and especially the middle lamella that binds the fibres together, remain and will be underlined.

Moreover, particular attention has been devoted to the presence of defects, often improperly reduced to the presence of dislocations [8]. Leading to a decrease in the 
mechanical properties at the composite scale [9], their influence at the fibre scale retains research gaps that will be highlighted.

Currently, modelling has introduced ways to complete the mechanical description of various materials. Plant fibres and especially flax are not spared by this tendency, which seems of tremendous interest to overcome experimental difficulties inherent to the characterization of such small size entities. Humble beginnings arising from the wood area and extending to hemp and flax will be addressed, as well as more advanced models and gaps that require greater knowledge.

Through this review, we will first describe flax fibres in detail from a cultural point of view to their ultrastructure. We will then propose a novel description of all kinds of defects found in plant fibres and their influence on the mechanical properties through a review of experimental and modelling work. The mechanical properties and numerical approaches to capture the complex mechanical behaviour of plants, especially flax fibres, will finally be addressed.

\section{Description of the flax fibre material down to its ultrastructure}

\section{A. Culture and fibre extraction}

In the category of non-wood fibres, flax is an annual plant that is predominantly cultivated in temperate climates of Western Europe, where it is usually planted from March to April and harvested from mid-July to August. However, flax varieties and cultures are also developed in China, India, Russia, or New Zealand and have been grown for thousands of years in the near and middle east [10]. In warm climates, it can be planted in November and harvested in March [11]. The influence of environmental 
factors such as weather, soil quality or cultural practices such as the seed rate is important [12]. Flax is usually divided into two main categories: oleaginous, which is grown for its high seed concentration or use of stows for paper-making, and fibrous flax used in textiles and composites. Among fibrous flax, a panel of selected cultivars are available and may influence the fibre properties [13]; they are chosen according to the local climate and nature of the soils. Only a few mechanical steps are required after harvesting the stems to obtain fibres of proper quality (Figure 2).

After harvesting, pectin-rich region degradation leads to the separation of the bast fibres from the rest of the stem (epidermis and shives) during a process called retting. This process consists of the partial selective degradation of the plant constituents by a panel of specific enzymes secreted by different microorganisms from bacterial and fungal communities [14]. This degradation influences both the yield and the quality of the product [15]. The aim of retting is to degrade the middle lamella (ML) without damaging the primary and secondary cell walls of fibres. Under-retting leads to bundles contaminated by shives and cuticularised epidermis, whereas over-retting results in excessive decomposition by enzymes that lead to degradation of the fibre cell walls [11]. The degradation of fibre cellulose is indeed an issue from a mechanical point of view. However, the individualization of bundles leads to better mechanical properties at the composite scale due to cleaner surfaces promoting adhesion with the matrix and an increased aspect ratio, among others [16]. Thus, field retting requires the best possible compromise and is only possible with substantial cultural knowledge. Several retting methods exist that more or less solve these issues. The main ones are water retting and dew retting. The highest quality fibres are obtained by water retting, which is still used, for instance, in Asia or Egypt, but criticized for its environmental impact. It has been 
replaced with dew retting in Europe since the beginning of the twentieth century due to the implementation of a policy from the European Union. Stems are mowed and left in the field to undergo microbial colonization favoured by the presence of moisture and temperature. The plants are generally turned over once to achieve more uniform retting [14]. Dew retting has proven to have beneficial environmental impacts with lower labour costs and a higher fibre yield compared to water retting, but a few disadvantages exist: a decrease in the fineness and quality compared to water retting, some inconsistency resulting from different weather conditions and therefore a dependency on the climate conditions, a darker fibre colour and the occupation of fields, among others [17].

Mechanical extraction follows the retting step to separate fibres from shives and the epidermis. During the scutching stage, the stems are first broken by fluted rollers and then beaten by scutching blades to remove the shives [11]. Depending of the final use of the fibres, an additional hackling step can be performed to remove smaller impurities and separate the fibres contained in the bundles. Finally, the fibres are transformed into slivers and roving. Hackling induces a substantial increase in the fibre cost but also the environmental impact [2]; in the composite sector, it is reserved for products with high added value, such as woven reinforcement or unidirectional reinforcement. The effects of retting, scutching and hackling conditions on the composites were highlighted by Hendrickx [18]. They showed that the intrinsic effect of retting was limited at the composite scale, but difficulties may arise from the further processing of under-retted or over-retted fibres. The fineness induced by hackling showed no influence on the longitudinal properties of composites. However, it led to a substantial increase in the transverse properties, approximately $20 \%$ in the stiffness and strength for coarse hackling. 


\section{B. Structure and composition}

Flax presents a hierarchical structure, as illustrated in Figure 3. At the macroscopic scale, flax stems are composed of multiple layers (Figure 4a). The outermost layer is the cuticle, followed by the epidermis, a thin wall of parenchyma cells, bast fibres organized in bundles, a layer of cambium and finally the innermost lignified core cells, xylem cells known as shives [11]. In a simple schematic representation, the flax stem can be seen as a sandwich structure with a unidirectional layer (the bast fibres) and a central foam (xylem) (Figure 4b). In addition to the obvious textile sector, the fibres of interest for the biocomposite industry are the bast fibres because of their reinforcing properties. Shives are more commonly used as fillers, but recent studies have highlighted their reinforcement possibilities [19].

Fibre bundles consist of unitary fibres bound together by a middle lamella mainly composed of amorphous macromolecules [20], largely associated with pectin [21]. Also called technical fibres, these fibre bundles are usually made of a few to tens of single fibres [22]. At a smaller scale, a unitary fibre is a multilayer composite, measuring in the case of flax or hemp approximately 12 to $24 \mu \mathrm{m}$ in diameter and 6 to $80 \mathrm{~mm}$ in length [23]. Those ranges are broad and can vary according to a literature review, often questioning if the scattering is related to a biological fact $[24,25]$ or if it is mostly due to measurement bias [26-28]. A comprehensive review of the factors affecting the performance of flax fibres designed for composites has identified at least 27 factors [25], and the influence of genes is currently being investigated $[29,30]$.

The conventional model of an elementary fibre is a four-layers model (Figure 5a) with a primary cell wall (PCW, thickness around $0.2 \mu \mathrm{m}$ ) and then the secondary cell wall, which 
is divided in S1, G and Gn layers, based on the recent literature descriptions [31-34]. The thick cell wall G, with a gelatinous appearance due to its specific matrix similar to tension wood fibres [35], is progressively formed from the conversion of the initially developed Gn layer; the $\mathrm{G}$ layer thickness regularly increases, giving a homogeneous and compacted layer, with strong mechanical performances and at maturity, having a final thickness of $5-10 \mu \mathrm{m}$ ( $~ 80 \%$ of the whole cross section). Generally, a residual and thick Gn layer is remaining at the end of parietal maturation. Other literature works suggest alternative models with more complex arrangements and existence of transition lad layers or subdivision of $\mathrm{Gn}$ layer $[22,36]$ but the more recent papers converge on the description we propose.

In addition, the intrinsic porosity of plant fibres, defined here as the ratio between the main central cavity of most plant fibres called lumen and the overall fibre volume, is a distinctive characteristic from most synthetic fibres that also needs to be considered. It is known to have great influence on the stress concentrations and driving failure within a fibre [37]. Transversal observations of bundles or stems embedded in a resin revealed lumen size discrepancies between plant fibres (Figure 6). In the case of flax and hemp bast fibres and under optimal growth conditions, the lumen represents only a few percent of the total fibre cross-section, in agreement with its role of mechanical support. Aslan et al. [38] reported a mean lumen ratio of $1.6 \%$ for cottonised flax fibres, with $85 \%$ of the fibres having a lumen content lower than $1 \%$. More than 800 flax fibre outlines were analysed by Charlet et al. [22], leading to a mean porosity of $3 \pm 2 \%$. However, the measurements were based on images at one location along each fibre, and the stringent quantification of the internal porosities along a fibre remains a challenge. Moreover, 
smaller porosities such as cavities and sublayer delamination related to defects will be further described in Part 2A.

The unitary fibre cell wall is mainly composed of cellulose crystalline microfibrils backboned with semi crystalline areas $[7,39]$ that are embedded in a matrix composed of hemicellulose [40], lignin [41], pectin [42] and minor elements on a weight basis. The relative quantity of each of the main components of flax as a percentage of dry matter (unless otherwise specified) is detailed in Table 1. A multilayer composite model was proposed by Rihouey et al. [31] based on chemistry and immunocytochemical data. Although the minor elements are often neglected, arguably due to the large biochemistry analytical technical panel required to quantify them, the role of some of the minor elements in the mechanical behaviour of the fibres has been proven. The extractives, for instance, representing a few percent of the dry matter mass, are known to influence wood properties, as well as the visco-elastoplastic behaviour of hemp shives cells [43]. The proteins are also part of the fibre minor constituting elements [44]. Although structural proteins are fundamental in plant defence [45] and other functions [46], those proteins are known to be involved in cell wall shaping, and some are even assumed to scaffold the biopolymer network in flax [45]. Moreover, minor components of fibre also include traces of hydroxycinnamate, such as ferulic acid, as well as lipids $[47,48]$. Morrison and Akin [49] reported quantifiable amounts of sterols (0.1 to $0.2 \%)$, wax ( 1 to $2 \%$ ) and cutin ( 0.1 to $0.3 \%$ ) in flax bast fibres. Finally, mineral elements of many species are reported, generally in ppm levels in fibres, and their total amount does not exceed $1 \%$ in mass. For instance, flax fibre calcium is approximately $0.2 \%$ in dry mass [50], but some authors report up to $4 \%$ on a dry matter basis [51]. However, a possible analytical bias may question these high results, as this mass is assumed to be the ash 
after pyrolysis, which is temperature-time dependent, and not the sum of each individual mineral element species. The differences in the values reported in Table 1 may arise from the differences in terms of the genetic (variety) [52], localization along the stem [53], growth and retting conditions [54], pedoclimatic and agricultural technics [55], stages of extraction [56], processing of the fibres [57], or analytical methods [31, $51,58]$. Moreover, differences between oleaginous and textile flax varieties have been reported $[13,49,59]$. The difficulty of finding the original reports from a chain of citations also has to be highlighted $[60,61]$. One can notice that for hemp, reports often described indifferently retted or non-retted fibre elements, which is an impacting factor, especially for peptic, hemicellulosic and lignin components. It is different for flax where the reports almost always deal with retted fibre elements, unless specified otherwise. However, the scale of study and retting or extraction conditions are not always specified in detail [62-65], making the comparison sometimes difficult. For polysaccharides, the dominant biochemical compartment, three main characterization methods have been identified and have to be taken into account when comparing the results. The first two methods exploit successive chemical extractions often followed by gravimetric analysis, the Van Soest method [66] and the $\mathrm{HCl} / \mathrm{NaOH}$ route [67], whereas the third method is a global chromatographic method [23]. In terms of successive chemical extractions, the $\mathrm{HCl} / \mathrm{NaOH}$ method has proven to be less aggressive and more selective than the Van Soest method because it can differentiate the matrix and structuring polysaccharides [68]. However, it does not differentiate the polysaccharides involved. Chromatographic methods are accurate for identifying monomers, but no direct indication of their localization in the cell wall is obtained. Indeed, upstream information about biochemical structuration of the walls is required to relate the monosaccharides to their related 
polysaccharides in the cell wall [23]. However, only immunolabelling [69], immunocytochemical and histochemical reactions or spectroscopic-related methods are available [70-72] to localize the cell wall components in situ [73]. Immunocytochemical techniques were exploited by Andeme-Onzighi et al. and His et al. [74, 75] to reveal the presence of different pectins throughout the secondary wall, rhamnogalacturonan I (RGI)-associated epitopes and galactan and arabinan epitopes, and in the middle lamella and cell junctions (homogalacturonans). Recent advances acknowledge the polymorphism of extracted RG-I by atomic force microscopy (AFM) [76]. Although it is difficult to obtain the spatial localization of cell components, tendencies can be observed by histochemical reactions. In this way, some authors have proved the predominant presence of lignin in the middle lamella and cell corners $[48,77]$. Lower quantities of mixed guaiacyl syringyl lignins were also detected in the secondary cell wall [78]. According to Morvan et al. [79], the secondary cell wall of mature cells contains a high level of cellulose and 5-15\% non-cellulosic polysaccharides. Flax fibres also contain $6 \%$ to $10 \%$ water by weight [80] (at ambient $\mathrm{RH}$ close to $50 \%$ ), which is supposed to act as a cell wall plasticizer $[81,82]$ and have a high impact on the viscoelastic [82-86] and rupture behaviours $[87,88]$. Based on these qualitative observations, Figure $5 \mathrm{~b}$ shows the most probable distribution of the middle lamella, primary and secondary cell wall biochemical components. This scheme is based on the values in Table 2, calculated with the average values of overall biochemical composition from Table 1 and estimations of the widths of the different layers constituting flax according to literature survey.

\section{Ultrastructure and related investigation methods}

The ultrastructure usually refers to the intermediate scale between the nanoscopic and microscopic features. For plant fibres, the ultrastructure refers mainly to cellulose: its 
crystallinity rate and the orientation of the microfibrils according to the normal axis of the fibre in the secondary cell wall, also called the microfibril angle (MFA). The organization of the matrix components surrounding the cellulose microfibrils is also addressed as an important parameter of the ultrastructure of flax. The ultrastructural parameters influence the strength and stiffness of the fibre, their nonlinear behaviour under tensile loading and their failure behaviour. For the MFA, different measurement techniques have been developed over the years, originating from study of wood [89]. Bourmaud et al. [23] described the advantages and drawbacks of different methods. First, some authors developed AFM measurements. However, the main drawback was the need for high magnification areas leading to a lack of reference with respect to the fibre axis as well as a need for chemical pretreatment to remove the primary cell wall to be able to access the secondary cell wall structure. Scanning electron microscopy (SEM) and optical microscopy under bright or polarized light have the same disadvantage. However, these techniques still provide useful information about the arrangement of cellulose microfibrils [90]. To obtain reliable MFA measurements, X-ray diffraction (XRD) techniques at both small (SAXS) and wide angles (WAXS) appeared as interesting alternatives that require no pretreatment. The work conducted by Cave on wood fibres [91] was pioneering in the domain. This principle is based on the direct relationship between the orientation of a microfibril and the X-ray beam diffracted by any of its crystallographic planes. Indeed, cellulose crystallites reflect incident light by behaving as Rayleigh scatterers. The phenomena are observed at particular angles called Bragg angles and are dependent on the spacing between the planes. Microfibrils are composed of several cellulose crystallites, and their alignment in the longitudinal axis can therefore be measured. The work conducted by Cave allows us to measure the distribution of the 
MFA with the intensity profiles of the 002 or 040 planes of cellulose [91]. From the intensity profile, the $0.6 \mathrm{~T}$ method permits the calculation of the MFA angle [92]. Reiterer et al. [93] also developed MFA measurements of different varieties of pine using SAXS 2D charts for multiple values of the rotation angle $(\beta)$ of the sample around the longitudinal direction. The advantage of SAXS is that no assumption is needed regarding the orientation of the cellulose crystal axis with respect to the fibril axis because the technique is sensitive to the density contrast between cellulose and the lignin/hemicellulose matrix. However, standard XRD measurements provide information over a larger specimen volume. Finally, WAXS provides information about periodic structures [94], which makes it complementary to SAXS measurements. Wang et al. [92] compared X-ray diffraction and SEM methods to assess the MFA value of oleaginous and textile flax bundles. They found a good correlation between both methods ( 6.2 to $7.2^{\circ}$ by the $0.6 \mathrm{~T}$ method and 5.8 to $7.3^{\circ}$ by SEM observations). However, SEM observation requires preliminary scraping of the fibre that might damage the surface and change the structure. Another study conducted by XRD at the bundle scale by Bourmaud et al. [13] reported MFA values between 8.3 and $9.5^{\circ}$. Astley and Donald [95] reported MFA values from 11 to $15^{\circ}$ depending on the hydration level of the flax bundles using SAXS. The development of new generation synchrotron radiation sources enabled access to the microscopic level through X-ray microbeams. By scanning the samples, Müller et al. [96] obtained maps of the parameters for flax fibres by using MSAXS. A mean MFA of $3.5^{\circ}$ was determined, which was a low value compared to the literature. However, in this case, a unitary fibre was studied, whereas in most cases, the experiment was conducted at the bundle scale. An additional signal created by refraction effects at the fibre edges was also reported. Finally, Kölln et al. [97] 
investigated the inhomogeneities of flax and wood fibres by scanning microdiffraction during in situ tensile testing, revealing the potential of the technique. The investigation of MFA in specific zones of defects would be of great interest with this technique.

Moreover, the convenience of the spectroscopic techniques for determining the ultrastructure of plant fibres has been proven. First, ${ }^{13} \mathrm{C}$ cross polarization - magic angle spinning (CP-MAS) nuclear magnetic resonance (NMR) provides reliable information on the morphology and crystallinity of cellulose [98]. Deconvolution methods suited to separate crystalline and less-ordered regions of cellulose were developed by Larsson et al. [99] and Newman et al. [100]. These methods enable us to obtain rich information about crystallinity, lateral fibril and fibril aggregate dimensions and the distribution of crystalline cellulose $I_{\alpha}, I_{\beta}$ and $I I$. Bourmaud et al. found the crystallinity index ranging from approximately 52 to $56 \%$ with NMR measurements, depending on the retting degree of the flax fibres, which was lower than the XRD data [101]. Differences can be explained based on the chemical selectivity: the signal obtained by XRD includes amorphous components other than cellulose, whereas NMR enables the differentiation of the signal from cellulose. The molecular dynamics of the samples can also be characterized by CP-MAS ${ }^{13} \mathrm{C}$ variable contact time (VCT) spectroscopy, providing indications of the mobility of the components [101, 102]. The strong adhesion of cellulose crystallites, hemicellulose and pectins was highlighted by relaxation time measurements [103]. Vibrational microspectroscopic techniques such as Fouriertransform infrared spectroscopy (FT-IR) and Raman microspectroscopy have also gained interest in recent decades, allowing the coupling of chemical and spatial analyses in a non-destructive way [72]. Indeed, polarized Raman microspectroscopy demonstrated its ability to determine the orientation of microfibrils as well as the cell wall composition 
of wood [104] and hemp fibres [105] and to assess crystallinity in correlation with WAXS measurements [106]. Recently, second-harmonic generation microscopy under controlled polarised light has proven its convenience to reveal MFA inhomogeneities in flax fibres [34]. Indeed, Melelli et al. reported varying MFAs between 0 and $10^{\circ}$ for flax fibres, with a mean value around $5^{\circ}$.

Finally, in situ studies enable the combination of useful information. The combination of Raman spectroscopy and tensile loading on flax fibres highlighted the molecular stress of cellulose [107]. The widespread coupling between the XRD measurements and tensile testing allows us to collect information about the changes in the MFA upon loading [108]. The combination of AFM and Raman spectroscopy revealed changes in the cellulose structure during the thickening of fibres [109]. Indeed, microfibril aggregation seems to produce a greater indentation modulus of the $\mathrm{G}$ mature layer compared to the Gn layer.

In conclusion, experimental characterization techniques enable an increasingly precise description of the structure and ultrastructure of flax fibres. Moreover, biochemical characterization gives an overview of the composition of the cell wall in terms of cellulosic and non-cellulosic polysaccharides as well as other relevant minor elements whose functions are currently under investigation. However, discrepancy of results highlights the experimental difficulties encountered and precise localization of components across the cell-wall layers remains a challenge. Therefore, finer scales of observation and innovative couplings are still required to better understand the complex organization of plant fibres as materials. Innovative techniques such as 
multiphoton microscopy and access to synchrotron facilities are promising in this respect.

\section{Defects in the plant fibres}

Some plant fibres, such as flax, hemp or ramie, exhibit beneficial mechanical properties. However, their use in structural composites is undermined by the presence of defects, having consequences at both the fibre and composite scales. Stress concentrations might occur at the matrix-fibre interphase close to defects, as evidenced by Hughes et al. [9] on hemp-epoxy composites containing dislocations.

A. How can we define defects?

Several authors have highlighted the presence of defects in plant fibres, which is often associated with a decline in performance. However, in the literature, defects are often restricted to well-studied dislocations, as reviewed by Hughes et al. [8]. In the present review, we present a broader definition, dividing defects into two types: material discontinuity and the presence of inhomogeneity. Surface and bulk categories can further distinguish defects depending on their localization [110]. Surface discontinuities refer mainly to impurities or surface microcracks [111], whereas bulk discontinuities include cracks and interlaminar decohesion. Moreover, some defects appear without discontinuities in the bulk material. We refer to them as inhomogeneities, including morphologic defects induced by hygro-thermo-mechanic stresses (e.g., twisting and collapse) or the well-known dislocations. A schematic illustration of the different kinds of defects present in plant fibres is suggested in Figure 7. A difficulty arising in the definition of defects in plant fibres is that no geometrical references exist due to their high variability compared to synthetic fibres. The first references to dislocations, the 
most described type of defect in the literature, date back to the beginning of the $20^{\text {th }}$ century for pulp fibres. Robinson [112] observed the appearance of dislocations (slip planes) followed by buckling of wood fibres under longitudinal compression. Dislocations in flax and cotton fibres were observed by Nodder et al. [113]. The term dislocation is a reference to the crystal organization and the field of metal, where it is defined as a linear discontinuity in the crystalline organization at the crystal scale. In plant fibres, dislocations appear at a larger scale since they can provide disorder to the entire cell wall width.

Currently, dislocations are often referred to as slip planes, cell wall folds, wrinkles, kink bands or zones of microcompression $[8,114]$, but the nuances between these terms are not well defined in the literature. Qi et al. [115] investigated ramie fibres and described nodes as circumferential dislocations transversely surrounding the cell wall, whereas kinks are defined as zones where the main axis of the fibre turns approximately $20^{\circ}$, and scales represent single striations. Some authors differentiate the terms depending on the severity of the deformation [114], and dislocation lengths from a few $\mu \mathrm{m}$ to $120 \mu \mathrm{m}$ have been reported for wood. Single scales would therefore correspond to a dislocation on only one cell wall, whereas the cross shape of dislocations could demonstrate a deformation along the entire cell wall depth $[113,116]$. However, this classification is not universally accepted, and dislocations are usually defined as areas where the MFA is greater than elsewhere [117]. The dislocations seem to occur first in the secondary cell wall, as observed by Bos et al. [88] during a compression test, which is in agreement with models developed for synthetic fibres. This would explain the fact that more dislocations are visible under polarized light than with SEM, the latter technique allowing us to observe only the largest dislocations where topological changes occur due 
to the buckling of the S1 layer or damage in the entire cell wall [116]. However, the review of Nyholm et al. [114] on dislocations in pulp fibres suggests a preferential occurrence of dislocations in the S1 layer, followed by different stages of deformation affecting the S2 layer.

Therefore, dislocations can be easily observed by direct methods giving surface (bright light microscopy and SEM) or volumetric (polarized light microscopy and X-ray microtomography) information (Figure 8). Thygesen et al. [118] developed a semiautomatic method to quantify dislocations in hemp fibres by polarized light microscopy and image analysis. Polarized Raman microspectroscopy was also used by Thygesen et al. [105] to investigate the structure of hemp fibre dislocations. The authors found a different and less homogeneous orientation of the microfibrils in the dislocations than in the nearby regions, with an MFA of approximately $30^{\circ}$. Large dislocations were surrounded by transition zones of intermediate orientation (with an MFA of approximately $10-15^{\circ}$ ). No differences in the composition or crystallinity were observed, contrary to the work of Dai et al. [119], which obtained a reduction of the lignin and hemicellulose content and a decrease in the crystallinity index of approximately $7 \%$ by the FT-IR technique in defective areas. However, the sampling method should be recalled: after tensile testing, fibre segments were cut close to the fracture point, assuming a higher dislocation content in the failure areas. Robinson et al. [112] found that lignin-stained xylems of different wood species highlighted dislocation zones, which may therefore contain more accessible lignin to the cytochemical chemicals. This finding could be related to the higher accessibility of cellulose in these zones. Cellulose in dislocations was traditionally assumed to be amorphous, but observation under polarized light reveals that it is birefringent and thus crystalline [120]. Cellulose 
microfibrils seem continuous throughout dislocations and neighbouring regions. Indeed, Thygesen et al. [121] observed the straightening of hemp dislocations during a tensile test. The viscosity measurements obtained by Hänninen et al. [122] corroborated these results, as the viscosity was higher in the fibres containing more defects. Indeed, if the cellulose polymer chain (main contribution to the viscosity of the fibre solution) was damaged, the viscosity would have decreased.

Some authors also demonstrated the "loosened" structure in dislocations, which might explain the higher chemical or enzymatic reactivity of these sites [11, 122-125]. The presence of pores has been observed by several authors $[88,113,115]$; however, a direct quantification to determine an average pore size specifically in dislocations seems difficult [123]. Terziev et al. [124] studied Norway spruce fibres subjected to compression and observed the buckling of fibres together with some openings in the cell lumen wall and splits in the compound middle lamella. The morphology of dislocations was revealed in detail by Hernandez et al. [126] based on axial sectioning of hemp fibres and TEM analysis. They observed large dislocations, consisting of a complex system of smaller dislocations, and axial delamination explained the increasing width of these areas and higher chemical susceptibility. The different orientations of microfibrils and cooperative buckling were also highlighted. The weak interface between the primary and secondary cell wall layers was shown, as the delamination between two fibres occurred in the cell wall instead of the middle lamella itself. Finally, the authors found void spaces in the buckled zones that could correspond to pores, which was in agreement with the work of Zhang et al. [127]. Indeed, FIB combined with SEM observation was used by Zhang et al. to highlight the higher pore density in the dislocated area (with diameters on the order of a micron), assuming that it could 
contribute to the failure of fibres, following the "weakest link" theory. Dislocations are created when the fibre wall is subjected to uniaxial compression in the direction of the fibres [124] or bending while still behaving as organized bundles [113]. They can appear during the growth of the fibres and bundles, during the phase of intrusive growth where the fibres are physically restricted $[115,123]$, or when they are subjected to environmental stresses such as wind or drought. However, Thygesen et al. [128] also found dislocations in hemp plants grown in wind-free conditions, but wind and dry conditions triggered more and larger dislocations: 18.5 and $21.3 \%$ of the relative dislocation area compared to $12 \%$ for wind-free conditions, with the largest dislocation area of 5.7 and $6.7 \%$ compared to $3.8 \%$ for the wind-free conditions. According to the results of the same authors, the increasing number and severity of dislocations may be related to either the longitudinal compression on the stem due to wind or plant stress during cellulose biogenesis, resulting in the stopping and restarting of cellulose crystal formation and thus disorder. In terms of the mechanical properties, fibre bundles grown in wind-free conditions exhibit a higher ultimate tensile stress than fibres from windy and dry growth conditions. This decrease of strength is mainly induced by creation of sensitive defects area, induced by stress localisation, but not in opposition with the principle of thigmomorphogenesis, according to which the response to external stress would be to reinforce the properties of the natural plant [129], and especially of the cell walls; the two phenomena may be concomitant. We suggest that a threshold effect might be observed, which is dependent on the maturity degree: if the stresses to which the fibres are subjected are too great, damage might overcome the fibre reinforcement. This behaviour has already been observed for flax fibres under lodging on the opposite side of the stem, for instance, where very thin cell walls observed with lumen 
constituting over $50 \%$ of the cross-sections [130]. Plant stems analysed after drying and remoistening contained fewer dislocations than stems analysed directly after harvesting. This is explained by the swelling of the fibres, which allows the dislocations to realign. Consequently, the former discussion reveals the need to control the storage conditions of the fibres or at least the plant stem decortication processing conditions. Moreover, this introduces the idea that while dislocations might act as defects in dry fibres or at a high testing speed, they may be stress dissipating regions in wet/living state fibres or at a low tensile testing speed [105]. Finally, the possible creation of dislocations upon drying fibres was developed by Barbulée [131]. Native fibres in living stems are saturated with water. Upon drying, compression stresses might be induced by the differential shrinkage between the amorphous and crystalline phases, leading to the buckling of cellulose microfibrils.

Process-related defects are reported as the main defects appearing during postharvest treatments, such as scutching and hackling processes [132], due to bending solicitations [88]. Thygesen [133] quantified the dislocations in hemp fibres in a quantitative manner by acid hydrolysis following the work initiated by Ander et al. [134] on wood fibres. The fibres were subjected to acid hydrolysis, which occurs preferentially at weak points, such as dislocations. They classified the length of the resulting fibres and compared two apparatuses. Hernandez et al. [135] adapted this indirect method to quantify the number of defects introduced during the extraction processes of hemp fibres. According to this method, the decortication (first stage of processing) seems to create more dislocations than the other following steps, such as carding and coarse separation, revealing a threshold level for the introduction of dislocations. The creation of defects during the processing of flax fibres was also highlighted by Hänninen et al. [122] using 
polarized microscopy. They observed a substantial increase in the defect content after decortication and carding, but the influence of the two processes was not studied separately. No differences were observed with further processing (cottonisation), highlighting the possible saturation of defect creation. Thygesen et al. [57] also observed a higher decrease in the tensile strength of hemp bundles after scutching than after carding. However, the dislocations were not quantified.

The distinction between growth-induced and process-induced dislocations is still challenging to determine. Hernandez et al [126] suggested that while both might suffer from microfibril misalignments, the growth-induced dislocations might have a more compact structure, whereas process-induced defects might present more delamination and voids, leading to higher accessibility for chemical or enzymatic treatments.

\section{B. Influence of defects on the mechanical properties}

In addition to the role of genuine defects in bast fibres, several studies have highlighted the effect of dislocations on the mechanical properties of fibres. In the wood community, Mott et al. [136] observed the failure of both virgin and recycled fibres under tension using environmental SEM. They reported predominant failure at the pit fields but also on the largest microcompressions. Moreover, recycled fibres took longer to fail under constant loading and following crack initiation, which was attributed to inter-laminar decohesion allowing the S1 layer to fail in advance. Strain concentrations were also observed in the dislocation regions of spruce fibres [137]. According to Müssig [11], fracture often appears at these weak points for flax fibres during the strength test. Bos et al. [132] studied the influence of dislocations on individual flax fibres by comparing standard decorticated and hand-isolated flax fibres. The individual fibres 
were subjected to a compressive load using the loop test and to tensile testing with different clamping lengths. A higher tensile strength was observed with hand-isolated fibres, with a higher scattering as well. The scattering was reduced in the decorticated fibres because the process eliminates the weakest fibres. The failure in compression occurred due to the formation of kink bands. The creation of damage upon compression was described in detail by Bos et al. in another study involving the elastic loop test and environmental SEM [88]. The primary cell wall showed brittle failure on the tension side, whereas cracks bridged by microfibrils were seen in the secondary cell wall. Similarities were made with a model developed for carbon fibres: the damage could occur first in the secondary cell wall, and the primary cell wall helped keep the fibre together. However, since kink bands not always affect the primary cell wall, the authors could not provide an overview of the fibre damage by only observing the surface with SEM. This is also a drawback of the study conducted by Zeng et al. [138], who observed the kink band and crease formation on the inner surface of flax fibres in a tight knot. Davies et al. [139] measured the dislocations in a qualitative way as a percentage of the bright areas under polarized light. They observed a clear decrease in both the static and dynamic tensile modulus and strength of elementary flax fibres as a function of damage. Baley [140] also observed the formation of kink bands during a bending test on flax fibres, appearing on the compression side of the fibre. No straightforward relationship could be drawn between the number or shape of the defects and the resulting tensile strength. However, they witnessed crack formation in kink bands. In addition, Aslan et al. [38] found a correlation between the number of defects and the shape of the stress-strain curves (linear or nonlinear) of elementary flax fibres by comparing green and cottonised fibres. The nonlinearities seem to be enhanced by the presence of dislocations, and the 
tensile properties decrease. They also demonstrated the complex failure mechanism of the fibres influenced by both surface and internal defects, divided into transverse and longitudinal categories (Figure 9a). The enhancement of the nonlinearities related to the presence of dislocations was also observed by Eder et al. [125] on Norway spruce fibres subjected to severe compression to create artificial defects. They found a small decrease in strength (approximately 20\%) and a re-stiffening of damaged fibres upon successive loading, presumably attributed to the straightening of dislocations. The hypothesis was confirmed by Placet et al. [117], who observed the reversible re-alignment of cellulose microfibrils in dislocation zones during the last part of the stress-strain curve of individual hemp fibres. However, the phenomenon seems reversible and timedependent, and the dislocations reappeared after the tensile load was released. The disappearance of dislocations during a tensile test was also observed for unitary hemp fibres by Thygesen et al. [121] using cross-polarized light. They found no clear correlation between the dislocation area fraction and the ultimate stress or modulus of elasticity. This contradictory report has generated some doubts about the dislocation influence. One explanation to bridge the former observation with the widely reported effect of dislocations is possibly that only sparsely damaged fibres were tested. Finally, Beaugrand et al. found kink bands in hemp fibres as preferential sites for the initiation of cracks (Figure 9b) [37]. At the composite scale, Hendrickx [18] studied the influence of the processing history on the mechanical properties of composites. No differences were observed between the broken, scutched and hackled fibres and it was hypothesized that if kink bands were indeed created during the processes, the absence of an effect at the composite scale could be due to reaching the damage saturation level that could occur already during the growth of the plant. At the composite scale, flax fibre 
failures in defective areas (kink bands, nodes and scales) that could occur across an entire bundle were observed by Rask et al. [141] using synchrotron X-ray tomography.

Apart from dislocations, only a few studies have investigated the creation and influence of other types of defects on the mechanical properties of plant fibres. Placet et al. [117] compared twisted and untwisted fibres upon repetitive loading cycles and evidenced an additional increase in the stiffness for the twisted fibres during the initial loading cycle, suggesting a structural modification at the cell wall scale. Moreover, cracks and interlaminar decohesion seemed to preferentially occur in dislocations, highlighting the interdependency between these types of defects. However, to the author's knowledge, the study of surface defects such as impurities and their effect on the mechanical properties at the fibre and bundle scales are scarce. Independent surface peeling, a sublayer delamination resulting from shearing at the surface of hemp fibres, was reported by Beaugrand et al. [22]. The authors also evidenced the connection of surface flaws to the lumen contributing to the transverse cracking of hemp fibres and bundles. At the composite scale, surface defects lead to lower interface quality, stress concentrations and early failure [142-144]. Given the lack of literature and importance for the manufacturing of composites, particular attention and additional research should be devoted to the study of surface defects in the future.

\section{Including defects in mechanical modelling}

In addition to experimental observations, few studies have attempted to model the role of dislocations (Table 3). Trivaudey et al. [145] built a 3D viscoelastic model aiming to explain the nonlinearities of hemp fibres subjected to tensile loads. The strain-induced crystallization of amorphous cellulose was also considered. The first simulations showed 
that the distribution of the dislocations at regular intervals had no influence on the tensile response. Therefore, they were modelled as a group in the same area, with an MFA of $30^{\circ}$. The authors observed that the dislocations seem to reduce the stiffness of the fibres, and a larger decrease in the MFA in these zones was observed, which is in agreement with experimental observations [117]. Moreover, stress concentrations were observed at the dislocation areas under the assumption of linear elastic behaviour, whereas no discontinuities appeared under the viscoelastic material assumption [145], which was closer to the real behaviour of plant fibres. The results obtained by Trivaudey et al. are consistent with the experimental results from Thygesen et al. [121]; therefore, the controversy about whether dislocations are predominant sites of failure initiation or not is highlighted. Nilsson et al. [146] developed a finite element model of hemp and flax fibres, including large dislocations such as kink bands but also waviness of the cellulose chains. The authors showed that the dislocations seem to reduce the stiffness of the fibre. Moreover, the yielding of hemicellulose in defective areas influences the shape of the stress-strain curve by allowing local rotation of the fibre, which straightens the dislocations. Another interesting feature is that they used an elasto-plastic constitutive law for hemicellulose, highlighting its role in the S-shaped stress-strain curves of flax fibres under tension. In addition, the decrease in the elastic stiffness with increasing fibre diameter could be explained by an increase in the dislocation angle, but this hypothesis must be experimentally validated. A drawback of the study is that the fibre cross-section is assumed to be circular even though it is not, and the elasto-plastic constitutive law implemented for hemicellulose is better suited for metals. Further modelling developed by Guessasma et al. [110] revealed that delaminated areas, weakly linked to the fibres, exhibited low stress and had a limited role during loading. At the 
wood cell wall scale, Deng et al. [147] developed a model based on molecular dynamics. They highlighted the influence of the MFA on the elastic modulus in agreement with experimental data. The authors also investigated the formation of kink bands in compression. They demonstrated the importance of the buckling of cellulose microfibrils in failure initiation and the role of hemicellulose in preventing microfibrils from buckling. The bending of cellulose crystals was investigated at the molecular scale by Chen et al. [148]. They reported amorphization at the kinking point and the possibility of interconverting cellulose types $I_{\alpha}$ and $I_{\beta}$ under bending solicitation. Molecular dynamics simulations were conducted by Khodayari et al. [149], including dislocations between the crystalline regions of $I_{\beta}$ cellulose. Consequently, they observed a decrease of $25 \%$ for the tensile modulus of such a model (109 GPa) compared to the fully crystalline model (146 GPa). Moreover, new insight in the recrystallization and size distribution of dislocated segments in cellulose microfibrils was recently proposed by Khodayari et al. [150] using molecular dynamics. It provides a new perspective for a quantitative understanding on the structure of dislocated cellulose in microfibrils and the composition of the plant cell wall. It also underlines the power of meshless modelling approaches to go beyond findings based on experimental methods. Finally, a finite element analysis capturing the damage mechanisms of flax fibre-reinforced polymer composites was developed by Sliseris et al. [151]. By taking into account the defects along fibres and bundles generated using a mesh-based approach, the simulation highlighted the main damage mechanisms at the composite scale. It includes fibre failure starting at the defect locations, damage in the polymer matrix and fibre debonding at the interface with the matrix and underlines the potential of multiscale finite element modelling to understand such complex behaviors. 
In conclusion, both the growing conditions and extraction processes are proven to influence the presence and severity of defects in plant fibres. Since reinforcement materials with a high fraction of individual fibres are targeted for composite applications, the extraction processes have to be optimized in order to obtain fibres with much fewer defects than the raw material, in particular for structural parts. Indeed, several studies have highlighted the decrease in the mechanical properties and increased chemical reactivity of defective areas. However, the direct observation of defects only reveals surface characteristics; therefore, the stringent quantification of defects is still a challenge. During the last decade, AFM and X-ray microtomography have been developed to obtain local property measurements for the first technique and volume information in the latter case. However, the experiments are tedious, and the difficulty of experimentally linking the presence of defects to the mechanical behaviour of the fibre remains. In this context, the development of a 3D numerical model, which addresses the complexity of the defect geometry and properties, is of great interest.

\section{Mechanical testing of flax fibres}

A. Overview of the testing methods for plant fibres

Numerous authors have studied the mechanical behaviour of flax fibres and bundles, unfortunately these studies have been performed without systematically clarifying the scale of investigation. Several types of tests have been adapted for plant fibres. The most classical ones are summarized in Table 4 and divided into global and local testing methods, referring to the bundle and fibre or cell wall properties, respectively. At the fibre scale, the properties depend not only on the cell wall properties but also on the fibre geometry and the thickness of the cell wall. Conventional tensile testing is the most 
common test. It was adapted for wood fibres in the 1950s [152, 153], and was later adapted for other plant fibres [154], inspired by the pioneer work of Griffith [155] on the tensile testing of glass fibres in the 1920s. The main adaptations for fibres are the effort transmission mode and the way of constraining the fibre extremities. Griffith recommended using a wax to permit the reorientation of the fibre and avoid stress concentrations at the extremities. Currently, the most common method is to glue the fibres on a paper frame whose edges are cut prior to the test [156]. Tensile testing can be coupled with imaging techniques during in situ measurements. The compressive properties can be obtained with an elastic loop test consisting of straining elementary fibres placed in a loop under a microscope [132]. The compressive strength is derived from the dimensional variation of the loop. Moreover, the three-point bending method at the stem scale can lead to estimations of the longitudinal properties at the fibre and bundle scale, thus producing results that are comparable to the tensile testing results [157]. The fracture properties can also be investigated with notched specimens subjected to uniaxial tensile loading [111]. Finally, efforts have been made to characterize the time-dependent behaviour of plant fibres through creep/recovery tests $[158,159]$ for applications such as identifying viscoelastic properties.

At the cell wall scale, nanoindentation and AFM are also widely used methods to determine the longitudinal and transverse mechanical properties of the cell wall at a local scale $[23,153]$. During a nanoindentation test, the cell wall is loaded by a Berkovich-type indenter at an approximate angle of $25^{\circ}$. This test gives information about both the hardness and longitudinal and transverse modulus [23]. AFM is based on the resonation of a cantilever due to interactions between the tip and the sample, allowing the surface properties of the cell wall to be mapped. Among different 
techniques, the promising peak-force quantitative nano-mechanical property mapping (PF-QNM) provides evidence of a possible stiffness gradient of fibres [160]. Nevertheless, the results are difficult to compare to those of tensile testing; the fibre longitudinal rigidity is underestimated because of the influence of both the geometry of the tip and the transverse and shearing modulus. The method is therefore relevant for making comparisons between the samples and highlighting differences in the indentation modulus in a multilayered or heterogeneous object [153].

Efforts have been made to explain and reduce the sources of variability. Feigel et al. [161] classified the intrinsic variability of fibre properties into three main categories: agronomic, physical and processing related. A summary of the different sources of variabilities encountered is presented in Figure 10. In terms of agronomic factors, differences may arise from differences in the flax variety and climatic conditions during growth, as highlighted by Bourmaud et al. [13]. The degree of retting also influences the mechanical properties of flax, especially when tested at the bundle scale, as well as the location of the fibre along the stem [53, 162]. In this regard, Charlet et al. [53] demonstrated that fibres extracted from the middle of the stem, benefiting from optimal growing conditions, exhibit better mechanical properties than fibres extracted from the upper or lower parts of the stem. The effect of the flax variety and cultivation year was analysed by Baley et al. [163], who synthetized the tensile properties of 50 different batches of flax fibres over a period of 18 years. The results showed variability within the batches but a global homogenous performance that was independent of the variety and cultivation year, paving the way for the blending of batches, as is commonly done in the textile field. Indeed, the majority of the tested batches had mechanical performances close to the average calculated results in terms of the Young's modulus 
and tensile strength, and only a few batches deviated; there may have been fibres with exceptional qualities that have benefited from optimal growth and cultivation conditions. Moreover, major crop accidents (pronounced hydric stress or lodging phenomena, for instance) may have resulted in fibres with weak properties; these two extremes nevertheless remain rare. Beyond the agronomic conditions, the intrinsic structural parameters of the fibres, such as the MFA, fibre composition, diameter and presence of defects, have a substantial impact on the mechanical properties of plant fibres [161]. Aslan et al. [38] referred to the distribution of defects along flax elementary fibres to explain the scattering of data and shape of the stress-strain curves. However, since a large amount of defects appears during the extraction of the fibres, it can also be classified as a process-related variability. Chemical and physical pretreatments intended to improve fibre adhesion with the matrix of composites may also influence the mechanical properties of the fibres [164]. Bourmaud et al. [23] also presented several experimental uncertainties that negatively affect the accuracy of the results, such as the determination of the useful cross-section area, the varied boundary conditions depending on the type and amount of glue used, the determination of the overall deformation and the elastic modulus determination after nonlinear regions. In addition, the gauge length and strain rate influence the tensile response and are to be checked before comparing the results. Efforts have been made to standardize the preparation and tensile testing conditions of plant fibres, resulting in a norm (AFNOR NF T 25-501). The main parameter values are the strain rate set to $1 \mathrm{~mm} / \mathrm{min}$ and the gauge lengths set to $10 \mathrm{~mm}$ and $75 \mathrm{~mm}$ for fibres and bundles, respectively. The environmental testing conditions are to be checked with particular care since plant fibres are sensitive to moisture. Another source of variability is the compliance of the tensile system, which 
can result in the underestimation of the Young's modulus and overestimation of the strain at failure [165]. Moreover, the determination of the flax fibre cross-section area (CSA) remains a debate today. It can result in a variation of up to $300 \%$ in the tensile strength data according to Haag et al. [166]. The classical estimation is based on the assumption of a circular section, with a mean diameter obtained by optical microscopy as an average of 3 to 6 measurements along the fibres and bundles. Barbulée et al. [131] recommended taking the variation in the cross-section shape of the fibre along its length into account by calculating an average of the surfaces along the fibre instead of an average of the diameters leading to a mean surface area. Another source of error is the assumption of a circular shape that overestimates the cross-section area and thus leads to an underestimation of the mechanical properties. Garat et al. [28] measured crosssectional areas by means of an automated laser scanning technique assuming an elliptical model that seemed to be more accurate for irregular cross-sectional shapes such as flax, hemp and nettle bundles. Based on the work of Garat et al. [28], among others, Summerscales et al. [167] suggested fibre area correction factors for numerous plant fibres, which was estimated from the mean circular cross-sectional area from the apparent diameter divided by the mean true cross-sectional area. Some authors considered the diameter of the fibre near the failure plane to better estimate the failure properties [86]. However, Haag et al. [166] highlighted experimental difficulties such as fibre splitting after breakage that result in substantial errors [62]. The assumption of a cylinder without a lumen also induces an underestimation of the mechanical properties. An error of $15 \%$ to $25 \%$ (for a lumen surface ratio between 10 and $20 \%$ ) was estimated for hemp fibres with mathematical model developed by Placet et al. [168]. In this context, the back-calculation of the fibre properties from the results of the impregnated 
fibre bundle test (IFBT) could thus be a promising alternative. A comparison between the experimental data and back-calculated tensile properties of flax fibres is presented in Figure 11. Sources of discrepancies were well defined by Shah et al. [169], divided between experimental errors and suitability of the rule of mixture used for the backcalculation. Among the experimental errors, the scale of the experiment was acknowledged by Charlet et al., who observed elementary fibre properties that were much higher than the back-calculated properties $[53,170]$. A comparison at the bundle scale might be more suitable since it is often the reinforcement unit in composites. Fibre testing parameters such as the strain rate, method of measuring the cross-section and analysing the data also need to be considered. For instance, the influence of the strain range at which the stiffness is determined was highlighted by Bensadoun et al. [171]. Regarding the applicability of the rule of mixture, assumptions such as a perfect interface, uniform fibre properties, the perfect orientation of the fibres, the presence of voids and the process history of the composites might contribute to the discrepancies between the experimental and back-calculated data [169]. Moreover, IFBT appears to be a promising alternative to tedious experiments to assess the compressive properties of flax fibres [172].

B. Tensile and compressive properties of flax fibres

The results of tensile and compressive tests on unitary flax fibres are summarized in Table 5, showing a scattering of values. The Young's modulus is generally between 45 and $70 \mathrm{GPa}$. The tensile strength varies between 850 and $1400 \mathrm{MPa}$, whereas the compressive strength is approximately $1200 \mathrm{MPa}$ [132]. Back-calculated compressive strengths of approximately $45 \%$ of the corresponding back-calculated tensile strengths 
were reported by Prapavesis et al. [172] using IFBT. Finally, the strain at failure lies within the range of $1.8-3.3 \%$.

Several authors observed a decrease in the Young's modulus upon increasing diameter of the flax unitary fibre. According to Baley et al. [154], this could be due to an increase in the lumen size. Placet et al. [168] studied the diameter dependence of the Young's modulus for elementary hemp fibres using a mathematical model. The authors did not experimentally observe the positive dependency between the surface area proportion of the lumen and the fibre diameter. Therefore, the assumption presented by Baley et al. could only partially explain the modulus-diameter dependency [154]. However, according to Charlet et al. [173], the Young's modulus/diameter dependency disappeared when the diameter was measured close to the rupture point, highlighting the controversy over the correlation between the Young's modulus and diameter. The dependency of the tensile strength on the gauge length and diameter at the fibre scale is effectively explained by the theory of the weakest link originally developed by Griffith [155] in the metal field. The strength is limited by the presence of critical flaws, and a longer or larger object will likely contain more defects and thus exhibit a lower tensile strength. Therefore, the variation in the strength due to size effects can be accurately predicted by a Weibull distribution [174]. Moreover, the tensile properties seem to be correlated to the biochemical composition of flax fibres. The cellulose content is correlated to the mechanical performance of the fibre, as demonstrated by Alix et al. [175], who explained the phenomenon based on a lower interfibrillar distance when more cellulose and less matrix is present. In addition, the excellent cellulose properties (with a Young's modulus of approximately $137 \mathrm{GPa}$ [176]) give a high weight to their relative content in the mechanical performance of the fibres. The contribution of 
cellulose to the mechanical properties of flax fibres was confirmed at the cell wall scale by Goudenhooft et al. [109] following an AFM study combined with Raman spectroscopy. Not only the cellulose content but also the orientation of the cellulose microfibrils was shown to play an important role in the mechanical properties of fibres. Indeed, Eder et al. [153] observed the dependency of the stiffness on the initial MFA of wood samples and elementary fibres. Differences in the microfibril orientation partly explain the heterogeneities between the bast fibres. Indeed, sisal and cotton, with a large MFA of approximately $20^{\circ}$, display lower mechanical properties than hemp and flax, which have a lower MFA [23]. Bourmaud et al. [13] confirmed the negative correlation between the MFA and Young's modulus for 9 varieties of flax fibres $\left(R^{2}=-\right.$ 0.75). They also highlighted the correlation between the pectin/hemicellulose ratio and the tensile properties of flax fibres. In particular, pectin acids showed a great impact on the Young's modulus and MFA. The importance of the pectin/hemicellulose ratio together with the hemicellulose content on the Young's modulus was confirmed by Lefeuvre et al. [67]. Thus, although cellulose is responsible for the high mechanical properties of plant fibres, the organization of the microfibrils in the non-cellulosic polymer matrix is of importance for ensuring optimal stress transfer.

1. Nonlinear stress/strain diagram

Plant fibres exhibit nonlinear tensile behaviour. Lefeuvre et al. [67] observed three different responses to tensile testing of flax unitary fibres (Figure 12a). The first type of stress-strain curve is linear (TI), the second type (TII) is composed of two linear sections, and the third type (TIII) is composed of a nonlinear section up to a threshold point followed by an increasing tangent modulus up to failure. The third type is the most 
common, exhibiting higher tensile properties, and is more correlated with the cell wall composition.

Several explanations have been proposed to understand these different behaviours. First, many authors have assumed that the partial reorientation of cellulose microfibrils along the flax and hemp fibre axes during the first moment of stretching is responsible for the nonlinearity of the behaviour $[97,117,154]$. However, the change in the MFA alone cannot explain the total increase in the stiffness [117]. An additional phenomenon is the shear strain of the amorphous polymers induced by the elongation of the fibre, leading to its longitudinal torsion [117]. Moreover, a stick-slip mechanism might occur due to excessive shear stress causing the breakage of hydrogen bonds and thus slippage of the matrix. Upon removal of excessive shear stress, the microfibrils lock into a new position due to the recovery of hydrogen bonds $[108,117]$. The increase in the fibre stiffness upon loading is also attributed to strain-induced crystallization of amorphous cellulose. Astley et al. [177] discovered the strain-induced crystallization of flax amorphous cellulose using SAXS and WAXS techniques and observed an increase in the (2 00 ) peak intensity during deformation. These results are complementary to the stickslip mechanism presented by Placet et al. [117], leading to the scenario illustrated for the TIII strain-stress curves of hemp in Figure $12 \mathrm{~b}$. During the first part of the curve, they observed linear behaviour coming from the elastic deformation of the fibres and irreversible strain coming from the straightening of the microfibrils. Beyond the yield point, the stick-slip mechanism occurs and induces both an irreversible strain and a decrease in the stiffness. Shear stress induced by the twisting of the fibres in the amorphous parts and at the interfaces could lead to partial crystallization of paracrystalline cellulose and irreversible stiffening of the fibres. The extension of the 
microfibrils explains the time-reversible behaviour. An additional mechanism is associated with the last part of the curve: the reversible re-alignment of the cellulose microfibrils in the dislocation zones. Moreover, a correlation was found by Lefeuvre et al. [67] between the coating polysaccharides (mainly hemicellulose, linked with the cellulose microfibrils) and the nonlinear part of the stress-strain curve. The matrix polysaccharides might influence the second part of the stress-strain curve, including the increase in the tangent modulus.

2. Influence of the middle lamella, the fibre interphase Plant fibres such as flax are difficult to fully separate at an industrial scale, and composite reinforcement generally includes a majority of bundles. It is therefore of interest to better understand the mechanical properties at this scale.

The middle lamella is usually difficult to distinguish from the primary walls of two adjacent cells, depending on the observation scale and the use or not of contrasting techniques. Therefore, Zamil et al. [178] used the notion of compound middle lamella $(\mathrm{CML})$ to refer to the two primary cell walls and middle lamella between them. The role of the middle lamella is to control the adhesion of the cells and to ensure the load transfer. It can be observed by optical microscopy by staining pectin or lignin, immunolabelling, fluorescence and TEM techniques. Different molecular interactions link the $\mathrm{ML}$ to the primary wall: Zamil et al. [178] observed $\mathrm{Ca}^{2+}$-mediated ionic interactions, $\mathrm{H}$-bonds, ester linkages and noncovalent interactions between proteins. Within the $M L$, covalent bonds linking the pectic backbone might be responsible for its strength and elastic properties. Geometrical issues might also explain the mechanical properties of the ML: since the tensile load applied on the bundle does not act 
perpendicularly on the middle lamella, it develops shear forces that might lead to hindered failure compared to the adjacent cell wall material. The authors managed to isolate a strip of two primary cell walls and the ML of onion epidermis tissue using a FIB. Since the cell walls were expected to be stiffer than the middle lamella based on their composition, the stretching was hypothetized to occur firstly in the ML and the overall mechanical properties would therefore reflect the ML behavior. However, as the failure occurred firstly in the cell wall, the above rational could not be applied, highlighting the experimental difficulties encountered to isolate the ML mechanical properties. Moreover, it is even more difficult to isolate the $\mathrm{ML}$ on cells such as flax, which are composed of a secondary cell wall. Wimmer et al. [179] investigated a lower scale of study using a microprobe to measure the hardness and Young's modulus of spruce wood fibres. They found a cell corner hardness of the ML as high as that of the S2 layer, attributed to the binding of $\mathrm{Ca}^{2+}$ ions to negatively charged groups of the constitutive lignin of the ML. The mechanical properties of the middle lamella of different plant fibres were investigated by Melelli et al. [180] by AFM in PF-QNM mode. They measured the indentation modulus of $\mathrm{ML}$ from $6 \mathrm{GPa}$ for the date palm leaf sheath to $16 \mathrm{GPa}$ for hemp, which may have been correlated to the organization of fibres in bundles. Palm fibres were organized in large bundles protected by a lignified external layer, which might explain their lower need for high mechanical properties. Some authors demonstrated the weaker properties of bundles compared to unitary fibres, attributed to the premature failure of the middle lamella. Moreover, the tensile strength appears to be strongly dependent on the gauge length. Indeed, several authors have studied this dependency [174, 181] and highlighted the effect of the middle lamella on the mechanical properties (Figure 13). At a low gauge length, the behaviour of the bundle is 
close to that of the elementary fibre, whereas above a threshold value (approximately $25 \mathrm{~mm}$ ), the bundle is considered an aligned short composite driven by the weaker mechanical properties of the ML. Moreover, following the weakest link theory developed by Griffith [155], the strength is also correlated to the tested volume and thus the gauge length. However, the disadvantage of these experiments is that only groups of several fibres have been studied. Charlet et al. [182] investigated the flax fibre-fibre interface within a bundle by mechanical extraction of pairs of fibres. The aim was to assess the interfacial shear properties (i.e., force needed to break the interface and displacement at the interface failure) by shearing two fibres along each other. The thickness of the middle lamella was estimated between 200 and $800 \mathrm{~nm}$, which is in agreement with observations made by Melelli et al. [180] for different plant fibres by AFM and by Thuault et al. using TEM methods [36]. Charlet et al. [182] found an interfacial shear modulus of $18.7 \mathrm{kPa} \pm 10.1 \mathrm{kPa}$, which was higher than the range of the pectin shear modulus assessed by rheological measurements (approximately $1 \mathrm{kPa}$ ). This is because it is not the only component of the middle lamella, and interactions between the fibres and the middle lamella might be stronger than a simple contact. Uncertainties arise from the fact that only the length was directly measured by optical microscopy: the width and thickness of the contact area were estimated by statistical measurements on bundles from the same batch. Another source of uncertainty is that the mechanical extraction of fibres might promote "weak fibres" that were already in this pair configuration. The mean interfacial strength is $2.9 \mathrm{MPa} \pm 2.4 \mathrm{MPa}$. The reported interfacial strength of flax is lower than most matrix/fibre values in composites. This statement enhances the need to individualize the bundles as much as possible prior to composite processing. 
3. Damage behaviour

The damage mechanisms involved in the failure of flax fibres and bundles are currently an area of interest. It is necessary to understand the fracture behaviour from the bundle scale to the nanofibril scale to understand the lack of performance and propose improvements, especially in order to develop the use of biocomposites as structural and safety critical parts.

Romhany et al. [174] conducted a study on flax bundles by in situ SEM and acoustic emission methods. They observed the following failure sequence: axial splitting of the elementary fibres followed by radial cracking and multiple fractures. Each failure mechanism was assigned to a specific acoustic emission amplitude range. They successfully described the strength of flax bundles by a two-component Weibull equation. Barbulée et al. [183] also used acoustic emission to assess the rupture mechanisms of flax slivers. They categorized three populations of damage mechanisms by correlating the tensile curves and acoustic emission data. Friction among unitary fibres in bundles and rupture of unitary fibres represented the first group with a low hit energy. The first group was followed by delamination and partial rupture of the bundles, leading to their final rupture at a higher energy. The rupture behaviour of flax at both unitary and bundle scales was examined by Ahmed et al. [90] through in situ scanning electron microscopy during a tensile test. Three distinct phases were captured: an initial rotation of the bundle due to the reorientation of the micro-fibrils of the S2 layer followed by segregation of unitary fibres from the bundle and ultimate failure without prior indication. The high work of fracture of the fibres is attributed to crack bridging and successive fibre pull-out (the meso-fibrils pulled out of the matrix and the microfibrils pulled out of the meso-fibrils). The fractured surfaces of the unitary fibres 
revealed zones of both tensile and compression failure, as well as crack bridging by micro-fibrils. The authors also observed no strain rate sensitivity; the explanation was that the tested strain rate range $\left(0.01\right.$ to $\left.0.08 \mathrm{~min}^{-1}\right)$ was too narrow to result in an appreciable difference in behaviour. Fuentes et al. [184] highlighted the differences between weak and strong hemp bundles by digital image analysis during tensile testing. Full-field strain analysis revealed that weak bundles failed at the interphase characterized by the mechanism of shear stress concentration. This could be due to a lower amount of substituted sugars in pectins and hemicellulose of the cell wall decreasing the amount of crosslinks in this region. The fracture of strong fibres occurred by elementary fibre breakage perpendicular to the tensile direction, with a late shear stress appearance. This was explained by a stronger interphase, more substituted polysaccharides and a more compact microstructure. However, the authors underlined that the correlation between the fibre and composite properties is not straightforward. Finally, Beaugrand et al. [37] studied the failure mechanisms of both hemp unitary fibres and bundles by in situ tensile testing and X-ray microtomography. The submicronic scale seemed relevant for identifying the involved mechanisms, and the damage area was forced by notching the specimens. The tests revealed predominant transverse cracking for unitary fibres and complex failure mechanism of the bundles at the microscale, involving the intrinsic tubular porosity, constitutive sublayer delamination and fibre extraction defects, illustrated in Figure 9b. The influence of defects on the failure behaviour of flax was further developed in part 2.B (Influence of defects on the mechanical properties).

In conclusion, numerous mechanical characterization techniques have been effectively adapted for plant fibres. Sources of variability are abundant, but work has been 
conducted to identify and limit the variabilities with the creation of a standard for tensile testing, for instance. Numerous authors described the nonlinear tensile behaviour of plant fibres leading to a scenario based on the "stick-slip mechanism" originating from the wood field. Fewer studies have addressed the bundle scale where the characterization of the middle lamella remains a challenge. The inherent difficulties in understanding the damage mechanisms involved in the failure of fibres and bundles pave the way for the complementary use of numerical models. Moreover, it is worth pointing out that experimental results are often described by a mean value and an associated standard deviation instead of a distribution law. However, one must keep in mind that mean values and associated standard deviation often underexploits the wealth of information provided by the experiment, and it does not fully describe the observed complex phenomena, especially for plant fibres exhibiting intrinsic variability. The use of distribution laws is of interest to promote stochastic models for accurately predicting the behaviour of plant fibres and composites $[185,186]$.

\section{Modelling plant fibres}

Plant fibres exhibit a hierarchical structure, leading to complex mechanical behaviour (see 3. Mechanical testing of flax fibres). Deciphering the origins of this behaviour in terms of physical phenomena requires exploring different scales from millimetres to the molecular scale. Consequently, numerical approaches such as the finite element analysis (FEA) are gaining increasing interest as complements to tedious experimental characterization.

The first models that were developed were analytical and therefore based on simple geometries and rather strong hypotheses. The great variability of plant fibres and the 
need to take into account a complex hierarchical structure led to the use of numerical methods such as the finite element analysis. The FEA enables us to discretize a continuous problem and obtain an approximated solution. Analytical and numerical work on plant fibres originated from wood in the 1950s and was extended to plant fibres such as flax and hemp in more recent years, as illustrated in Figure 14. Industrial interests have most likely been driving the research in the area of wood, and emerging numerical work on plant fibres is still constrained by the difficulty of obtaining experimental data to corroborate the models. With only a few dozen papers on this topic, the modelling of plant fibres remains an open challenge. The different models presented in this literature review and their main characteristics are listed in Table 6. Moreover, the overall process involved in a FEA is presented in Figure 15. The first step is to define the physical system to be analysed and convert it into a mathematical model that can be either mesh-based (FEA) or meshless (molecular dynamics). The discretisation of the mathematical model leads to a finite element model. Within the context of fibre mechanical modelling, the procedure is the following: defining the fibre geometry, meshing the geometry with structural elements, defining the boundary and loading conditions (displacement-based and force-based), specifying the material model (isotropic, anisotropic, elastic, elasto-plastic, etc.), and performing the analysis (static, dynamic, transient). Under the assumption of linear elasticity, the calculations are based on the generalized Hooke's law predicting deformations caused by an arbitrary combination of stresses in a material. The stress can be expressed in matrix form with the following equation:

$$
[\sigma]=[C] *[\varepsilon]
$$


where $\sigma$ is the stress matrix, $\varepsilon$ the strain matrix and $C$ the tensor of elasticity, a $6 \times 6$ symmetric matrix containing a maximum of 21 independent parameters. The number of independent variables is reduced depending on the symmetry of the system. More complex behaviour laws, taking into account viscoelasticity or plasticity, for instance, can be implemented depending on the material. After solving the equation system using either direct or indirect solvers, the convergence and correctness of the model are checked, and these steps might require refinement. The final output is an approximate solution of the initial problem. Experimental data are required at different steps to strengthen the model: at the nanoscopic or microscopic scale to help define a realistic model and at the macroscopic scale to check the correctness of the model. Moreover, fibre geometries have to be implemented in the model. Simple to more complex geometries closer to the intricate shape of plant fibres can be used, as depicted in Figure 16.

A. Hierarchical modelling originating from wood The hierarchical modelling of wood paved the way for the modelling of bast fibres such as hemp and flax and was the object of a review by Hofstetter et al. [187]. The authors described the usefulness of multiscale approaches based on homogenization techniques relying on literature in the field of wood science. Bergander et al. [188] analysed the influence of the elastic properties of cellulose, hemicellulose and lignin on the properties of wood cell walls with an analytical model. They highlighted the influence of cellulose on the longitudinal properties of the cell wall represented as a laminated composite and of hemicellulose on its transverse properties. Two arrangements of the matrix polymers were tested (a matrix of hemicellulose and lignin and a matrix of hemicellulose with separate lignin layers), showing no substantial influence on the transverse properties. 
The thickness and MFA of the S1 layer seemed to have a great influence on the transverse properties of the cell wall. However, the fibre geometry was not taken into account in this model. Neagu et al. [189] developed a multilayer finite element model to investigate the link between the MFA and hygroelastic behaviour of wood fibres. They studied different boundary conditions and found that constrained fibres exhibit a stiffer response, resembling the behaviour of plant fibres constrained by their neighbours. Changes in the MFA were correlated with changes in the compliance values. The dominating deformation mechanism under moisture content changes was the twisting of the fibres. The model was further developed by Joffre et al. [190] using a 3D reconstruction of the S2 layer obtained by X-ray microtomography. The hygroexpansion coefficients were estimated by comparing the predicted and experimental geometries in the wet state (Figure 16e). They minimized the geometrical approximation, but only the elastic behaviour was studied. Finally, a multi-scale finite element analysis was developed by Saavedra Flores et al. [191], covering the tensile behaviour from microfibrils to bulk Palmetto wood. The influence of microscopic features such as the MFA, cellulose content and crystallinity rate, cell wall thickness and porosity on the macroscopic behaviour was highlighted by parametric studies on the Young's modulus and density. Among others, the authors noticed an increase in the longitudinal modulus of bulk wood following an increase in cellulose volume fraction or an increase in cellulose crystallinity degree.

\section{B. Hierarchical modelling of plant fibres}

Plant fibres such as flax and hemp have received particular attention from several authors. Gassan et al. [192] proposed an analytical and finite element model to predict the elastic properties of flax and hemp. The first model was an anti-symmetrical 
laminated structure, and the second model took into account a central lumen and elliptical geometry. Using the first model, the authors observed a decreasing longitudinal modulus and anisotropy with increasing MFA, which fit well with the experimental data. Moreover, the modulus increased with cellulose content, even if the result was less fitted with experimental data. This could be explained by the highly elliptic structure assumed in the first model leading to an overestimation of the elastic modulus of approximately $30 \%$ when compared to the second model. However, it should be considered that only the elastic behaviour was investigated. A mathematical model was built by Placet et al. [168] to explain the diameter dependence of hemp fibres on their Young's modulus. In the elastic domain, the size of the lumen and outer fibre diameter partly explain this dependence according to the authors. Ultrastructural parameters such as the microfibril angle and cellulose crystallinity seem to be the main parameters involved in the phenomena, as revealed by a sensitivity analysis.

According to Placet et al. [168], additional research is needed to understand the influence of the elastic modulus of crystalline cellulose and the shear modulus of amorphous cellulose on the Young's modulus. Del Masto et al. [193] further completed a finite element model developed by the same team to assess the influence of the 3D geometry of hemp unitary fibres on their tensile behaviour. The geometry of the fibre was considered a monolayer cylindrical tube of different elliptical shapes extracted from microscopic observations (Figure 16c). Cell wall elasticity constants were assessed by homogenization based on the main component values obtained from the literature. Viscoelasticity was taken into account by the inverse method based on creep tests, following experimental work developed by Cisse et al. and Guicheret et al. [84, 158]. Real and elliptical simplified cross-sectional shapes were considered. Results of the 
tensile test simulations showed a strong influence of the degree of ellipticity on the shape of the nonlinearity response. Other parameters, such as the cellulose MFA and viscoelasticity of the fibre wall, were involved in the shape of the tensile response and linked to the generation of heterogeneous local fields of stress and strain. The authors neglected the variation in the cross-section along the length of the fibres and used simplified cross-sectional contours of the fibres since they had limited influence on the shape of the tensile response. However, these parameters induce stress concentrations that cannot be neglected when investigating the failure behaviour of fibres. Complementary work conducted by Del Masto et al. [194] investigated the origin of the differences between hemp and flax mechanical properties using a two-step sensitivity analysis. The strength was assessed by the Hashin failure criterion, which assumes perfect bonding between the microfibrils and matrix. They concluded that the higher average tensile properties of flax are linked to the lower scattering of some ultrastructural and morphological properties compared to hemp. Another sensitivity analysis on flax fibres was conducted by Thuault et al. [195]. The fibre was represented as a multilayer cylindrical tube taking into account the S1, S2 and S3 layers and a matrix composed of cellulose and hemicellulose. The microfibril angle and its reorientation were considered by using a composite element: a quadratic 3D element representing the hemicellulose matrix and a 1D bar representing the cellulose microfibril. The authors highlighted the influence of the amorphous matrix properties on the shape of the strainstress curve, corroborating the experimental results presented in part 3 (3. Mechanical testing of flax fibres). A softer matrix induced by environmental conditions, for instance increasing relative humidity, enhances the nonlinearity of the curve by allowing the microfibrils to realign more easily. Moreover, the S2 layer thickness and MFA, cellulose 
content and associated mechanical properties seem to greatly influence the fibre mechanical properties. A limit of the model arises from the fact that only cylindrical geometries were considered.

Numerical modelling of the middle lamella is very challenging due to the difficulty of obtaining experimental data. The experimental characterization of the flax interfacial properties conducted by Charlet et al. [196] promoted a bilinear cohesive zone model developed by Beakou et al. [197]. They adopted a staggered longitudinal arrangement and scaled up the fibre diameter to reduce the computation time. The authors found that the bundle strength decreases up to a gauge length of $25 \mathrm{~mm}$, where it remains constant. The findings are therefore in agreement with the experimental data despite the approximations of the geometry and interfacial properties.

\section{Damage-based models}

Some studies have considered the damage mechanisms involved in the failure of plant fibres through a numerical approach. In the study of wood, a refined analytical model was developed by Sedighi-Gilani $[198,199]$ at the fibre scale, taking into account the elasto-plasticity of the amorphous components, MFA heterogeneities (Figure 16b) demonstrated by confocal laser microscopy and damage of the fibre. The latter two seemed to influence the tensile behaviour of the fibre the most. The damage, occurring in the matrix of hemicellulose and lignin, was assumed to initiate in the weakest location of the fibre corresponding to a zone with a higher MFA. The damage is modelled in the matrix as a zone of reduced mechanical properties, contrary to the stick-slip mechanism developed by Keckes et al. [108], which assumed that shear relaxation does not damage the matrix. Microfibrils are able to straighten in this zone, resulting in a decreasing MFA 
and thus recovering the initial reduction in the stiffness. The damage can therefore initiate in a second-weakest zone e.g. until complete failure of the fibre. Limitations of the model arise from the geometry of the fibres, a circular monolayer tube and the assumption of isotropic damage. Beaugrand et al. [111] developed a finite element simulation assessing the inner extension of damage based on 2D crack propagation characterization using a high-speed camera and notched hemp fibres and bundles. Different stress criteria were tested, and non-prescribed crack propagation was implemented by allowing the creation of new nodes defining microcrack flaws. The results showed a combination of microcrack growth in the transverse direction and coalescence in the longitudinal direction. A sensitivity to the notch type and dimension of the fibre element was also highlighted. However, some limitations, such as the approximation of a single layer fibre, are highlighted. Finally, Guessasma et al. [110] developed a computation model to highlight the effect of defects (both surface flaws and bulk defects such as kink bands) at a submicrometric scale. The computational model is based on results from in situ tensile testing and X-ray microtomography of hemp fibres and bundles that were notched in $U$ and $V$ shapes prior to the test to concentrate stresses (Figure 16d). The tomograms were converted into 3D meshes to be implemented in the FEA. They showed complex damage behaviour that depends on the type of stress criterion implemented and variabilities in terms of the surface defects, fibre geometry and lumen size. The analysis of the damage ratio as a function of the load increment reveals a three-stage evolution composed of an onset followed by damage growth and saturation. The most severely damaged areas are the fibre ends, notches and lumen area. However, no separation between the different layers of the fibres and the middle lamella is considered in this model, and the hypothesis of a linear elastic 
isotropic material seems rather strong and perfectible. Finally, a study conducted at the nanoscale by Khodayari et al. [200] investigated the cellulose-hemicellulose interactions using molecular dynamics. They evidenced the failure within the hemicellulose fraction rather than at the interface with cellulose upon shear testing. This work therefore illustrates well the potential of modelling to confirm hypothesis of microscopic scale mechanisms based on macroscopic observations.

To conclude, following the work accomplished in the study of wood, the modelling of plant fibres is currently in development. Starting from simple geometries and rather strong hypotheses, researchers are now able to model realistic structures of fibres and take into account more complex behaviours, such as the viscoelasticity and microfibril realignment. However, representing the damage mechanisms involved in the failure of fibres is still a challenge. One must remember that progress in modelling is closely related to the availability of results provided by experimental work. As mentioned in part 3 (3. Mechanical testing of flax fibres), experimental work on plant fibres has experienced fast development, suggesting prompt growth in the modelling area as well.

\section{Conclusion}

Through this review, we highlighted the great efforts achieved to characterize flax fibres among other plant fibres in terms of the structure to the nanoscopic scale, type and influence of the defects. The potential of numerical work to complete the mechanical characterization of plant fibres was also described.

First, the current knowledge about the organization of flax fibre material to the cell wall structure was reviewed, enabled by increasingly precise characterization techniques. 
The potential of innovative couplings and synchrotron sources to achieve finer scales of observation was highlighted.

A novel description of defects in plant fibres was proposed, including both i) discontinuities such as impurities, cracks or interlaminar decohesion and ii) inhomogeneities such as dislocations and morphological defects. Their origin and influence at both the fibre and composite scales were discussed, highlighting the need to better optimize extraction processes to minimize the appearance of defects. The latest quantification techniques were also reviewed, as well as the promising development of numerical models focusing on the geometry and properties of defective areas.

Mechanical characterization techniques adapted for plant fibres and sources of variabilities were highlighted, emphasizing the interest in using distribution laws and stochastic models to better predict the complex behaviour of plant fibres such as flax. The nonlinear behaviour of flax was described, with a focus at the bundle scale and related challenges to fully describe the role of the middle lamella as a composite matrix. Finally, the complex failure of plant fibres and related experimental difficulties paves the way to the complementary use of numerical models. Closely linked to the availability of experimental results, the potential and existing models for plant fibres were finally introduced.

By presenting a wide range of experimental and numerical works on the characterization and modelling of plant fibre behaviour, the review highlights the potential of these materials, especially flax, as reinforcing fibres, as well as the scientific shortcomings, despite a substantial amount of research work carried out over the last 20 years. This 
report highlights the need for a cross and transdisciplinary approach, already initiated by many teams, which will make it possible to remove some of the existing limitations in the coming years. For example, a better understanding of the areas of fragility exacerbated by fibre structural defects is essential for the development of biobased composites and the improvement of their performance. It also requires a better definition and management of the fibre quality regarding the defects that could be introduced ex planta, including revisiting the extraction and transformation processes in order to minimize them. The contribution of advanced coupled investigation techniques, supplemented by a numerical approach, is essential to acquire an everincreasing knowledge of plant fibres. In particular, in situ mechanical testing as well as fine description of the composition and interactions between the polymers at the cell wall level and within the middle lamella are needed to strengthen current knowledge, including the use of high-resolution microscopy or solid-state NMR for instance. In this respect, numerical modelling appears as a promising approach under development to confirm the validity of microscopic scale mechanisms thanks to knowledge of embedded microstructural details in the modelling scheme and confrontation to macroscopic observations. For instance, investigation of the fibre cell wall biopolymers interactions using molecular dynamics would provide, under a simple rupture criterion, a precise view of the failure dynamics knowing the details of the fibre ultrastructure. Finite element computation would also allow to capture the failure either by allowing material discontinuity to occur physically (i.e., crack simulation) or by local decrease of the stiffness. In the former case, meshless methods do not need continuity requirement as only the local electrostatic force balance is sufficient to draw a detailed picture of the elastic stress and elastic strain distributions. The latter case would need the continuity 
but would permit more elaborated stress-strain relationships to be considered including

elasticity and plasticity.

Finally, the plant fibre material is hygroscopic by nature, and mostly polymeric, so its physical properties can vary drastically according to environment (relative humidity and temperature). Those variables are yet sufficiently depicted in a perspective of composite long-term service.

\section{Acknowledgements}

The authors thank Pr Christophe Baley (UBS, France) for the beneficial discussions on the literature and for providing rare books, as well as partners of the FLOWER project.

\section{Funding}

The authors thank the INTERREG VA FCE Program, FLOWER project, Grant Number 23 for funding this work.

\section{Reference list}

[1] Flax and hemp fiber composites, a market reality - The biobased solutions for the industry. 2018, JEC Group France. p. 100.

[2] Le Duigou, A., P. Davies, and C. Baley, Environmental Impact Analysis of the Production of Flax Fibres to be Used as Composite Material Reinforcement. Journal of Biobased Materials and Bioenergy, 2011. 5(1): p. 153-165.

[3] Albersheim, P., et al., Plant cell walls, from chemistry to biology. 2011: Garland science. 430.

[4] Del Masto, A., Transition d'échelle entre fibre végétale et composite UD : propagation de la variabilité et des non-linéarités, thesis, in Institut Femto-st, Département Mécanique Appliquée. 2018, Bourgogne Franche-Comte. p. 236.

[5] Madsen, B. and E.K. Gamstedt, Wood versus Plant Fibers: Similarities and Differences in Composite Applications. Advances in Materials Science and Engineering, 2013: p. 1-14.

[6] Youngs, L.R. and M.F. Hamza, Wood: History of Use. Reference Module in Materials Science and Materials Engineering, 2016: p. 1-7.

[7] Chen, C., et al., Structure-property-function relationships of natural and engineered wood. Nature Reviews Materials, 2020. 5: p. 642-666.

[8] Hughes, M., Defects in natural fibres: their origin, characteristics and implications for natural fibre-reinforced composites. Journal of Materials Science, 2011. 47(2): p. 599609. 
[9] Hughes, M., et al., An investigation into the effects of micro-compressive defects on interphase behaviour in hemp-epoxy composites using half-fringe photoelasticity. Composite Interfaces, 2000. 7(1): p. 13-29.

[10] Shekhar Sharma, H.S. and C.F. Van Sumere, The biology and processing of flax. 1992, Belfast: M Publication.

[11] Müssig, J., Industrial applications of natural fibres: Structure, properties and technical applications. Renewable Resources. 2010: Wiley. 538.

[12] Casa, R., et al., Environmental effects on linseed (Linum usitatissimum L.) yield and growth of flax at different stand densities. European Journal of Agronomy 1999(11): $p$. 267 - 278.

[13] Bourmaud, A., et al., Relationships between micro-fibrillar angle, mechanical properties and biochemical composition of flax fibers. Industrial Crops and Products, 2013. 44: p. 343-351.

[14] Djemiel, C., S. Grec, and S. Hawkins, Characterization of Bacterial and Fungal Community Dynamics by High-Throughput Sequencing (HTS) Metabarcoding during Flax DewRetting. Frontiers in Microbiology, 2017. 8: p. 2052.

[15] Akin, D.E., Linen most useful: perspectives on structure, chemistry, and enzymes for retting flax. ISRN Biotechnol, 2013: p. 186534.

[16] Martin, N., et al., Influence of the degree of retting of flax fibers on the tensile properties of single fibers and short fiber/polypropylene composites. Industrial Crops and Products, 2013. 49: p. 755-767.

[17] Van Sumere, C., Retting of flax with special reference to enzyme-retting, in The biology and processing of flax, H.S.a.C.V. Sumere, Editor. 1992, M Publications: Belfast, Northern Ireland. p. 153-193.

[18] Hendrickx, K., Extraction optimisation for and hygroscopic behaviour of flax fibres in composite applications, thesis. 2019, KU Leuven. p. 201.

[19] Nuez, L., et al., The potential of flax shives as reinforcements for injection moulded polypropylene composites. Industrial Crops and Products, 2020. 148: p. 112324.

[20] Goudenhooft, C., A. Bourmaud, and C. Baley, Flax (Linum usitatissimum L.) Fibers for Composite Reinforcement: Exploring the Link Between Plant Growth, Cell Walls Development, and Fiber Properties. Frontiers in Plant Science, 2019. 10(411).

[21] Ray F. Evert, S.E.E., Esau's Plant Anatomy: Meristems, Cells, and Tissues of the Plant Body: Their Structure, Function, and Development, 3rd Edition. 2006: p. 624.

[22] Charlet, K., et al., Multi-scale morphological characterisation of flax: From the stem to the fibrils. Carbohydrate Polymers, 2010. 82(1): p. 54-61.

[23] Bourmaud, A., et al., Towards the design of high-performance plant fibre composites. Progress in Materials Science, 2018. 97: p. 347-408.

[24] Haag, K., et al., Influence of flax fibre variety and year-to-year variability on composite properties. Industrial Crops and Products, 2017. 98: p. 1-9.

[25] Baley, C., et al., Variability of mechanical properties of flax fibres for composite reinforcement. A review. Industrial Crops and Products, 2019: p. 111984.

[26] Le Moigne, N., M. van den Oever, and T. Budtova, A statistical analysis of fibre size and shape distribution after compounding in composites reinforced by natural fibres. Composites Part a-Applied Science and Manufacturing, 2011. 42(10): p. 1542-1550.

[27] Hamdi, S.E., et al., X-ray computed microtomography and $2 D$ image analysis for morphological characterization of short lignocellulosic fibers raw materials: $A$ benchmark survey. Composites Part A: Applied Science and Manufacturing, 2015. 76: $p$. 1-9.

[28] Garat, W., et al., Analysis of the morphometric variations in natural fibres by automated laser scanning: Towards an efficient and reliable assessment of the cross-sectional area. Composites Part A: Applied Science and Manufacturing, 2018. 108: p. 114-123. 
[29] Mokshina, N., et al., Genes with bast fiber-specific expression in flax plants - Molecular keys for targeted fiber crop improvement. Industrial Crops and Products, 2020. 152: $\mathrm{p}$. 112549.

[30] Wang, Y.-F., et al., Fiber Flax Breeding in China and Europe. Journal of Natural Fibers, 2018. 15(3): p. 309-324.

[31] Rihouey, C., et al., Flax fibers: assessing the non-cellulosic polysaccharides and an approach to supramolecular design of the cell wall. Cellulose, 2017. 24(5): p. 1985-2001.

[32] Clair, B., et al., Is the G-Layer a Tertiary Cell Wall? Frontiers in Plant Science, 2018. 9: p. 1-4.

[33] Gorshkova, T., et al., Plant 'muscles': fibers with a tertiary cell wall. New Phytologist, 2018. 218: p. 66-72.

[34] Melelli, A., et al., Microfibril angle of elementary flax fibres investigated with polarised second harmonic generation microscopy. Industrial Crops and Products, 2020. 156: p. 112847.

[35] Gorshkova, T., et al., Aspen Tension Wood Fibers Contain beta-(1---> 4)-Galactans and Acidic Arabinogalactans Retained by Cellulose Microfibrils in Gelatinous Walls. Plant Physiology, 2015. 169(3): p. 2048-63.

[36] Thuault, A., et al., Investigation of the internal structure of flax fibre cell walls by transmission electron microscopy. Cellulose, 2015. 22(6): p. 3521-3530.

[37] Beaugrand, J., S. Guessasma, and J.E. Maigret, Damage mechanisms in defected natural fibers. Scientific Reports, 2017. 7(1): p. 14041.

[38] Aslan, M., et al., Strength variability of single flax fibres. Journal of Materials Science, 2011. 46(19): p. 6344-6354.

[39] Eichhorn, S.J., et al., Review: Current international research into cellulosic fibres and composites. Journal of Materials Science, 2001. 36(9): p. 2107-2131.

[40] Scheller, H.V. and P. Ulvskov, Hemicelluloses, in Annual Review of Plant Biology, Vol 61, S. Merchant, W.R. Briggs, and D. Ort, Editors. 2010, Annual Reviews: Palo Alto. p. 263289.

[41] Terrett, O.M. and P. Dupree, Covalent interactions between lignin and hemicelluloses in plant secondary cell walls. Current Opinion in Biotechnology, 2019. 56: p. 97-104.

[42] Wang, T., et al., Cellulose-Pectin Spatial Contacts Are Inherent to Never-Dried Arabidopsis Primary Cell Walls: Evidence from Solid-State Nuclear Magnetic Resonance. 2015. 168(3): p. 871-884.

[43] Bag, R., et al., Viscoelastic properties of woody hemp core. Holzforschung, 2011. 65(2): p. 239-247.

[44] Day, A., et al., Identification of cell wall proteins in the flax (Linum usitatissimum) stem. Proteomics, 2013. 13(5): p. 812-25.

[45] Corbin, C., et al., A genome-wide analysis of the flax (Linum usitatissimum L.) dirigent protein family: from gene identification and evolution to differential regulation. Plant Molecular Biology, 2018. 97(1-2): p. 73-101.

[46] Chabi, M., et al., A Cell Wall Proteome and Targeted Cell Wall Analyses Provide Novel Information on Hemicellulose Metabolism in Flax. Molecular \& Cellular Proteomics, 2017. 16(9): p. 1634-1651.

[47] Crônier, D., B. Monties, and B. Chabbert, Structure and chemical composition of bast fibers isolated from developing hemp stem. Journal of Agricultural and Food Chemistry, 2005. 53: p. 8279-8289.

[48] Akin, D.E., et al., Chemical and Structural Analysis of Fibre and Core Tissues from Flax. Journal for the Science of Food and Agriculture, 1996. 72: p. 155-165.

[49] Morrison, W.H. and D.E. Akin, Chemical composition of components comprising bast tissue in flax. Journal of Agricultural and Food Chemistry, 2001. 49: p. 2333-2338.

[50] Akin, D.E., et al., Progress in Enzyme-Retting of Flax. Journal of Natural Fibers, 2004. 1(1): p. 21-47. 
[51] Thygesen, A., et al., On the determination of crystallinity and cellulose content in plant fibres. Cellulose, 2005. 12(6): p. 563.

[52] Brutch, N.B., et al., Characters of Fibre Quality in Lines of Flax Genetic Collection. Journal of Natural Fibers, 2008. 5(2): p. 95-126.

[53] Charlet, K., et al., Characteristics of Hermès flax fibres as a function of their location in the stem and properties of the derived unidirectional composites. Composites Part A: Applied Science and Manufacturing, 2007. 38(8): p. 1912-1921.

[54] Placet, V., A. Day, and J. Beaugrand, The influence of unintended field retting on the physicochemical and mechanical properties of industrial hemp bast fibres. Journal of Materials Science, 2017. 52(10): p. 5759-5777.

[55] Norton, A.J., et al., Determining the physical properties of flax fibre for industrial applications: the influence of agronomic practice. The Annals of applied biology, 2006. 149(1): p. 15-25.

[56] Mazian, B., et al., Influence of field retting duration on the biochemical, microstructural, thermal and mechanical properties of hemp fibres harvested at the beginning of flowering. Industrial Crops and Products, 2018. 116: p. 170-181.

[57] Thygesen, A., et al., Cellulosic Fibers: Effect of Processing on Fiber Bundle Strength. Journal of Natural Fibers, 2011. 8(3): p. 161-175.

[58] Love, G.D., et al., Determination of phenolic structures in flax fibre by solid-state $13 \mathrm{C}$ NMR. Phytochemistry, 1994. 35(2): p. 489-491.

[59] Bourmaud, A., et al., Main criteria of sustainable natural fibre for efficient unidirectional biocomposites. Composites Part A: Applied Science and Manufacturing, 2019. 124: p. 105504.

[60] Faruk, O., et al., Biocomposites reinforced with natural fibers: 2000-2010. Progress in Polymer Science, 2012. 37(11): p. 1552-1596.

[61] Bismarck, A., I. Aranbefwi-Askargorta, and J. Springer, Surface characterization of flax, hemp and cellulose fibers; surface properties and the water uptake behavior. Polymer Composites 2004. 23: p. 872-894.

[62] Castellani, R., et al., Lignocellulosic fiber breakage in a molten polymer. Part 1. Qualitative analysis using rheo-optical observations. Composites Part A: Applied Science and Manufacturing, 2016. 91: p. 229-237.

[63] Mondragon, G., et al., A common strategy to extracting cellulose nanoentities from different plants. Industrial Crops and Products, 2014. 55: p. 140-148.

[64] Ansari, I.A., G.C. East, and D.J. Johnson, Structure-Property Relationships in Natural Cellulosic Fibres. Part I: Characterisation. Journal of the Textile Institute, 1999. 90(4): p. 469-480.

[65] Astruc, J., et al., Isolation of cellulose-II nanospheres from flax stems and their physical and morphological properties. Carbohydrate Polymers, 2017. 178: p. 352-359.

[66] Van Soest, P.J., Use of detergents in the analysis of fibrous feeds. 2. A rapid method for the determination of fiber and lignin. Journal of the Association of Official Agricultural Chemists, 1963. 46: p. 829-835.

[67] Lefeuvre, A., et al., Elementary flax fibre tensile properties: Correlation between stressstrain behaviour and fibre composition. Industrial Crops and Products, 2014. 52: p. 762769.

[68] Lefeuvre, A., Contribution à l'étude des propriétés des fibres de lin (Linum Usitatissimum L., variétés Marylin et Andréa) en fonction des pratiques culturales sur le plateau du Neubourg. Fibres destinées au renforcement de matériaux composites, thesis. 2014: Rouen.

[69] Hernandez-Gomez, M.C., et al., Developmental features of cotton fibre middle lamellae in relation to cell adhesion and cell detachment in cultivars with distinct fibre qualities. BMC Plant Biology, 2017. 17(1): p. 69. 
[70] Ghaffari, M., et al., Multi-excitation hyperspectral autofluorescence imaging for the exploration of biological samples. Analytica Chimica Acta, 2019. 1062: p. 47-59.

[71] Terryn, C. and G. Paës, Fluorescence Lifetime Imaging of Plant Cell Walls, in Plant Cell Morphogenesis: Methods and Protocols, F. Cvrčková and V. Žárský, Editors. 2019, Springer New York: New York, NY. p. 77-82.

[72] Gierlinger, N., New insights into plant cell walls by vibrational microspectroscopy. Applied Spectroscopy Reviews, 2018. 53(7): p. 517-551.

[73] Himmelsbach, D.S., S. Khalili, and D.E. Akin, FT-IR microspectroscopic imaging of flax (Linum usitatissimum L.) stems. Cellular and molecular biology 1998. 44(1): p. 99-108.

[74] Andeme-Onzighi, C., et al., Immunocytochemical characterization of early-developing flax fiber cell walls. Protoplasma, 2000. 213: p. 235-245.

[75] His, I., et al., Microscopic Studies on Mature Flax Fibers Embedded in LR White: Immunogold Localization of Cell Wall Matrix Polysaccharides. The Journal of Histochemistry \& Cytochemistry, 2001. 49: p. 1525-1535.

[76] Petrova, A.A., et al., AFM analysis reveals polymorphism of purified flax rhamnogalacturonans I of distinct functional types. Carbohydrate Polymers, 2019. 216: p. 238-246.

[77] Gorshkova, T., Composition and Distribution of Cell Wall Phenolic Compounds in Flax (Linum usitatissimum L.) Stem Tissues. Annals of Botany, 2000. 85(4): p. 477-486.

[78] Day, A., et al., Lignification in the flax stem: evidence for an unusual lignin in bast fibers. Planta, 2005. 222(2): p. 234-45.

[79] Morvan, C., et al., Building flax fibres: more than one brick in the walls. Plant Physiology and Biochemistry 2003. 41: p. 935-944.

[80] Baley, C., et al., Influence of drying on the mechanical behaviour of flax fibres and their unidirectional composites. Composites Part A: Applied Science and Manufacturing, 2012. 43(8): p. 1226-1233.

[81] Salmen, N.L. and E.L. Back, Influence of water on glass-transition temperature of cellulose. Tappi, 1977. 60(12): p. 137-140.

[82] Salmén, L. and J.S. Stevanic, Effect of drying conditions on cellulose microfibril aggregation and "hornification". Cellulose, 2018. 25(11): p. 6333-6344.

[83] Garat, W., et al., Swelling of natural fibre bundles under hygro- and hydrothermal conditions: determination of hydric expansion coefficients by automated laser scanning. Composites Part A: Applied Science and Manufacturing, 2020(131): p. 105803.

[84] Guicheret-Retel, V., et al., Creep behaviour of single hemp fibres. Part II: Influence of loading level, moisture content and moisture variation. Journal of Materials Science, 2015. 50(5): p. 2061-2072.

[85] Le Duigou, A., et al., Humidity responsive actuation of bioinspired hygromorph biocomposites (HBC) for adaptive structures. Composites Part A: Applied Science and Manufacturing, 2019. 116: p. 36-45.

[86] Placet, V., O. Cisse, and M.L. Boubakar, Influence of environmental relative humidity on the tensile and rotational behaviour of hemp fibres. Journal of Materials Science, 2012. 47(7): p. 3435-3446.

[87] Baley, C., C. Morvan, and Y. Grohens, Influence of the Absorbed Water on the Tensile Strength of Flax Fibers. Macromolecular Symposia, 2005. 222(1): p. 195-202.

[88] Bos, H. and A. Donald, In situ ESEM study of the deformation of elementary flax fibres. Journal of Materials Science, 1999. 34: p. 3029 - 3034.

[89] Donaldson, L.A., Microfibril angle: Measurement, variation and relationships - a review. lawa Journal, 2008. 29: p. 345-386.

[90] Ahmed, S. and C. Ulven, Dynamic In-Situ Observation on the Failure Mechanism of Flax Fiber through Scanning Electron Microscopy. Fibers, 2018. 6(1). 
[91] Cave, I.D., Theory of X-ray measurement of microfibril angle in wood, Part 1. The condition for reflection $X$-ray diffraction by materials with fibre type symmetry. Wood Science and Technology, 1997. 31: p. 143 - 152.

[92] Wang, C., et al., Investigation of Microfibril Angle of Flax Fibers Using X-Ray Diffraction and Scanning Electron Microscopy. Journal of Natural Fibers, 2018. 17(7): p. 1001-1010.

[93] Reiterer, A., et al., Spiral angle of elementary cellulose fibrils in cell walls of Picea abies determined by small angle X-ray scattering. Wood Science and Technology, 1998. 32: p. 335 - 345.

[94] Burgert, I., Exploring the micromechanical design of plant cell walls. American Journal of Botany, 2006. 93: p. 1391 - 1401.

[95] Astley, O. and A. Donald, A Small-Angle X-ray Scattering Study of the Effect of Hydration on the Microstructure of Flax Fibers. Biomacromolecules, 2001. 2: p. 672-680.

[96] Müller, M., et al., Direct Observation of Microfibril Arrangement in a Single Native Cellulose Fiber by Microbeam Small-Angle X-ray Scattering. Macromolecules, 1998. 31: p. 3953 - 3957.

[97] Kölln, K., et al., Mechanical properties of cellulose fibres and wood. Orientational aspects in situ investigated with synchrotron radiation. Journal of Synchrotron Radiation, 2005. 12: p. 739-44.

[98] Zuckerstätter, G., et al., The elucidation of cellulose supramolecular structure by ${ }^{13} \mathrm{C} \mathrm{CP}$ MAS NMR. Lenzinger Berichte, 2009. 87: p. 38-46.

[99] Larsson, P.T., K. Wickholm, and T. Iversen, $A C P / M A S^{13} C$ NMR investigation of molecular ordering in celluloses. Carbohydrate Research, 1997. 302: p. 19-25.

[100] Newman, R.G., Estimation of the lateral dimensions of cellulose crystallites using ${ }^{13} \mathrm{C}$ NMR signal strengths. Solid State Nuclear Magnetic Resonance, 1999. 15: p. 21-29.

[101] Bourmaud, A., et al., Evolution of flax cell wall ultrastructure and mechanical properties during the retting step. Carbohydrate Polymers, 2019. 206: p. 48-56.

[102] Lahaye, M., et al., Cellulose, pectin and water in cell walls determine apple flesh viscoelastic mechanical properties. Carbohydrate Polymers, 2020. 232: p. 115768.

[103] Duchemin, B., et al., Ultrastructure of cellulose crystallites in flax textile fibres. Cellulose, 2012. 19(6): p. 1837-1854.

[104] Gierlinger, N., et al., Molecular Changes during Tensile Deformation of Single Wood Fibers Followed by Raman Microscopy. Biomacromolecules, 2006. 7: p. 2077 - 2081.

[105] Thygesen, L.G. and N. Gierlinger, The molecular structure within dislocations in Cannabis sativa fibres studied by polarised Raman microspectroscopy. Journal of Structural Biology, 2013. 182(3): p. 219-25.

[106] Agarwal, U.P., $1064 \mathrm{~nm}$ FT-Raman spectroscopy for investigations of plant cell walls and other biomass materials. Frontiers in Plant Science, 2014. 5: p. 490.

[107] Eichhorn, S.J. and R.J. Young, Deformation micromechanics of natural cellulose fibre networks and composites. Composites Science and Technology, 2003. 63(9): p. 12251230.

[108] Keckes, J., et al., Cell-wall recovery after irreversible deformation of wood. Nature Materials, 2003. 2(12): p. 810-4.

[109] Goudenhooft, C., et al., Investigation of the Mechanical Properties of Flax Cell Walls during Plant Development: The Relation between Performance and Cell Wall Structure. Fibers, 2018. 6(1).

[110] Guessasma, S. and J. Beaugrand, Damage Kinetics at the Sub-micrometric Scale in Bast Fibers Using Finite Element Simulation and High-Resolution X-Ray Micro-Tomography. Frontiers in Plant Science, 2019. 10(194): p. 1-11.

[111] Beaugrand, J. and S. Guessasma, Scenarios of crack propagation in bast fibers: Combining experimental and finite element approaches. Composite Structures, 2015. 133: p. 667-678. 
[112] Robinson, W., The microscopical features of mechanical strain in timber and the bearing of these on the structure of the cell-wall in plants Philosophical Transactions of the Royal Society B, 1921(210): p. 49-82.

[113] Nodder, C.R., A Study of Flax and Kindred Fibres. Journal of the Textile Institute Proceedings and Abstracts, 1922. 13(10): p. 213-219.

[114] Nyholm, K., et al., Dislocations in pulp fibres - Their origin, characteristics and importance - A review. Nordic Pulp And Paper Research Journal, 2001. 16: p. 376-384.

[115] $\mathrm{Qi}, \mathrm{H}_{\text {., }}$ et al., Investigation of the structure of ramie fibers by enzymatic peeling. Cellulose, 2019. 26(5): p. 2955-2968.

[116] Thygesen, L.G., J.B. Bilde-Sørensen, and P. Hoffmeyer, Visualisation of dislocations in hemp fibres: A comparison between scanning electron microscopy (SEM) and polarized light microscopy (PLM). Industrial Crops and Products, 2006. 24(2): p. 181-185.

[117] Placet, V., O. Cissé, and M. Lamine Boubakar, Nonlinear tensile behaviour of elementary hemp fibres. Part I: Investigation of the possible origins using repeated progressive loading with in situ microscopic observations. Composites Part A: Applied Science and Manufacturing, 2014. 56: p. 319-327.

[118] Thygesen, L.G. and P. Hoffmeyer, Image analysis for the quantification of dislocations in hemp fibres. Industrial Crops and Products, 2005. 21(2): p. 173-184.

[119] Dai, D. and M. Fan, Investigation of the dislocation of natural fibres by Fourier-transform infrared spectroscopy. Vibrational Spectroscopy, 2011. 55(2): p. 300-306.

[120] Thygesen, L.G., et al., Role of supramolecular cellulose structures in enzymatic hydrolysis of plant cell walls. Journal of Industrial Microbiology and Biotechnology, 2011. 38(8): p. 975-83.

[121] Thygesen, L.G., M. Eder, and I. Burgert, Dislocations in single hemp fibresinvestigations into the relationship of structural distortions and tensile properties at the cell wall level. Journal of Materials Science, 2007. 42(2): p. 558-564.

[122] Hänninen, T., et al., Mechanical processing of bast fibres: The occurrence of damage and its effect on fibre structure. Industrial Crops and Products, 2012. 39: p. 7-11.

[123] Hidayat, B.J., et al., Cellulose is not just cellulose: a review of dislocations as reactive sites in the enzymatic hydrolysis of cellulose microfibrils. Cellulose, 2012. 19(5): p. 1481-1493.

[124] Terziev, N., G. Daniel, and A. Marklund, Dislocations in Norway spruce fibres and their effect on properties of pulp and paper. Holzforschung, 2005. 59(2): p. 163-169.

[125] Eder, M., et al., The effect of (induced) dislocations on the tensile properties of individual Norway spruce fibres. Holzforschung, 2008. 62(1): p. 77-81.

[126] Hernandez-Estrada, A., M. Reza, and M. Hughes, The Structure of Dislocations in Hemp (Cannabis sativa L.) Fibres and Implications for Mechanical Behaviour. BioResources, 2020. 15: p. 2579-2595.

[127] Zhang, H., et al. Multi-modal Microscopy Characterisation of Nodal Markings in Flax Fibre. in World Congress on Engineering 2015. London.

[128] Thygesen, L.G. and M.R. Asgharipour, The effects of growth and storage conditions on dislocations in hemp fibres. Journal of Materials Science, 2008. 43(10): p. 3670-3673.

[129] Niez, B., et al., Water-stressed or not, the mechanical acclimation is a priority requirement for trees. Trees, 2018. 33(1): p. 279-291.

[130] Ibragimova, N.N., M.V. Ageeva, and T.A. Gorshkova, Development of gravitropic response: unusual behavior of flax phloem G-fibers. Protoplasma, 2017. 254(2): p. 749762.

[131] Barbulée, A., Compréhension des effets du défibrage sur la morphologie, les propriétés et le comportement mécanique des faisceaux de fibres de lin. Etude d'un composite dérivé lin-époxyde, thesis. 2015, Université de Caen Basse-Normandie.

[132] Bos, H., A. Van Den Oever, and O. Peters, Tensile and compressive properties of flax fibres for natural fibre reinforced composites. Journal of Materials Science, 2002. 37: $p$. 1683 - 1692. 
[133] Thygesen, L.G., Quantification of dislocations in hemp fibers using acid hydrolysis and fiber segment length distributions. Journal of Materials Science, 2008. 43(4): p. 13111317.

[134] Ander, P. and G. Daniel, Dislocations counting and comparison of pulp fibre properties after $\mathrm{HCl}$ treatment and fibre length determination. Proceedings of the Fifth Plant Bio mechanics Conference, 2006. I: p. 169-174.

[135] Hernandez-Estrada, A., et al., Assessing the susceptibility of hemp fibre to the formation of dislocations during processing. Industrial Crops and Products, 2016. 85: p. 382-388.

[136] Mott, L., et al., The tensile testing of individual wood fibers using environmental scanning electron microscopy and video image analysis. Tappi Journal, 1995. 78: p. 143-148.

[137] Mott, L., S.M. Shaler, and L. Groom, A technique to measure strain distributions in single wood pulp fibers. Tappi Journal, 1996. 28(4): p. 429-437.

[138] Zeng, X., S.J. Mooney, and C.J. Sturrock, Assessing the effect of fibre extraction processes on the strength of flax fibre reinforcement. Composites Part A: Applied Science and Manufacturing, 2015. 70: p. 1-7.

[139] Davies, G. and D. Bruce, Effect of Environmental Relative Humidity and Damage on the Tensile Properties of Flax and Nettle Fibers. Textile Research Journal, 1998. 68: p. 623629.

[140] Baley, C., Influence of kink bands on the tensile strength of flax fibers. Journal of Materials Science, 2004. 39: p. 331 - 334.

[141] Rask, M., et al., In situ observations of microscale damage evolution in unidirectional natural fibre composites. Composites Part A: Applied Science and Manufacturing, 2012. 43(10): p. 1639-1649.

[142] Van de Weyenberg, I., et al., Influence of processing and chemical treatment of flax fibres on their composites. Composites Science and Technology, 2003. 63(9): p. 1241-1246.

[143] Coroller, G., et al., Effect of flax fibres individualisation on tensile failure of flax/epoxy unidirectional composite. Composites Part A: Applied Science and Manufacturing, 2013. 51: p. 62-70.

[144] Le Duigou, A., et al., Interfacial properties of flax fibre-epoxy resin systems: Existence of a complex interphase. Composites Science and Technology, 2014. 100: p. 152-157.

[145] Trivaudey, F., et al., Nonlinear tensile behaviour of elementary hemp fibres. Part II: Modelling using an anisotropic viscoelastic constitutive law in a material rotating frame. Composites Part A: Applied Science and Manufacturing, 2015. 68: p. 346-355.

[146] Nilsson, T. and P.J. Gustafsson, Influence of dislocations and plasticity on the tensile behaviour of flax and hemp fibres. Composites Part A: Applied Science and Manufacturing, 2007. 38(7): p. 1722-1728.

[147] Deng, Q., S. Li, and Y. Chen, Mechanical properties and failure mechanism of wood cell wall layers. Computational Materials Science, 2012. 62: p. 221-226.

[148] Chen, $\mathrm{P}$., et al., $1 \alpha$ to $1 \mathrm{~B}$ mechano-conversion and amorphization in native cellulose simulated by crystal bending. Cellulose, 2018. 25(8): p. 4345-4355.

[149] Khodayari, A., et al., Tensile behaviour of dislocated/crystalline cellulose fibrils at the nano scale. Carbohydrate Polymers, 2020. 235: p. 115946.

[150] Khodayari, A., et al., Recrystallization and size distribution of dislocated segments in cellulose microfibrils-a molecular dynamics perspective. Cellulose, 2021.

[151] Sliseris, J., L. Yan, and B. Kasal, Numerical modelling of flax short fibre reinforced and flax fibre fabric reinforced polymer composites. Composites Part B: Engineering, 2016. 89: p. 143-154.

[152] Jayne, B.A., Mechanical properties of wood fibers. Tappi Journal, 1959. 42: p. 461-467.

[153] Eder, M., et al., Experimental micromechanical characterisation of wood cell walls. Wood Science and Technology, 2012. 47(1): p. 163-182.

[154] Baley, C., Analysis of the flax fibres tensile behaviour and analysis of the tensile stiffness increase. Composites Part A: Applied Science and Manufacturing, 2002. 33: p. 939 - 948. 
[155] Griffith, A.A., The phenomena of rupture and flow in solids Philosophical Transactions od the Royal Society of London. Series A, Containing Papers of a Mathematical of Physical Character, 1921. 221: p. 163-198.

[156] Burgert, I., et al., Microtensile Testing of Wood Fibers Combined with Video Extensometry for Efficient Strain Detection. Holzforschung, 2003. 57(6).

[157] Réquilé, S., et al., Exploring the link between flexural behaviour of hemp and flax stems and fibre stiffness. Industrial Crops and Products, 2018. 113: p. 179-186.

[158] Cisse, O., et al., Creep behaviour of single hemp fibres. Part I: viscoelastic properties and their scattering under constant climate. Journal of Materials Science, 2014. 50(4): p. 1996-2006.

[159] Olsson, A.-M., et al., Mechano-sorptive creep in wood fibres. Wood Science and Technology, 2006. 41(1): p. 59-67.

[160] Arnould, O., et al., Better insight into the nano-mechanical properties of flax fibre cell walls. Industrial Crops and Products, 2017. 97: p. 224-228.

[161] Feigel, B., et al., Assessment of Mechanical Property Variation of As-Processed Bast Fibers. Sustainability, 2019. 11(9).

[162] Bourmaud, A., et al., Influence of the morphology characters of the stem on the lodging resistance of Marylin flax. Industrial Crops and Products, 2015. 66: p. 27-37.

[163] Baley, C. and A. Bourmaud, Average tensile properties of French elementary flax fibers. Materials Letters, 2014. 122: p. 159-161.

[164] Zafeiropoulosa, N.E., et al., Engineering and characterisation of the interface in flax fibre/polypropylene composite materials. Part I. Development and investigation of surface treatments. Composites Part A: Applied Science and Manufacturing, 2002. 33: p. 1083 - 1093.

[165] Turek, D.E., On the tensile testing of high modulus polymers and the compliance correction. Polymer Engineering And Science, 1993. 33(6): p. 328-333.

[166] Haag, K. and J. Müssig, Scatter in tensile properties of flax fibre bundles: influence of determination and calculation of the cross-sectional area. Journal of Materials Science, 2016. 51(17): p. 7907-7917.

[167] Summerscales, J., A.S. Virk, and W. Hall, Fibre area correction factors (FACF) for the extended rules-of-mixtures for natural fibre reinforced composites. Materials Today: Proceedings, 2020. 31.

[168] Placet, V., et al., Diameter dependence of the apparent tensile modulus of hemp fibres: A morphological, structural or ultrastructural effect? Composites Part A: Applied Science and Manufacturing, 2012. 43(2): p. 275-287.

[169] Shah, D.U., R.K. Nag, and M.J. Clifford, Why do we observe significant differences between measured and 'back-calculated' properties of natural fibres? Cellulose, 2016. 23(3): p. 1481-1490.

[170] Charlet, K., et al., Mechanical Properties of Flax Fibers and of the Derived Unidirectional Composites. Journal of Composite Materials, 2010. 44(24): p. 2887-2896.

[171] Bensadoun, F., et al., Impregnated fibre bundle test for natural fibres used in composites. Journal of Reinforced Plastics and Composites, 2017. 36(13): p. 942-957.

[172] Prapavesis, A., et al., Back calculated compressive properties of flax fibers utilizing the Impregnated Fiber Bundle Test (IFBT). Composites Part A: Applied Science and Manufacturing, 2020. 135: p. 105930.

[173] Charlet, K., et al., Tensile deformation of a flax fiber. Procedia Engineering, 2009. 1(1): p. 233-236.

[174] Romhany, G., J. Karger-Kocsis, and T. Czigany, Tensile Fracture and Failure Behavior of Technical Flax Fibers. Journal of Applied Polymer Science, 2003. 90: p. 3638 - 3645.

[175] Alix, S., et al., Effect of chemical treatments on water sorption and mechanical properties of flax fibres. Bioresource Technology, 2009. 100(20): p. 4742-9. 
[176] Sakurada, I., Y. Nubushina, and T. Ito, Experimental determination of the elastic modulus of crystalline regions in oriented polymers. Journal Of Polymer Science 1962. 57: p. 651660.

[177] Astley, O. and A. Donald, The tensile deformation of flax fibres as studied by X-ray scattering. Journal of materials science, 2003. 38: p. 165-171.

[178] Zamil, M.S. and A. Geitmann, The middle lamella-more than a glue. Physical Biology, 2017. 14(1): p. 015004.

[179] Wimmer, R. and N.B. Lucas, Comparing mechanical properties of secondary wall and cell corner middle lamella in spruce wood. lawa Journal, 2007. 18: p. 77-88.

[180] Melelli, A., et al., The Middle Lamella of Plant Fibers Used as Composite Reinforcement: Investigation by Atomic Force Microscopy. Molecules, 2020. 25(3).

[181] Bos, H., The Potential of Flax Fibres as Reinforcement for Composite Materials, thesis. 2004, Technische Universiteit Eindhoven.

[182] Charlet, K. and A. Beakou, Interfaces within flax fibre bundle: Experimental characterization and numerical modelling. Journal of Composite Materials, 2013. 48(26): p. 3263-3269.

[183] Barbulée, A., et al., Damage to flax fibre slivers under monotonic uniaxial tensile loading. Composites Part A: Applied Science and Manufacturing, 2014. 64: p. 107-114.

[184] Fuentes, C.A., et al., Effect of the middle lamella biochemical composition on the nonlinear behaviour of technical fibres of hemp under tensile loading using strain mapping. Composites Part A: Applied Science and Manufacturing, 2017. 101: p. 529-542.

[185] Virk, A.S., Numerical models for natural fibre composites with stochastic properties, thesis. 2010, University of Plymouth.

[186] Del Masto, A., et al., Multiscale stochastic model and simulation for the study of the nonlinear behaviour of plant fibre composites, in International Conference on Composite Materials. 2017: Xi'an; China.

[187] Hofstetter, K. and E.K. Gamstedt, Hierarchical modelling of microstructural effects on mechanical properties of wood. A review COST Action E35 2004-2008: Wood machining - micromechanics and fracture. Holzforschung, 2009. 63(2).

[188] Bergander, A. and L. Salmen, Cell wall properties and their effects on the mechanical properties of fibers. Journal of Materials Science, 2002. 37: p. 151-156.

[189] Neagu, R.C. and E.K. Gamstedt, Modelling of effects of ultrastructural morphology on the hygroelastic properties of wood fibres. Journal of Materials Science, 2007. 42(24): p. 10254-10274.

[190] Joffre, T., et al., A Method to Measure Moisture Induced Swelling Properties of a Single Wood Cell. Experimental Mechanics, 2016. 56(5): p. 723-733.

[191] Saavedra Flores, E.I. and S. Haldar, Micro-macro mechanical relations in Palmetto wood by numerical homogenisation. Composite Structures, 2016. 154: p. 1-10.

[192] Gassan, J., A. Chate, and A.K. Bledzki, Calculation of elastic properties of natural fibers. Journal of Materials Science, 2001. 36: p. 3715-3720.

[193] Del Masto, A., et al., Nonlinear tensile behaviour of elementary hemp fibres: a numerical investigation of the relationships between $3 D$ geometry and tensile behaviour. Journal of Materials Science, 2017. 52: p. 6591-6610.

[194] Del Masto, A., et al., Investigation of the possible origins of the differences in mechanical properties of hemp and flax fibres: A numerical study based on sensitivity analysis. Composites Part A: Applied Science and Manufacturing, 2019. 124: p. 105488.

[195] Thuault, A., et al., Numerical study of the influence of structural and mechanical parameters on the tensile mechanical behaviour of flax fibres. Journal of Industrial Textiles, 2013. 44: p. 22-39.

[196] Charlet, K. and A. Béakou, Mechanical properties of interfaces within a flax bundle - Part I: Experimental analysis. International Journal of Adhesion and Adhesives, 2011. 31(8): p. 875-881. 
[197] Beakou, A. and K. Charlet, Mechanical properties of interfaces within a flax bundle-Part II: Numerical analysis. International Journal of Adhesion and Adhesives, 2013. 43: p. 5459.

[198] Sedighi-Gilani, M., A micromechanical approach to the behaviour of single wood fibers and wood fracture at cellular level, thesis. 2006, EPFL.

[199] Sedighi-Gilani, M. and P. Navi, Experimental observations and micromechanical modeling of successive-damaging phenomenon in wood cells' tensile behavior. Wood Science and Technology, 2006. 41(1): p. 69-85.

[200] Khodayari, A., et al., Cellulose-hemicellulose interactions - A nanoscale view. Carbohydrate Polymers, 2021. 270.

[201] Jawaid, M. and H.P.S. Abdul Khalil, Cellulosic/synthetic fibre reinforced polymer hybrid composites: A review. Carbohydrate Polymers, 2011. 86(1): p. 1-18.

[202] Goudenhooft, C., A. Bourmaud, and C. Baley, Varietal selection of flax over time: Evolution of plant architecture related to influence on the mechanical properties of fibers. Industrial Crops and Products, 2017. 97: p. 56-64.

[203] Charlet, K., et al., Scattering of morphological and mechanical properties of flax fibres. Industrial Crops and Products, 2010. 32(3): p. 220-224.

[204] Alves Fidelis, M.E., et al., The effect of fiber morphology on the tensile strength of natural fibers. Journal of Materials Research and Technology, 2013. 2(2): p. 149-157.

[205] Yan, L., et al., Effects of resin inside fiber lumen on the mechanical properties of sisal fiber reinforced composites. Composites Science and Technology, 2015. 108: p. 32-40.

[206] Liu, K., et al., Effect of physicochemical structure of natural fiber on transverse thermal conductivity of unidirectional abaca/bamboo fiber composites. Composites Part A: Applied Science and Manufacturing, 2012. 43(8): p. 1234-1241.

[207] Schäfer, T. and B. Honermeier, Effect of sowing date and plant density on the cell morphology of hemp (Cannabis sativa L.). Industrial Crops and Products, 2006. 23(1): p. 88-98.

[208] Richely, E., et al., Novel Insight into the Intricate Shape of Flax Fibre Lumen. Fibers, 2021. 9(4).

[209] Alix, S., et al., Pectinase treatments on technical fibres of flax: Effects on water sorption and mechanical properties. Carbohydrate Polymers, 2012. 87(1): p. 177-185.

[210] Depuydt, D., et al., Digital image correlation as a strain measurement technique for fibre tensile tests. Composites Part A: Applied Science and Manufacturing, 2017. 99: p. 76-83.

[211] Perremans, D., et al., Effect of chemical treatments on the mechanical properties of technical flax fibres with emphasis on stiffness improvement. Composites Science and Technology, 2018. 160: p. 216-223.

[212] Van Hazendonk, J.M., et al., Structural analysis of acetylated hemicellulose polysaccharides from fibre flax ( Linum usitatissimum L.). Carbohydrate Research, 1996. 291: p. 141-144.

[213] Batra, S.K., Handbook of Fibre Science And Technology: Other Long Vegetable Fibers. Fibre Chemistry, 1998. 4: p. 505-571.

[214] Bochek, A.M., et al., Isolation of Pectins from Flax Pedicels and Fibers and Their Characterization. Russian Journal of Applied Chemistry, 2002. 75(9): p. 1517-1521.

[215] Van Sumere, C. and H.S. Shekhar Sharma, Analysis of fine flax fibre produced by enzymatic retting Aspects of Applied Biology, 1991. 28: p. 15-20.

[216] Girault, R., et al., Identification and partial characterization of proteins and proteoglycans encrusting the secondary cell walls of flax fibres. Planta, 2000. 211(2): p. 256-264.

[217] Akin, D.E., et al., Plant factors influencing enzyme retting of fiber and seed flax. 2001. 49(12): p. 5778-5784.

[218] Gamble, G.R., et al., Phenolic constituents in flax bast tissue and inhibition of cellulase and pectinase. Biotechnology Letters, 2000. 22(9): p. 741-746. 
[219] Mayer-Laigle, C., et al., Unravelling the consequences of ultra-fine milling on physical and chemical characteristics of flax fibres. Powder Technology, 2019.

[220] Chabbert, B., et al., Multimodal assessment of flax dew retting and its functional impact on fibers and natural fiber composites. 2020. 148: p. 112255.

[221] Garat, W., et al., Dimensional Variations and Mechanical Behavior of Various Plant Fibre Species under Controlled Hydro / Hygrothermal Conditions. Revue Des Composites Et Des Materiaux Avances-Journal of Composite and Advanced Materials, 2019. 29(5): p. 299-304.

[222] De Prez, J., et al., Flax treatment with strategic enzyme combinations: Effect on chemical fiber composition and ease of fiber extraction. Biotechnology Reports, 2019. 23: p. e00358.

[223] Cadu, T., et al., Cyclic hygrothermal ageing of flax fibers' bundles and unidirectional flax/epoxy composite. Are bio-based reinforced composites so sensitive? Industrial Crops and Products, 2019. 141.

[224] Pandey, R., et al., Novel Methods of Degumming and Bleaching of Indian Flax Variety Tiara. Journal of Natural Fibers, 2019: p. 1-11.

[225] Dymińska, L., et al., Spectroscopic characterization of genetically modified flax fibers. Journal of Molecular Structure, 2014. 1074: p. 321-329.

[226] Tserki, V., et al., A study of the effect of acetylation and propionylation surface treatments on natural fibres. Composites Part A: Applied Science and Manufacturing, 2005. 36(8): p. 1110-1118.

[227] Bourmaud, A. and C. Baley, Nanoindentation contribution to mechanical characterization of vegetal fibers. Composites Part B: Engineering, 2012. 43(7): p. 28612866.

[228] Pillin, I., et al., Could oleaginous flax fibers be used as reinforcement for polymers? Industrial Crops and Products, 2011. 34(3): p. 1556-1563.

[229] Bourmaud, A., M. Gibaud, and C. Baley, Impact of the seeding rate on flax stem stability and the mechanical properties of elementary fibres. Industrial Crops and Products, 2016. 80: p. 17-25.

[230] Joffre, T., et al., Modelling of the hygroelastic behaviour of normal and compression wood tracheids. Journal of Structural Biology, 2014. 185(1): p. 89-98. 


\section{- $\quad$ Figure captions:}

Figure 1: Classification of plant fibres, adapted from [23, 201]

Figure 2: Schematic overview of flax processing steps

Figure 3: Schematic representation of the flax hierarchical structure, from the stem to the microfibrils

Figure 4: a. Light microscopy of a flax stem cross-section with toluidine blue coloration showing the cuticle, epidermis, fibre bundles, cambium and inner shives from primary and secondary xylem.

b. Schematic overview of the sandwich-like structure of the flax stem and values of relative areas from Goudenhooft et al. [202]

Figure 5: a. Schematic model of flax fibres established based on [31, 34]

b. Relative composition representation and values of flax cell-wall layers represented on a fibre cross-section, following the values established in Table 2

Figure 6: Percentage of porosity (lumen/total surface ratio) for different plant fibres obtained from transversal observations [22, 38, 203-207], adapted from [208]

Figure 7: Schematic illustration of different kinds of defects present in plant fibres divided between discontinuities and inhomogeneities at the surface or in the bulk: surface impurities (A), cracks (B) with permission of Baley et al. [140], interlaminar decohesion (C) reprinted from Hernandez et al. [126], dislocations (D) with permission of Qi et al. [115] and twisting (E) with permission of Placet et al. [117]. Scalebars homogeneized for reading conveniency

Figure 8: Defects of flax observed under a. bright light on a unitary fibre, b. polarized light on the same fibre, c. SEM on a unitary fibre and $d$. X-ray microtomography on a bundle of fibres (internal view)

Figure 9: a. Fracture behaviour of flax unitary fibres from an optical microscopy and schematic representation, with permission of [38], b. Damage mechanism in a bundle of hemp fibres: 1: $\mu$-crack departure from surface flaw, 2: surface peeling, 3: crack branching, 4: lumen crack departure, 5: intra-lumen damage, 6: inter-lumen damage, 7: inter-fibre cracking and branching, 8: interfacial cracking. Reprinted from [37].

Figure 10: Sources of variabilities regarding mechanical properties, inspired by [161].

Figure 11: Measured and back-calculated tensile properties of flax fibres from [53, 169171]. 
Figure 12: a. Stress-strain curves of TI, TII and TIII, inspired by Lefeuvre et al. [67] , b. Scenario proposed by Placet et al. to explain the TIII complex tensile behaviour of hemp fibres, adapted from [117]

Figure 13: Flax bundle strength as a function of the gauge length, from $[131,174,181$, 209-211]

Figure 14: Publication metrics in the study of wood and plant fibres modelling as a function of the year (left) and ratio between the plant fibres and wood (right) (source: Web of Science, 2020)

Figure 15: FEA principle applied to plant fibres

Figure 16: Fibre geometries based on experimental work: a. hemicellulose (left) and dislocations in embedded cellulose (right) with permission of [146], b. earlywood fibre (left) and corresponding model geometry, with heterogeneities replaced by MFA nonuniformities [198], c. morphology reconstruction of hemp fibres from optical images, with permission of [193], d. hemp fibre reconstructed from X-ray microtomography scans reprinted from [110], e. wood fibre geometry obtained by X-ray microtomography, with permission of [190] 


\section{Table captions:}

Table 1: Analytical methods and biochemical composition of flax fibre elements at the mature development stage (unless otherwise specified)

Table 2: Estimation of the biochemical components in different cell-wall layers of flax, based on estimated layer widths, and average values of biochemical composition from the literature review of Table $1^{(1)}$

Table 3: Synthesis of models including defects

Table 4: Multiscale mechanical characterization of plant fibres

Table 5: Tensile properties of flax unitary fibres, unspecified development stage and retting process

Table 6: Synthesis of models investigating plant fibres 


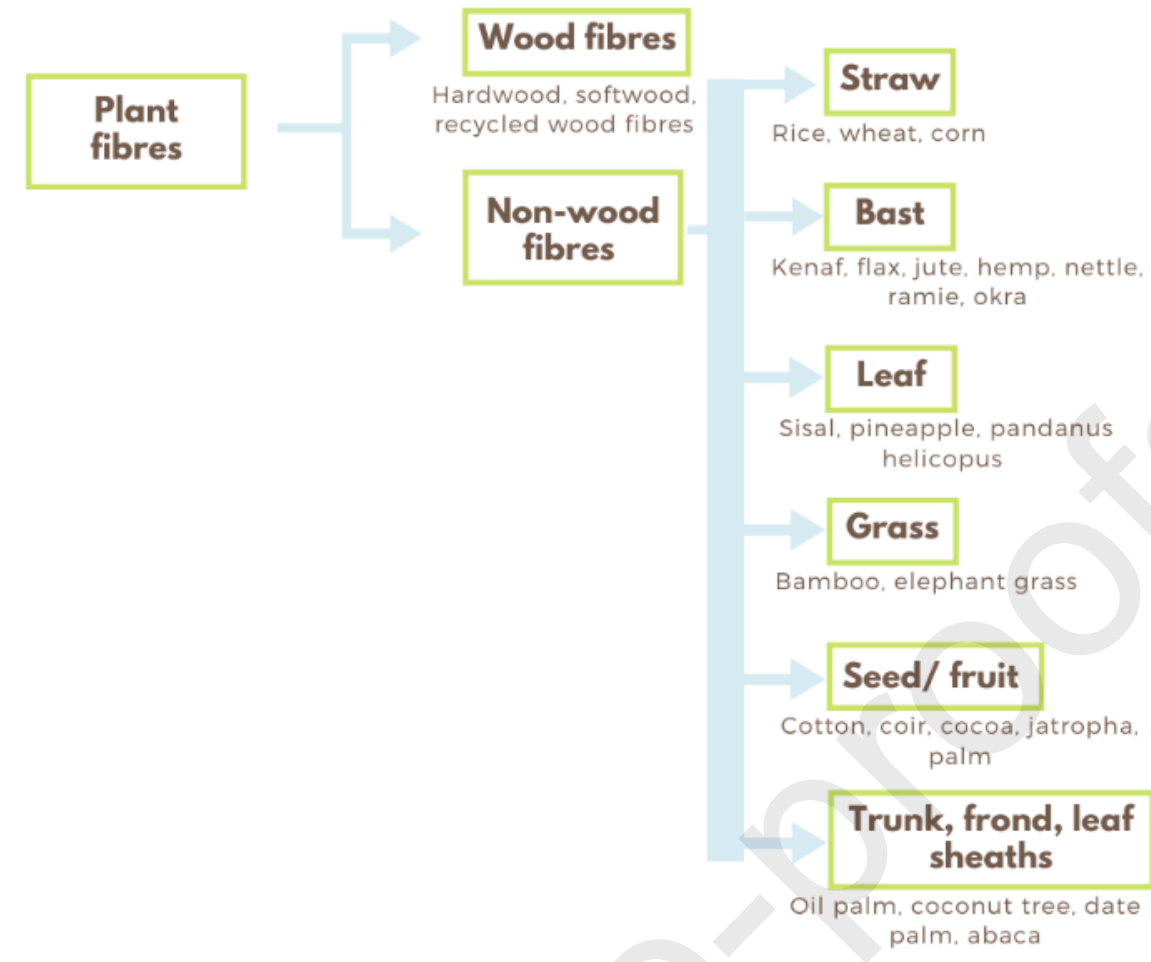

Figure 1: Classification of plant fibres, adapted from [23, 201] 


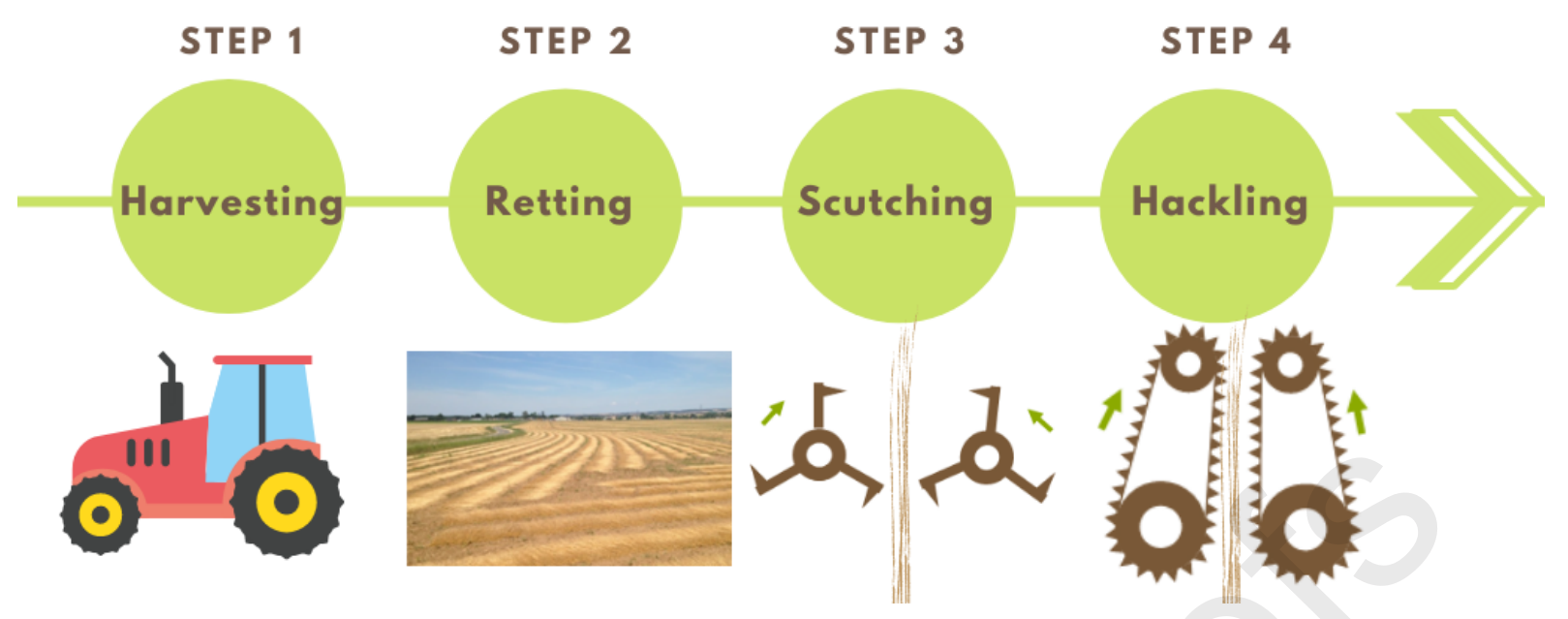

Figure 2: Schematic overview of flax processing steps 
MACROSCOPIC MESOSCOPIC MICROSCOPIC NANOSCOPIC

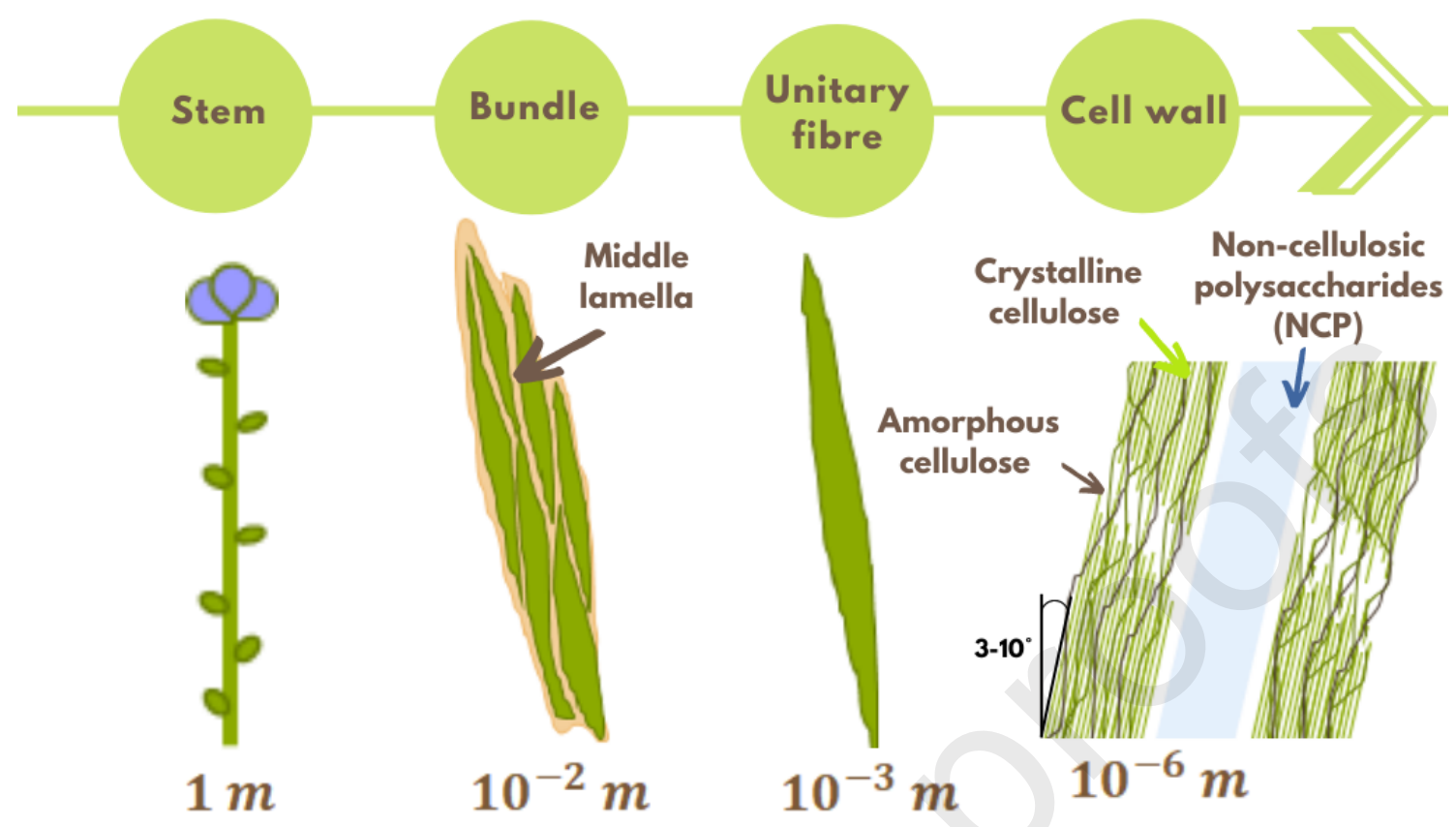

Figure 3: Schematic representation of the flax hierarchical structure, from the stem to the microfibrils 


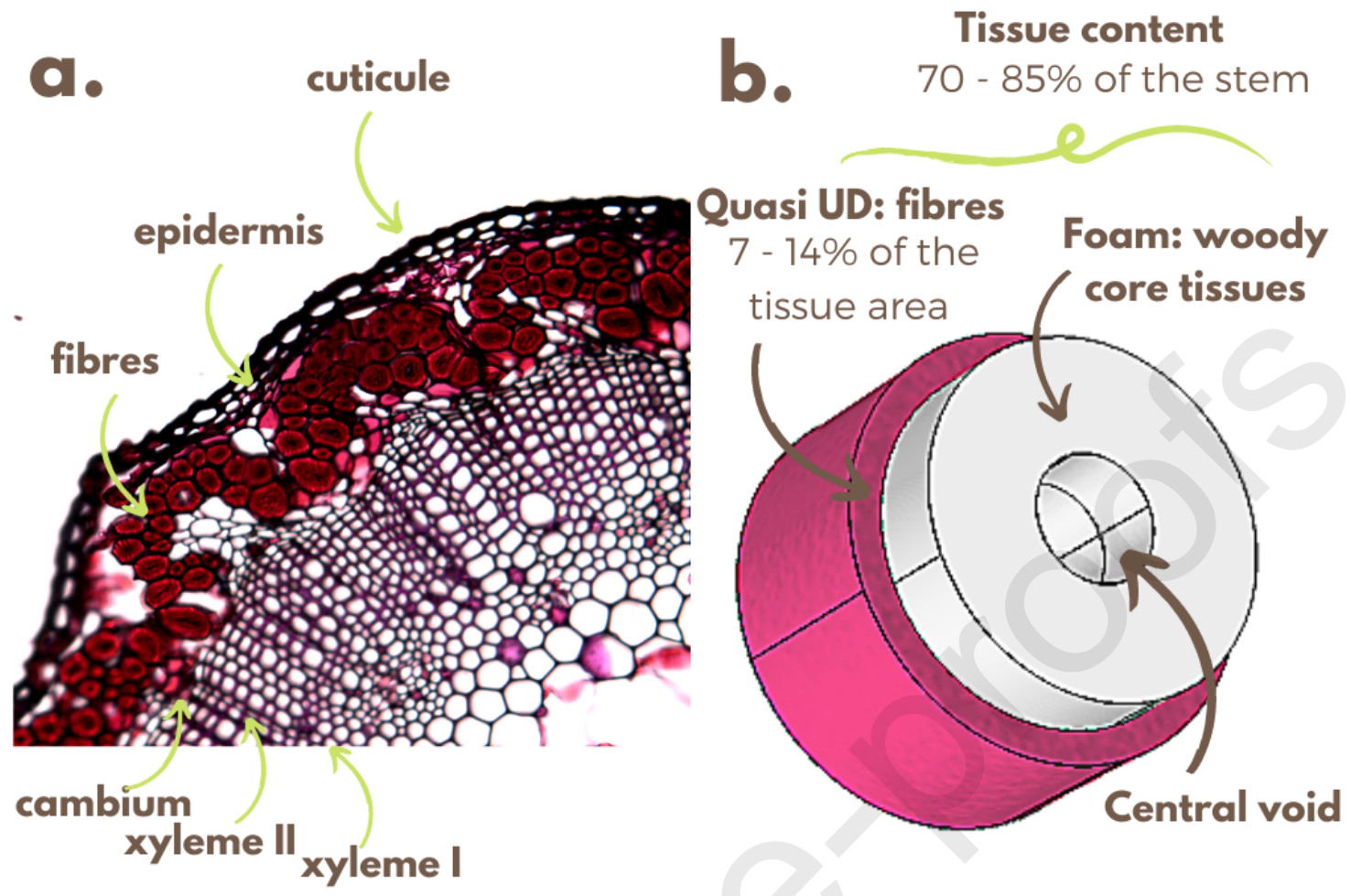

Figure 4: a. Light microscopy of a flax stem cross-section with toluidine blue coloration showing the cuticle, epidermis, fibre bundles, cambium and inner shives from primary and secondary xylem.

b. Schematic overview of the sandwich-like structure of the flax stem and values of relative areas from Goudenhooft et al. [202] 
Q.
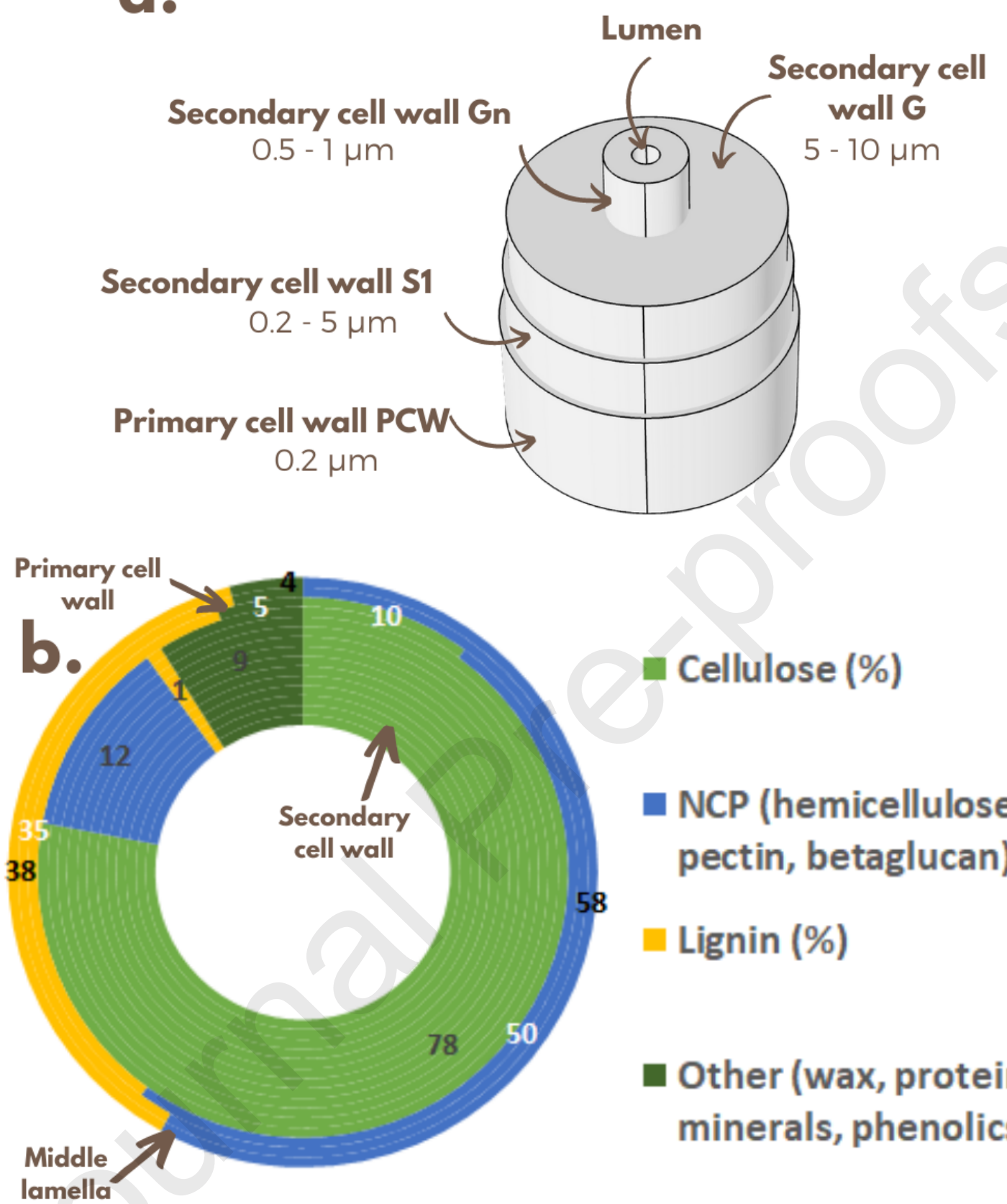

Cellulose (\%)

NCP (hemicellulose, pectin, betaglucan) (\%)

Lignin (\%)

- Other (wax, proteins, minerals, phenolics...) (\%)

Figure 5: a. Schematic model of flax fibres established based on [31, 34]

b. Relative composition representation and values of flax cell-wall layers represented on a fibre cross-section, following the values established in Table 2 


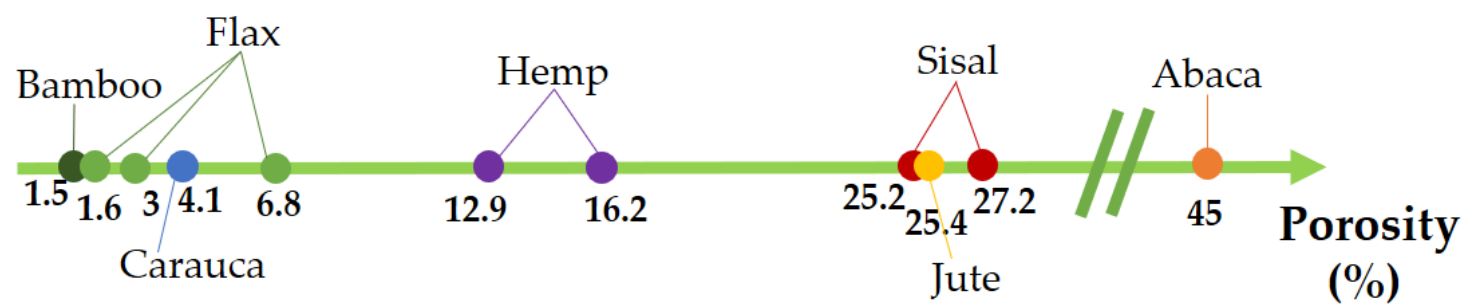

Figure 6: Percentage of porosity (lumen/total surface ratio)for different plant fibres obtained from transversal observations [22, 38, 203-207], adapted from [208] 


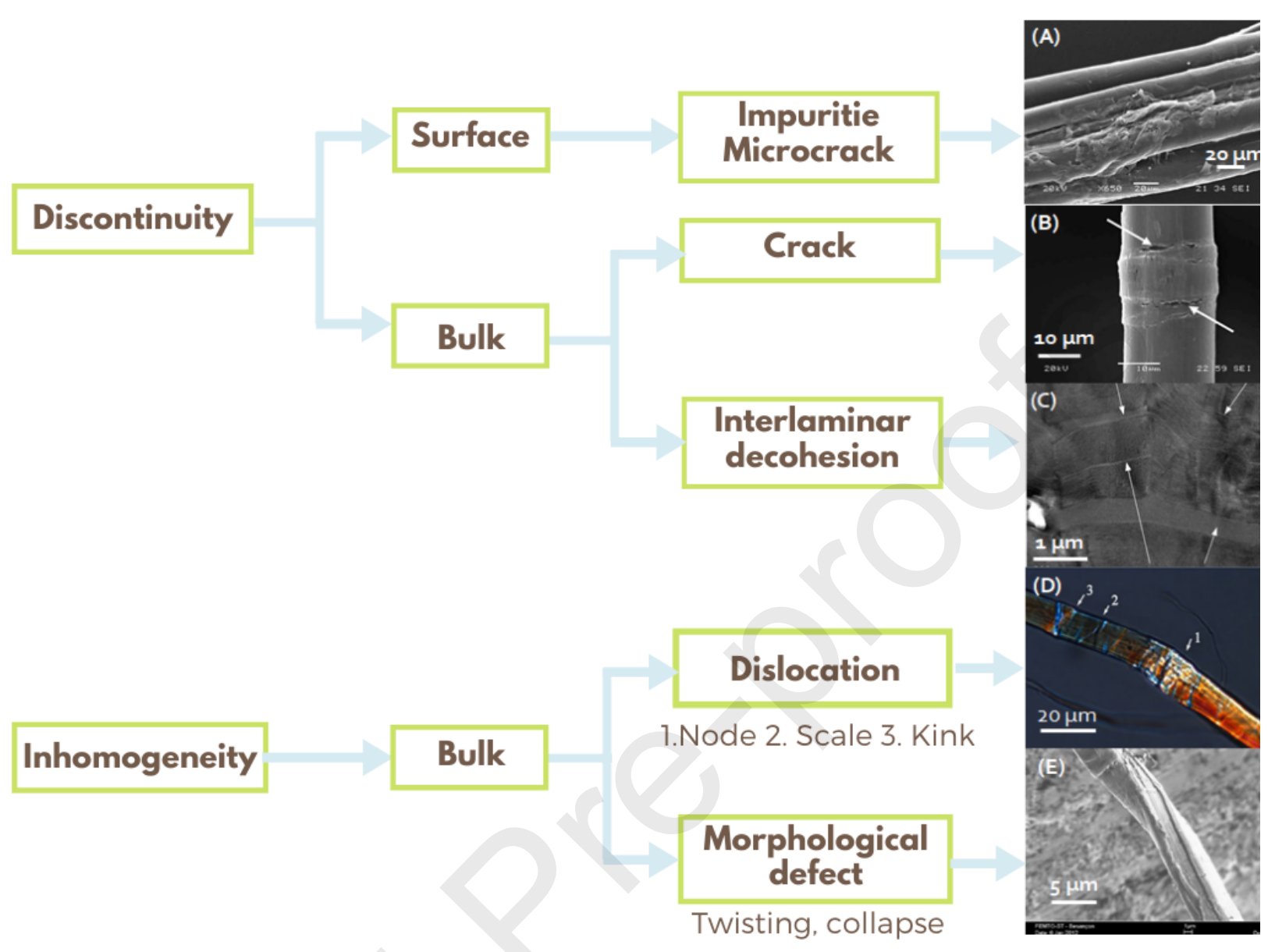

Figure 7: Schematic illustration of different kinds of defects present in plant fibres divided between discontinuities and inhomogeneities at the surface or in the bulk fibre: surface impurities (A), cracks (B) with permission of Baley et al. [140], interlaminar decohesion (C) reprinted from Hernandez et al. [126], dislocations (D) with permission of Qi et al. [115] and twisting (E) with permission of Placet et al. [117]. Scalebars homogenized for reading conveniency 


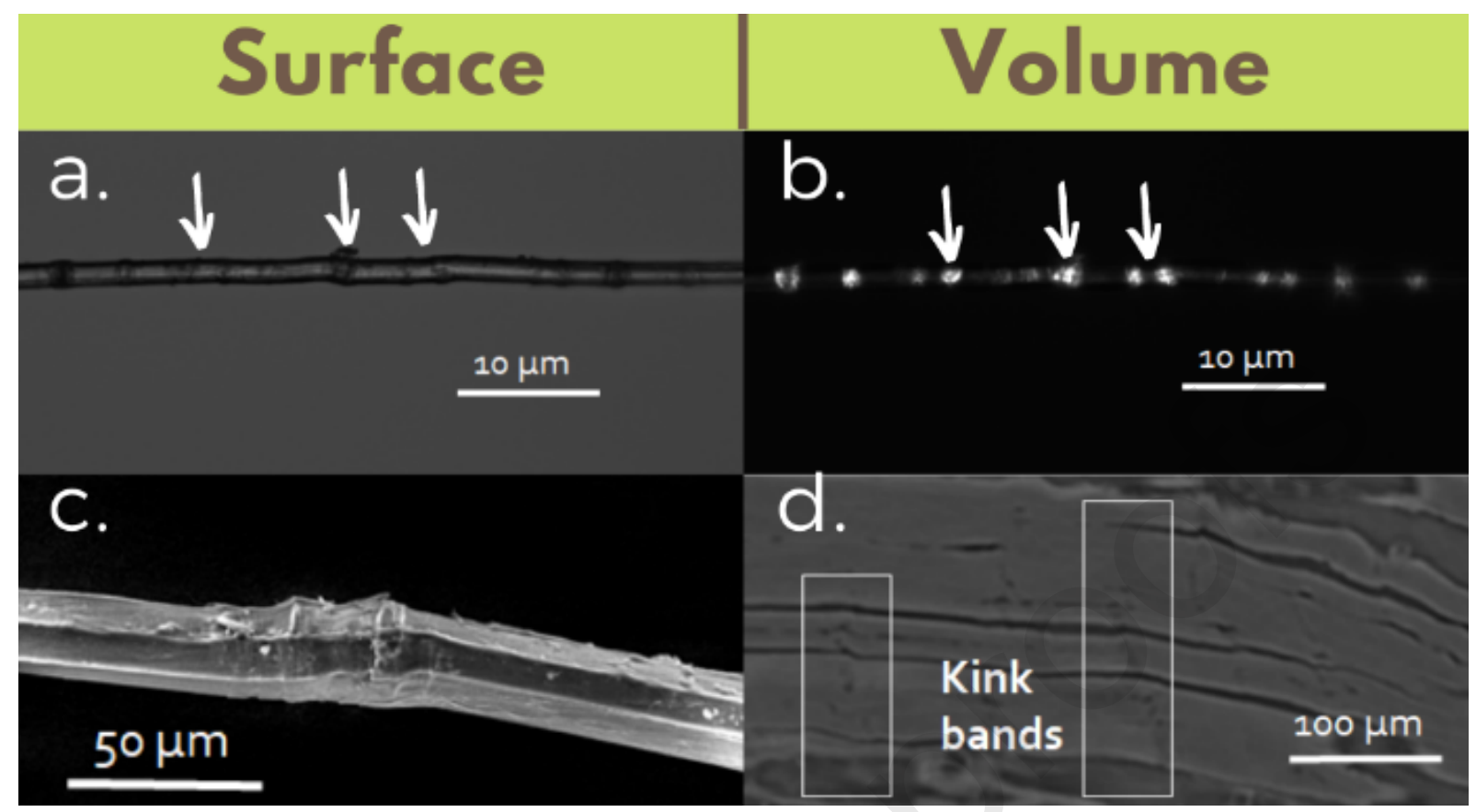

Figure 8: Defects of flax observed under $a$. bright light on a unitary fibre, b. polarized light on the same fibre, c. SEM on a unitary fibre and $d$. X-ray microtomography on a bundle of fibres (internal view) 


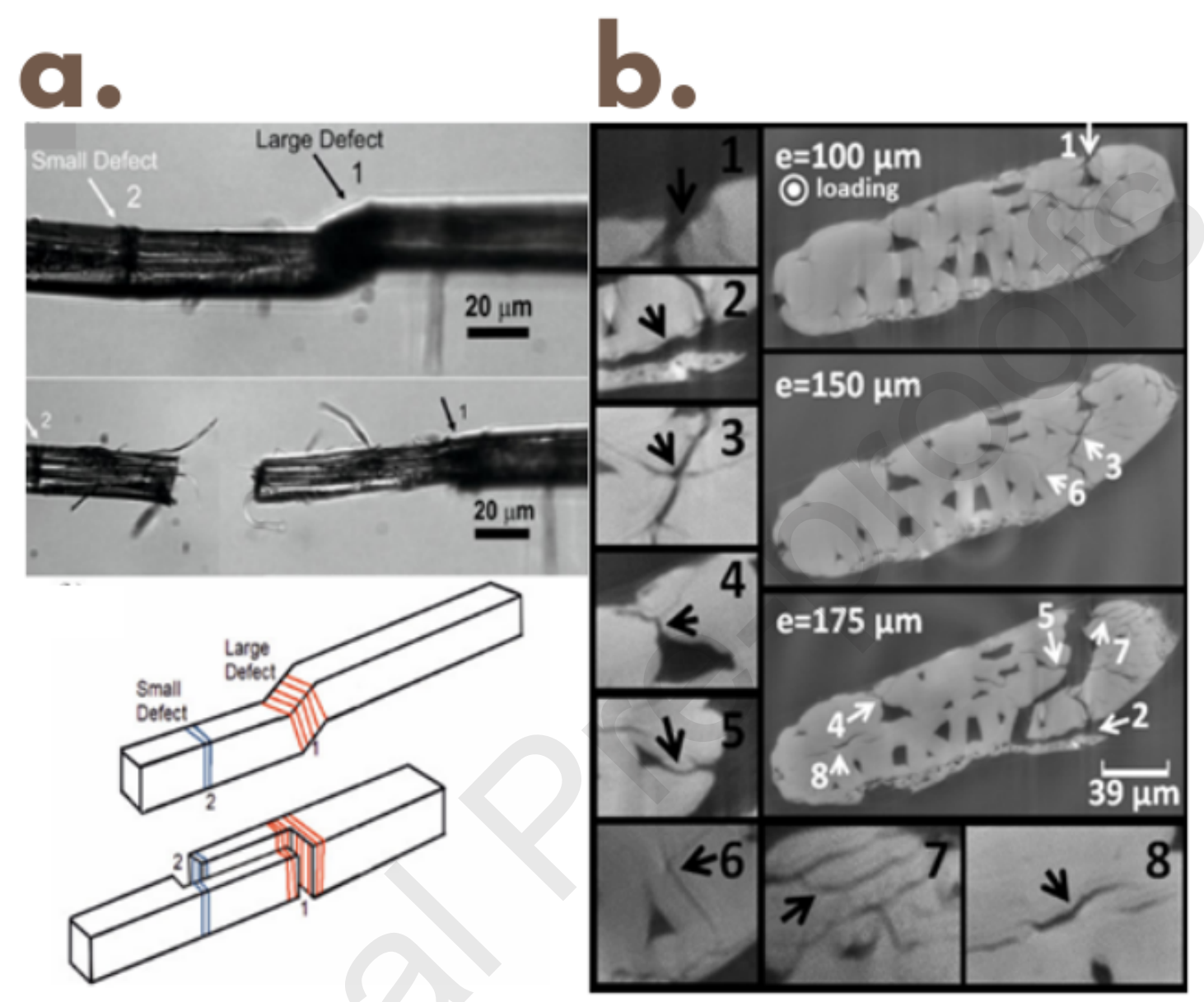

Figure 9: $\boldsymbol{a}$. Fracture behaviour of flax unitary fibres from an optical microscopy and schematic representation, with permission of [38], $\boldsymbol{b}$. Damage mechanism in a bundle of hemp fibres: 1: $\mu$ crack departure from surface flaw, 2: surface peeling, 3: crack branching, 4: lumen crack departure, 5: intra-lumen damage, 6: inter-lumen damage, 7: inter-fibre cracking and branching, 8: interfacial cracking. Reprinted from [37] 


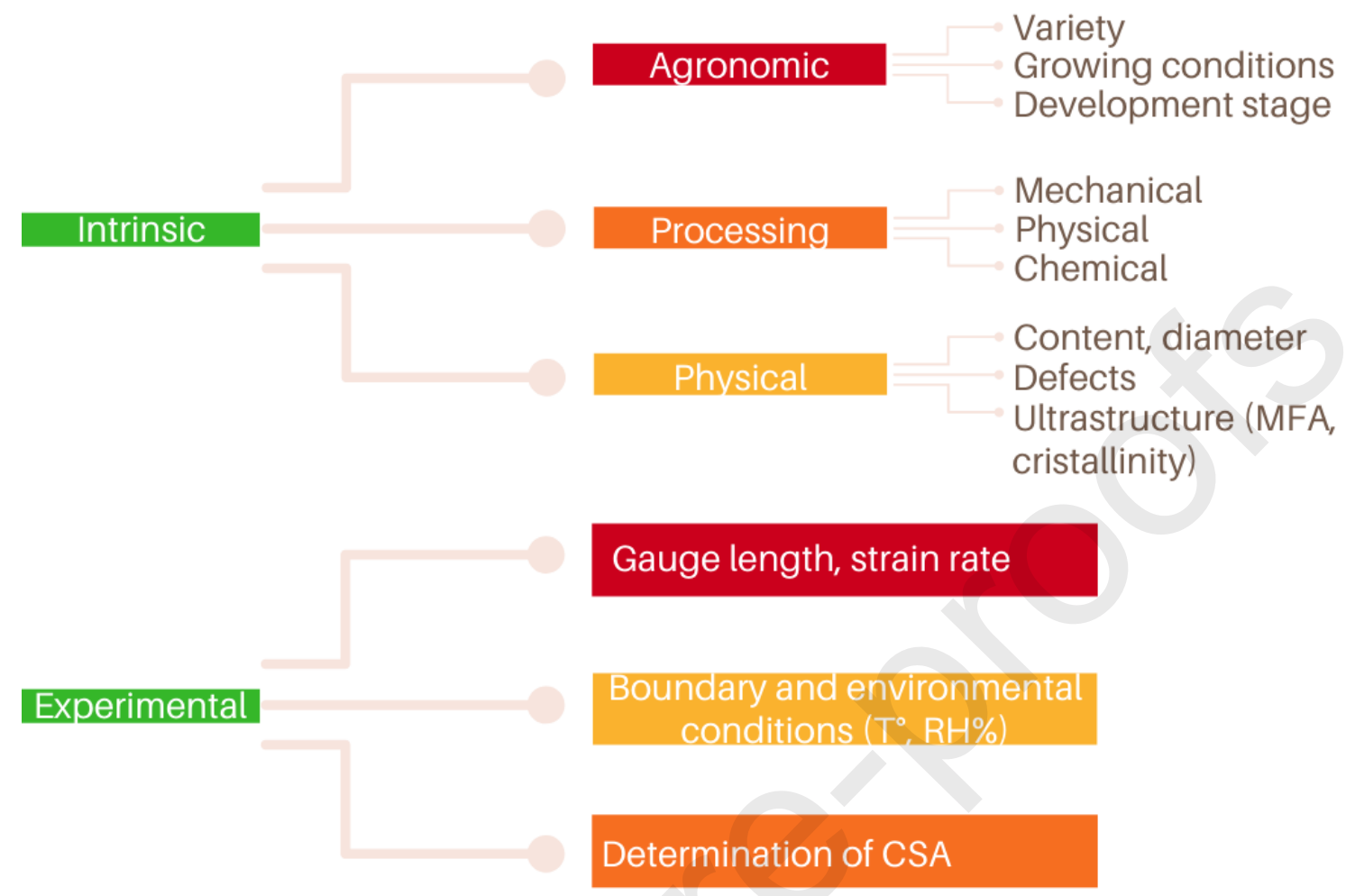

Figure 10: Sources of variabilities regarding mechanical properties, inspired by [161] 


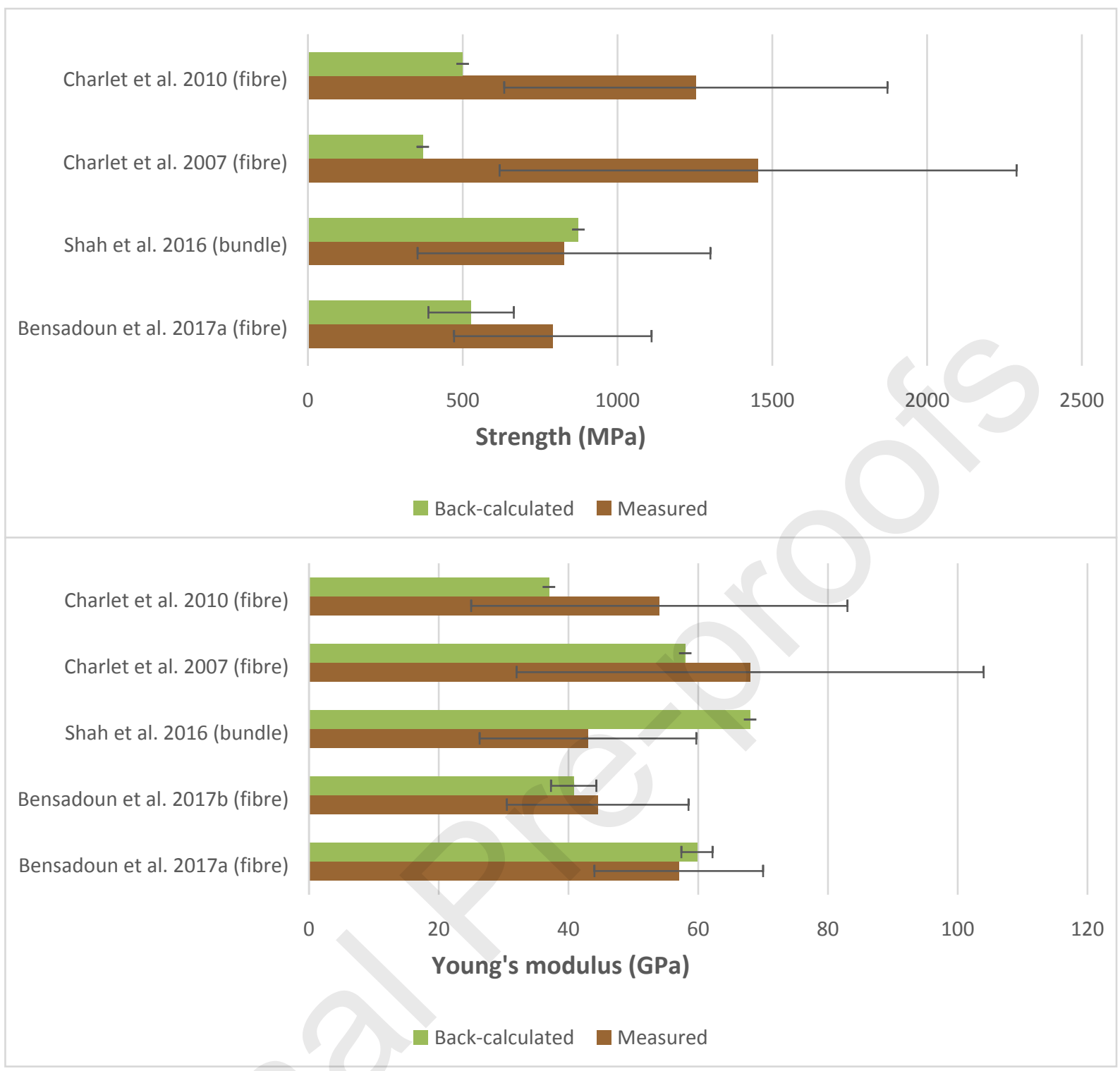

Figure 11: Measured and back-calculated tensile properties of flax fibres from [53, 169-171] 
C. 1000

900

800

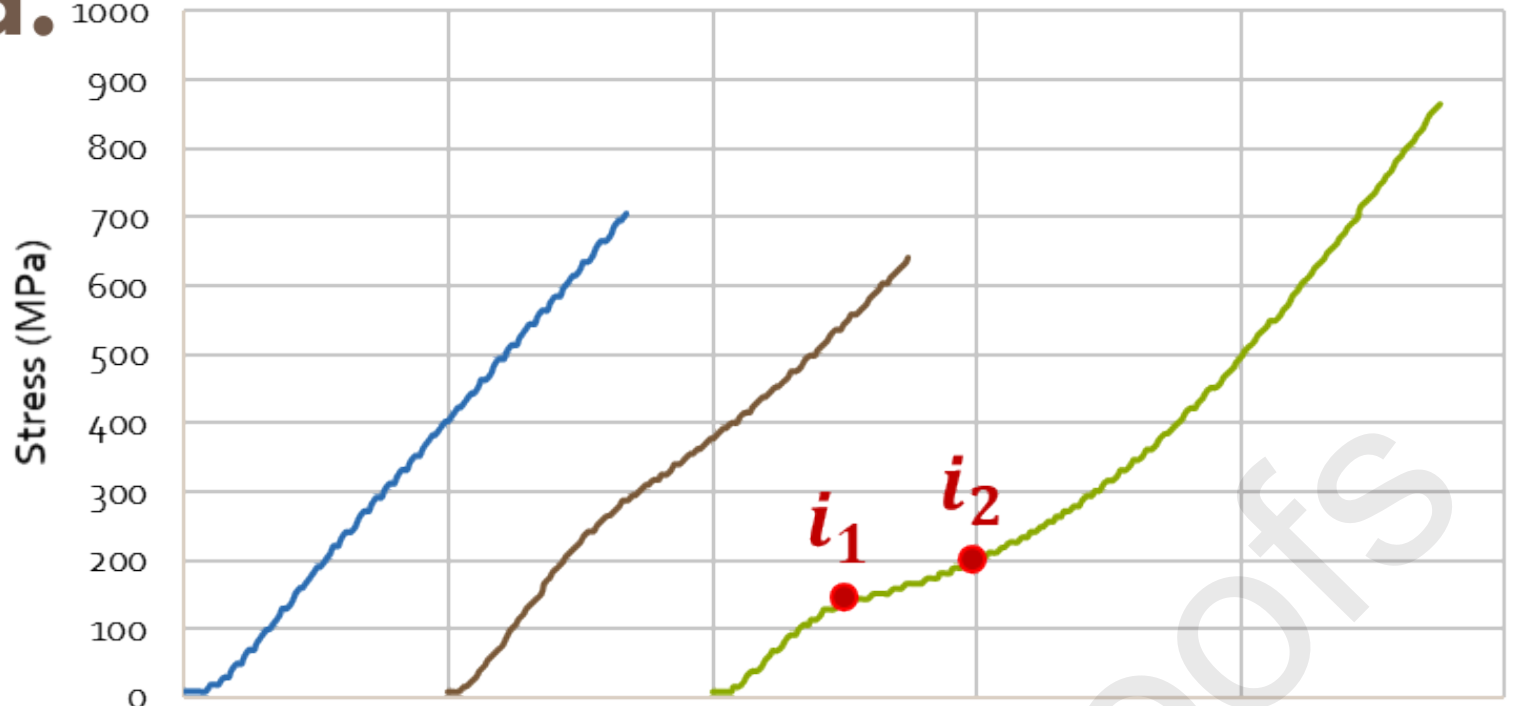

ผู 500

㐫 400

300

200

100

o

O

1

2

3

4

Strain (\%)

- Type I

— Type II — Type III

\section{b. 正itial}

Before yield level $\left(i_{1}\right)$

Shear between
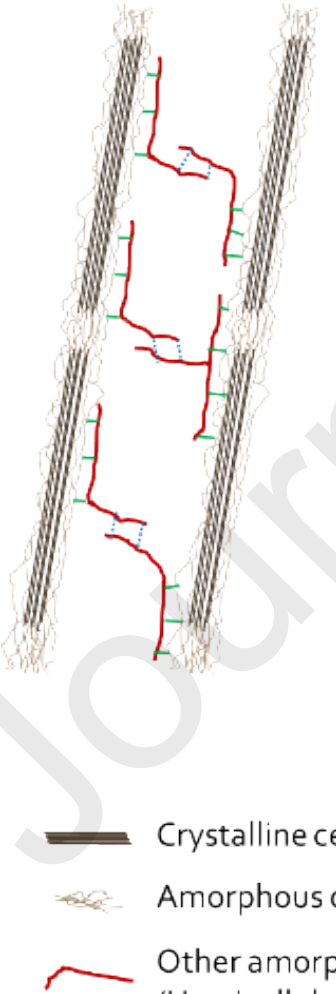

Crystalline cellulose

Amorphous cellulose

Other amorphous polymer

(Hemicelluloses, pectins)

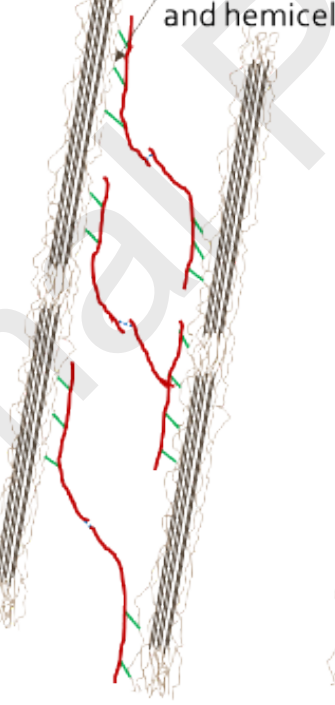

Covalentbond Hydrogen bond

\section{After yield}

level $\left(i_{1}\right)$

Shear stressinduced cristallisation of amorphous cellulose

\section{After inflection point $\left(i_{2}\right)$}

Cellulose microfibrils reorientation amorphous cellulose
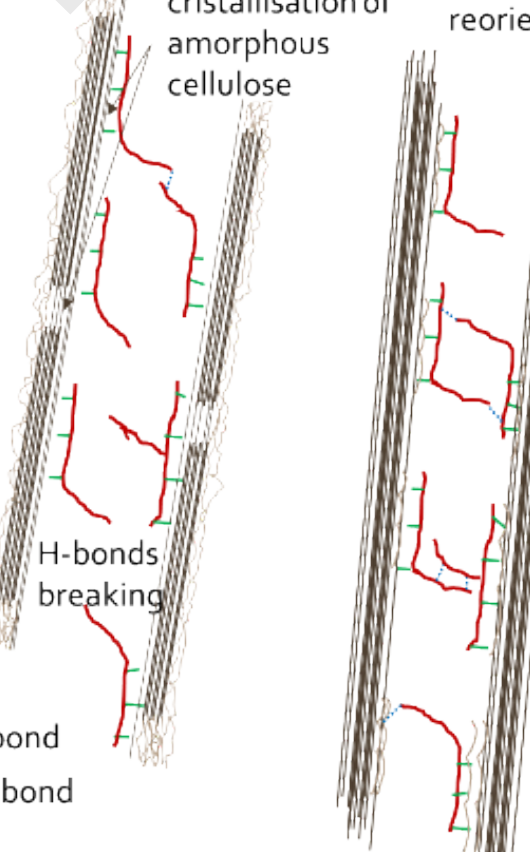

$\mathrm{H}$-bonds reformation

Figure 12: a. Stress-strain curves of TI, TII and TIII, inspired by Lefeuvre et al. [67], b. Scenario proposed by Placet et al. to explain the TIII complex tensile behaviour of hemp fibres, adapted from [117] 


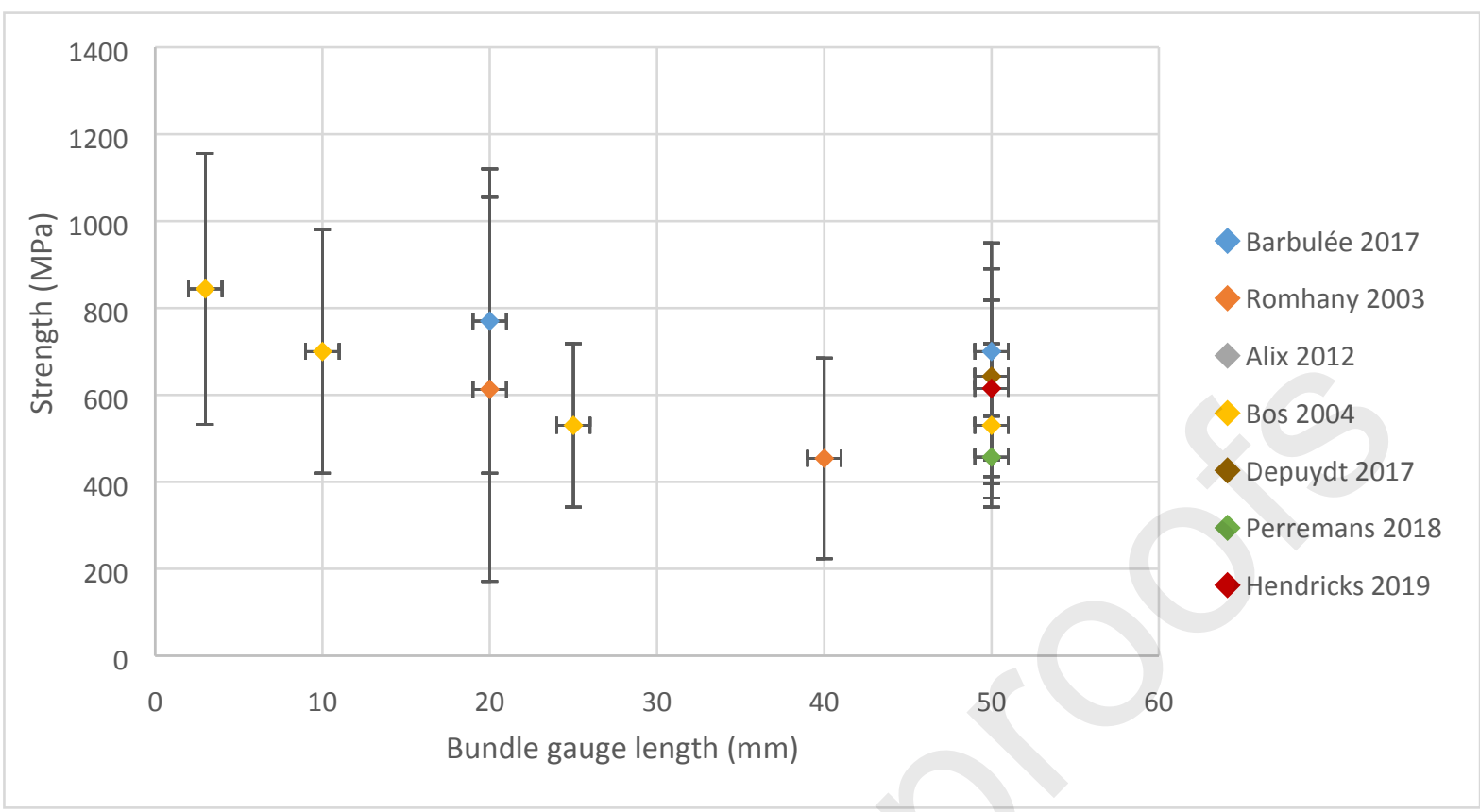

Figure 13: Flax bundle strength as a function of the gauge length, from [131, 174, 181, 209211] 


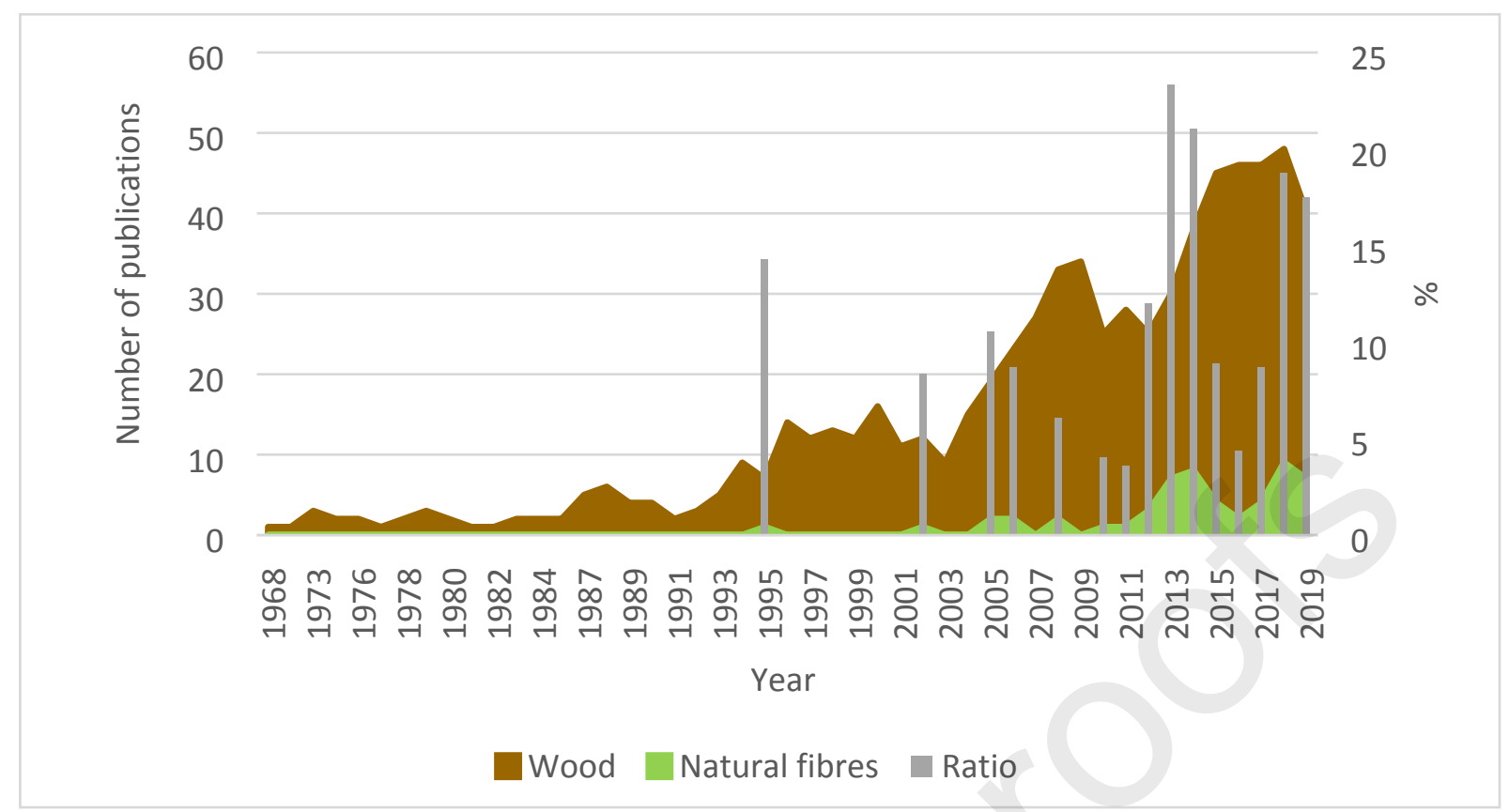

Figure 14: Publication metrics in the study of wood and plant fibres modelling as a function of the year (left) and ratio between the plant fibres and wood (right) (source: Web of Science,

2020) 


\section{Model:}

- Elasticity, viscosity, plasticity etc...

- Type of study: quasi-static, dynamic

\section{Boundary conditions:}

Tensile testing, compression etc

\section{Material properties:}

- Elasticity, viscosity, plasticity etc...

- Dimensions

- Symmetries

- Sensitivity to water, temperature,

- Geometry:

CAO / 2D microscopy/3D X-ray tomography

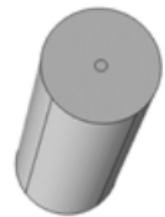

\section{Problem classification}

Idealisation

Mathematical model

Discretisation

\section{FE model}

Improve

Solve equations

Output:

Stress / strain field

Convergence? No

Correctness?

Yes

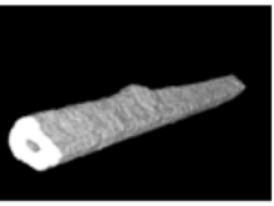

Post-processing

Figure 15: FEA principle applied to plant fibres 


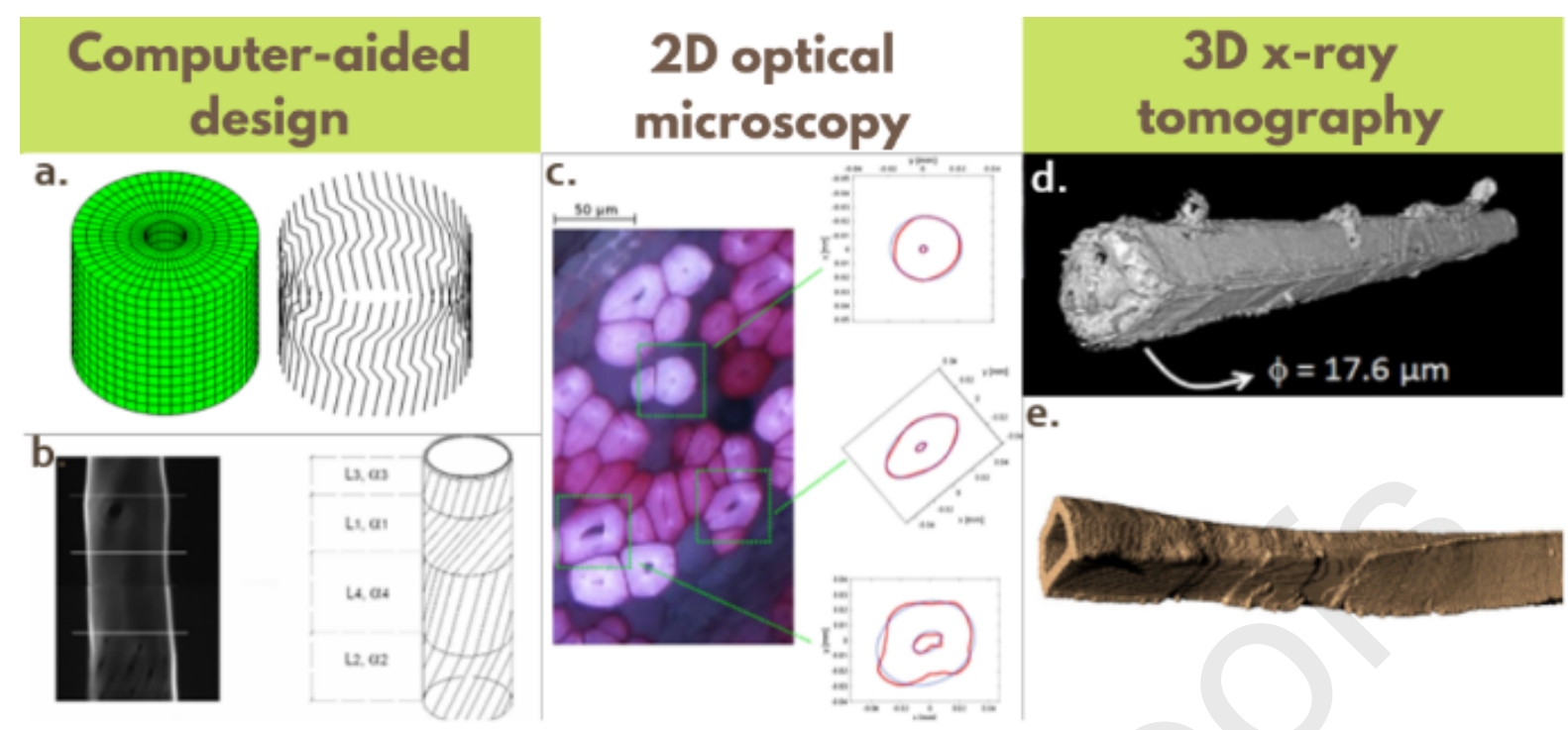

Figure 16: Fibre geometries based on experimental work: a. hemicellulose (left) and dislocations in embedded cellulose (right) with permission of [146], b. earlywood fibre (left) and corresponding model geometry, with heterogeneities replaced by MFA non-uniformities [198], c. morphology reconstruction of hemp fibres from optical images, with permission of [193], $d$. hemp fibre reconstructed from X-ray microtomography scans reprinted from [110], e. wood fibre geometry obtained by X-ray microtomography, with permission of [190] 
Table 1: Analytical methods and biochemical composition of flax fibre elements at the mature development stage (unless otherwise specified)

\begin{tabular}{|c|c|c|c|c|c|c|c|c|c|}
\hline Material & Method & $\begin{array}{l}\text { Cellulose } \\
\text { (\%) }\end{array}$ & $\begin{array}{l}\text { Hemicellulose } \\
\text { (\%) }\end{array}$ & $\begin{array}{l}\text { Pectin } \\
\text { (\%) }\end{array}$ & $\begin{array}{l}\text { Lignin } \\
\text { (\%) }\end{array}$ & $\begin{array}{l}\text { Lipid and wax } \\
\text { (\%) }\end{array}$ & $\begin{array}{c}\text { Water } \\
\text { soluble (\%) }\end{array}$ & $\begin{array}{l}\text { Proteins } \\
\text { (\%) }\end{array}$ & Reference \\
\hline Flax bundles & Review of various methods & $60-85$ & $14-20.6$ & $1.8-15$ & $1-3$ & $1-6$ & - & - & [23] \\
\hline $\begin{array}{l}\text { Retted flax } \\
\text { bundles }\end{array}$ & Review of various methods & 71 & $18.6-20.6$ & 2.3 & 2.2 & 1.5 (waxes) & - & - & [60] \\
\hline $\begin{array}{l}\text { Water-retted and } \\
\text { scutched flax } \\
\text { bundles }\end{array}$ & $\begin{array}{l}\text { Successive solvent extractions, } \\
\text { chromatography and NMR } \\
\left(1 \mathrm{H},{ }^{13} \mathrm{C}\right)\end{array}$ & 75.3 & $14.6^{1}$ & 6.5 & - & $\begin{array}{c}3.6 \text { (fatty } \\
\text { substances) }\end{array}$ & - & - & [212] \\
\hline $\begin{array}{l}\text { Dew-retted, } \\
\text { scutched and } \\
\text { carded flax } \\
\text { bundles }\end{array}$ & $\begin{array}{l}\text { Successive solvent extractions } \\
\text { and gravimetric analysis }\end{array}$ & 68.7 & 12.9 & 4 & 4.7 & - & $\begin{array}{c}9.7 \\
\text { (residuals) }\end{array}$ & - & [57] \\
\hline
\end{tabular}

${ }^{1}$ O-acetylation in C-2 and C-3, ratio 0.5 to 0.2 according to extracted fractions. Mostly RG-1 type. 


\begin{tabular}{|c|c|c|c|c|c|c|c|c|c|}
\hline $\begin{array}{l}\text { Retted and } \\
\text { carded flax } \\
\text { bundles }\end{array}$ & $\begin{array}{l}\text { Successive solvent extractions } \\
\text { and gravimetric analysis } \\
\text { coupled with chromatography }\end{array}$ & 87 & 9 & 2 & 2 & - & - & - & [122] \\
\hline Flax bundles & $\begin{array}{l}\text { Successive solvent extractions } \\
\text { and gravimetric analysis } \\
\text { coupled with chromatography }\end{array}$ & 64.1 & 16.7 & 1.8 & 2 & 1.5 & 3.9 & - & [213] \\
\hline Flax bundles & - & 65 & 16 & 3 & 2.5 & 1.5 & - & 3 & {$[61]$} \\
\hline Short fibres & $\begin{array}{c}\text { Gravimetric analysis } \\
\text { - cellulose: Kurschner-Hoffer's } \\
\text { procedure } \\
\text { - lignin: Komarov's procedure } \\
\text { - pectin: calcium pectate } \\
\text { procedure }\end{array}$ & 71.1 & 14.8 & 1.6 & 5.2 & 1.5 & - & - & [214] \\
\hline $\begin{array}{l}\text { Dew-retted, } \\
\text { scutched and } \\
\text { hackled bundles }\end{array}$ & $\begin{array}{c}\text { Solvent extraction and } \\
\text { chromatography }\end{array}$ & - & \multicolumn{2}{|c|}{13 to 14} & - & - & - & - & [31] \\
\hline $\begin{array}{l}\text { Oleaginous }(\mathrm{O}) \\
\text { and textile }(\mathrm{T}) \\
\text { individual fibres }\end{array}$ & $\begin{array}{l}\text { Solvent extraction followed by } \\
\text { colorimetric technics }\end{array}$ & $\begin{array}{c}\text { T: } 84-86 \\
\text { O: } 76-84 \\
\text { (\% sugars) }\end{array}$ & \multicolumn{2}{|c|}{$\begin{array}{l}\text { T: } 14-16 \\
\text { O: } 16-24 \\
\text { (\% sugars) }\end{array}$} & - & - & - & - & [13] \\
\hline $\begin{array}{c}\text { Bleached } \\
\text { individual flax } \\
\text { fibres }\end{array}$ & $\begin{array}{c}\text { Gravimetric analysis: } \\
\text { - cellulose, hemicellulose: Van } \\
\text { Soest's extraction } \\
\text { - lignin: acid detergent } \\
\text { method } \\
\text { - pectin: Doree's method }\end{array}$ & 88.8 & 3.8 & 0.96 & 1.4 & 1.2 (wax) & - & - & [215] \\
\hline
\end{tabular}




\begin{tabular}{|c|c|c|c|c|c|c|c|c|c|}
\hline $\begin{array}{l}\text { Decorticated or } \\
\text { rolled oleaginous } \\
\text { flax bundles }\end{array}$ & $\begin{array}{c}\text { Sequential degradation } \\
\text { (Soutar's method) and } \\
\text { gravimetric analysis }\end{array}$ & $51.6-52.5$ & $13.1-13.8$ & $\begin{array}{c}17.8- \\
20.5\end{array}$ & $2-2.1$ & $1.7-1.9$ & $9-9.31$ & - & [64] \\
\hline $\begin{array}{l}\text { Depectinased } \\
\text { unitary fibres }\end{array}$ & $\begin{array}{l}\text { Solvent extraction and } \\
\text { gravimetric analysis }\end{array}$ & - & - & - & - & & - & $\begin{array}{c}0.1- \\
0.4 \%^{2}\end{array}$ & [216] \\
\hline $\begin{array}{l}\text { Retted, scutched } \\
\text { and hackled flax } \\
\text { bundles }\end{array}$ & $\begin{array}{c}{ }^{13} \mathrm{C} \text { NMR, colorimetric (acetyl } \\
\text { bromide method, } \mathrm{AB} \text { ) or } \\
\text { gravimetric analysis (Van } \\
\text { Soest, VS) }\end{array}$ & - & - & - & $\begin{array}{l}\text { NMR: } \\
0.9 ; \\
\text { VS: } 3.2 \\
\text { AB: } 2.4\end{array}$ & - & - & - & [58] \\
\hline $\begin{array}{l}\text { Enzymatically- } \\
\text { retted and } \\
\text { manually } \\
\text { separated flax } \\
\text { fibres }\end{array}$ & Chromatography & $58.5 \pm 3.3$ & 8 & & - & $\begin{array}{l}0.5 \text { (waxes) + } \\
0.27 \text { cutin }\end{array}$ & - & - & [217] \\
\hline $\begin{array}{l}\text { Unretted flax } \\
\text { bundles }\end{array}$ & $\begin{array}{c}\text { Solvent extraction, } \\
\text { chromatography and }{ }^{13} \mathrm{C} \text { NMR }\end{array}$ & - & - & - & $\begin{array}{c}2.6 \\
\text { (flavono } \\
\text { ids) }\end{array}$ & - & - & - & [218] \\
\hline $\begin{array}{c}\text { Dew-retted, } \\
\text { scutched and } \\
\text { hackled bundles }\end{array}$ & $\begin{array}{c}\text { Neutral sugars: } \\
\text { chromatography } \\
\text { Acid sugars: } \mathrm{m}- \\
\text { hydroxybiphenyl method }\end{array}$ & $72 \pm 1.5$ & $11 \pm$ & & - & - & - & - & [219] \\
\hline
\end{tabular}

2 structural proteins AGP, HRP 


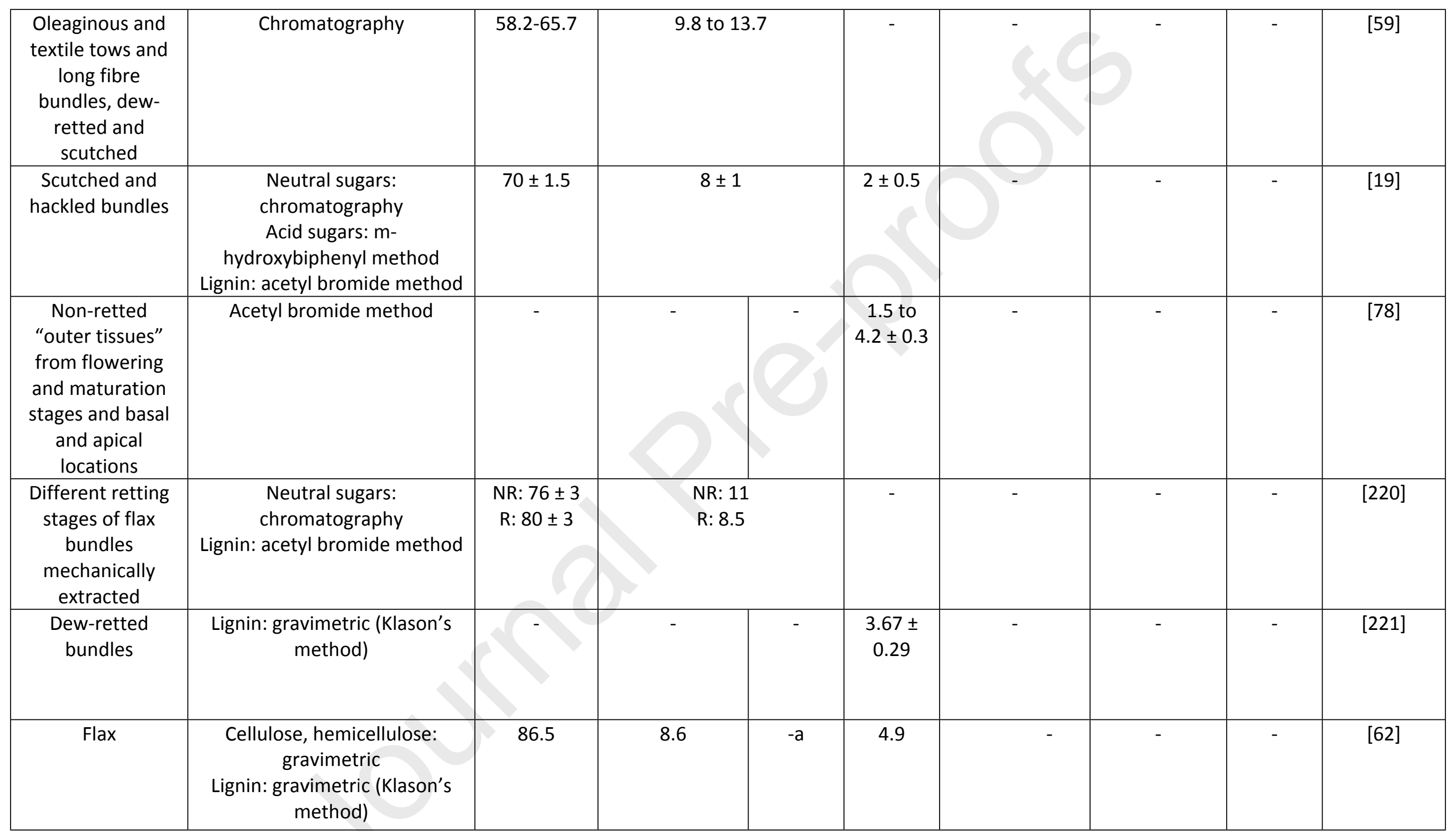




\begin{tabular}{|c|c|c|c|c|c|c|c|c|c|}
\hline $\begin{array}{l}\text { Non-retted (NR) } \\
\text { and dew-retted } \\
\text { (DR) manually } \\
\text { extracted bundles }\end{array}$ & $\begin{array}{l}\text { Cellulose, hemicellulose, } \\
\text { lignin: gravimetric } \\
\text { Pectin: spectroscopic }\end{array}$ & $\begin{array}{l}\text { NR: } 64 \pm 2 \\
\text { DR: } 72 \pm 2\end{array}$ & $\begin{array}{l}\text { NR: } 13.3 \pm 1 \\
\text { DR: } 9.7 \pm 0.4\end{array}$ & $\begin{array}{c}\text { NR : } 6.1 \\
\quad \pm 0.4 \\
\text { DR }: 4.0 \\
\pm 0.1\end{array}$ & $\begin{array}{c}\text { NR }: 4.9 \\
\quad \pm 1.2 \\
\text { DR }: 3.8 \\
\pm 0.1\end{array}$ & - & - & - & [222] \\
\hline $\begin{array}{l}\text { Quasi-UD flax } \\
\text { tape }\end{array}$ & $\begin{array}{l}\text { Gravimetric analysis (Van } \\
\text { Soest's method) }\end{array}$ & - & 4 & - & - & & - & - & {$[223]$} \\
\hline $\begin{array}{l}\text { Refined industrial } \\
\text { flax stem fibres }\end{array}$ & Gravimetric analysis & 64.8 & 15.7 & - & 3.9 & - & 6.2 & - & [65] \\
\hline Flax fibres & $\begin{array}{c}\text { Gravimetric analysis (TAPPI } \\
\text { standards) }\end{array}$ & $66.3 \pm 3.5$ & $18.8 \pm 2.7$ & - & $2.2 \pm 0.1$ & - & $\begin{array}{c}2.6 \pm 0.2 \\
\text { (extractives) }\end{array}$ & - & [63] \\
\hline $\begin{array}{l}\text { Non-retted (NR) } \\
\text { and dew-retted } \\
\text { (DR) manually } \\
\text { extracted bundles }\end{array}$ & Chromatography & $\begin{array}{c}\text { NR: } 43.4 \pm \\
1.8 \\
\text { DR: } 64.9 \pm \\
3.9\end{array}$ & $\begin{array}{l}\text { NR: } 10.6 \\
\text { DR: } 9.5\end{array}$ & - & $\begin{array}{c}\text { NR: } 0.7 \\
\pm 0.2 \\
\text { DR: } \\
\text { trace } \\
\text { (phenoli } \\
\text { cs) }\end{array}$ & - & - & - & [48] \\
\hline $\begin{array}{l}\text { Water-retted, } \\
\text { scutched and } \\
\text { hackled bundles }\end{array}$ & $\begin{array}{l}\text { Solvent extraction and } \\
\text { gravimetric analysis }\end{array}$ & 79.7 & - & - & 8.7 & 1.4 (wax) & - & - & [224] \\
\hline $\begin{array}{l}\text { Oleaginous }(\mathrm{O}) \\
\text { and textile }(\mathrm{T}) \\
\text { hand- } \\
\text { decorticated } \\
\text { bundles }\end{array}$ & Chromatography & $\gamma$ & - & - & $\begin{array}{c}\text { O: } 2.1 \\
\text { T: } 0.5 \\
\text { (aromati } \\
\text { cs) }\end{array}$ & $\begin{array}{l}\text { O: } 2.8 \\
\text { T: } 1.3 \\
\text { (wax) }\end{array}$ & - & - & [49] \\
\hline
\end{tabular}




\begin{tabular}{|c|c|c|c|c|c|c|c|c|}
\hline $\begin{array}{c}\text { Dew-retted and } \\
\text { "processed" } \\
\text { bundles }\end{array}$ & $\begin{array}{c}\text { Cellulose: colorimetric } \\
\text { (anthrone reagent) } \\
\text { Lignin: acetyl bromide method } \\
\text { Pectin: m-hydroxybiphenyl } \\
\text { method }\end{array}$ & $64.1 \pm 0.9$ & - & $3.7 \pm 0.3$ & $2.7 \pm 0.1$ & - & - \\
\hline Flax & Van Soest and Wine method & 79 & 11 & - & 3 & 7 (minerals, proteins, pectins, tannins) & {$[225]$} \\
\hline
\end{tabular}


Table 2: Estimation of the biochemical components in different cell-wall layers of flax, based on estimated layer widths, and average values of biochemical composition from the literature review of Table ${ }^{(1)}$

\begin{tabular}{|c|c|c|c|c|c|c|}
\hline & $\begin{array}{c}\text { Layer } \\
\text { width } \\
(\mu \mathrm{m})\end{array}$ & $\begin{array}{c}\text { Relative } \\
\text { layer } \\
\text { width (\%) }\end{array}$ & $\begin{array}{c}\text { Cellulose } \\
(\%)\end{array}$ & $\begin{array}{c}\text { NCP (hemicellulose, } \\
\text { pectin, betaglucan) } \\
(\%)\end{array}$ & Lignin (\%) & $\begin{array}{c}\text { Other (wax, } \\
\text { proteins, minerals, } \\
\text { phenolics...) (\%) }\end{array}$ \\
\hline $\begin{array}{c}\text { Middle } \\
\text { lamella }\end{array}$ & 0.4 & 5 & 0 & 58 & 38 & 4 \\
\hline $\begin{array}{c}\text { Primary } \\
\text { cell wall }\end{array}$ & 0.2 & 2.5 & 10 & 50 & 35 & 5 \\
\hline $\begin{array}{c}\text { Secondary } \\
\text { cell wall }\end{array}$ & 7.4 & 92.5 & 78 & 12 & 1 & 9 \\
\hline Total & 8 & 100 & 72.4 & 15.3 & 3.7 & 8.7 \\
\hline $\begin{array}{c}\text { Average } \\
\text { (Table) }\end{array}$ & - & - & $71.7^{(1)}$ & $14.6^{(1)}$ & $3.2^{(1)}$ & 10.2 \\
\hline $\begin{array}{c}\text { Standard } \\
\text { deviation }\end{array}$ & - & - & $9.5^{(1)}$ & $6.3^{(1)}$ & $1.6^{(1)}$ & - \\
\hline
\end{tabular}


Table 3: Synthesis of models including defects

\begin{tabular}{|c|c|c|c|c|c|c|}
\hline Authors & $\begin{array}{l}\text { Type of } \\
\text { fibres }\end{array}$ & Behaviour & $\begin{array}{l}\text { Type of } \\
\text { solution }\end{array}$ & Parameters & Geometry & Scale \\
\hline $\begin{array}{l}\text { Trivaudey } \\
\text { et al. [145] }\end{array}$ & Hemp & Viscoelastic & FEA & $\begin{array}{l}\text { MFA and cellulose } \\
\text { crystallinity, } \\
\text { dislocations }\end{array}$ & $\begin{array}{l}\text { Monolayer thick- } \\
\text { walled cylinder }\end{array}$ & Unitary fibre \\
\hline $\begin{array}{l}\text { Nilsson et } \\
\text { al. [146] }\end{array}$ & $\begin{array}{l}\text { Flax and } \\
\text { hemp }\end{array}$ & $\begin{array}{l}\text { Elastic cellulose } \\
\text { Elastic-plastic } \\
\text { hemicellulose }\end{array}$ & FEA & $\begin{array}{l}\text { Dislocations, elastic- } \\
\text { plastic constitutive law }\end{array}$ & Monolayer tube & Unitary fibre \\
\hline $\begin{array}{c}\text { Deng et al. } \\
{[147]}\end{array}$ & Wood & Elastic, damage & $\begin{array}{l}\text { Molecular } \\
\text { dynamics }\end{array}$ & $\begin{array}{l}\text { MFA, } \\
\text { Water }\end{array}$ & $\begin{array}{l}\text { Parallel cellulose } \\
\text { microfibrils and } \\
\text { hemicellulose } \\
\text { chains }\end{array}$ & Cell wall layer \\
\hline $\begin{array}{c}\text { Chen et al. } \\
{[148]}\end{array}$ & $\begin{array}{l}\text { Cellulose } \\
\mathrm{I}_{\alpha} \text { and } \mathrm{I}_{\beta}\end{array}$ & Elastic & $\begin{array}{l}\text { Molecular } \\
\text { dynamics }\end{array}$ & Crystal size & $\begin{array}{c}5 \times 8 \text { cellulose } \\
\text { chain }\end{array}$ & $\begin{array}{l}\text { Cellulose } \\
\text { microfibril }\end{array}$ \\
\hline $\begin{array}{l}\text { Khodayari } \\
\text { et al. [149] }\end{array}$ & $\begin{array}{c}\text { Cellulose } \\
\mathrm{I}_{\beta}\end{array}$ & Elastic & $\begin{array}{l}\text { Molecular } \\
\text { dynamics }\end{array}$ & $\begin{array}{l}\text { Dislocations: dihedral } \\
\text { angles, hydrogen } \\
\text { bonds; water }\end{array}$ & $\begin{array}{c}6 \times 6 \text { cellulose } \\
\text { chain }\end{array}$ & $\begin{array}{l}\text { Cellulose } \\
\text { microfibril }\end{array}$ \\
\hline $\begin{array}{l}\text { Khodayari } \\
\text { et al. [150] }\end{array}$ & $\begin{array}{c}\text { Cellulose } \\
\qquad \mathrm{I}_{\beta}\end{array}$ & Elastic & $\begin{array}{l}\text { Molecular } \\
\text { dynamics }\end{array}$ & $\begin{array}{l}\text { Dislocations of various } \\
\text { lengths, temperature }\end{array}$ & $\begin{array}{c}6 \times 6 \text { cellulose } \\
\text { chains } \\
\text { Cleaved model }\end{array}$ & $\begin{array}{l}\text { Cellulose } \\
\text { microfibril }\end{array}$ \\
\hline $\begin{array}{l}\text { Sliseris et } \\
\text { al. [151] }\end{array}$ & Flax & $\begin{array}{c}\text { Damage } \\
\text { Non-linear } \\
\text { plasticity model }\end{array}$ & FEA & $\begin{array}{l}\text { Dislocations, fibre } \\
\text { length-to-diameter } \\
\text { ratios, fibre } \\
\text { orientations }\end{array}$ & $\begin{array}{c}\text { Monolayer } \\
\text { cylindrical tubes } \\
\text { embedded in a } \\
\text { matrix }\end{array}$ & Composite \\
\hline
\end{tabular}


Table 4: Multiscale mechanical characterization of plant fibres

\begin{tabular}{|l|l|l|l|l|}
\hline \multicolumn{1}{|c|}{ Type of test } & Testing scale & $\begin{array}{l}\text { Information } \\
\text { scale }\end{array}$ & \multicolumn{1}{|c|}{ Type of information } & Reference \\
\hline $\begin{array}{l}\text { Impregnated fibre } \\
\text { bundle test (IFBT) }\end{array}$ & Composite & Bundle & Tensile and compressive properties & {$[169,172]$} \\
\hline $\begin{array}{l}\text { Three-point bending } \\
\text { test }\end{array}$ & Stem & Fibre & Tensile properties & {$[157]$} \\
\hline Tensile testing & Fibre or bundle & Fibre or bundle & Tensile properties & $\begin{array}{l}{[37,38,67,90,111,} \\
154,157,174]\end{array}$ \\
\hline Elastic loop test & Fibre & Fibre & Compressive properties & {$[132]$} \\
\hline $\begin{array}{l}\text { Tensile testing of } \\
\text { notched specimens }\end{array}$ & Fibre or bundle & Fibre or bundle & Rupture behaviour & {$[111]$} \\
\hline Creep/recovery tests & Fibre or bundle & Fibre or bundle & Viscoelastic properties & {$[158,159]$} \\
\hline $\begin{array}{l}\text { Nano-indentation } \\
\text { and AFM }\end{array}$ & Cell wall & Cell wall & $\begin{array}{l}\text { Transverse and longitudinal } \\
\text { modulus }\end{array}$ & {$[23,227]$} \\
\hline
\end{tabular}


Table 5: Tensile properties of flax unitary fibres, unspecified development stage and retting process

\begin{tabular}{|c|c|c|c|c|c|}
\hline $\begin{array}{c}\text { Mode of } \\
\text { extraction }\end{array}$ & $\begin{array}{c}\text { Standards and testing } \\
\text { parameters }\end{array}$ & $\begin{array}{c}\text { Young's modulus } \\
\text { (GPa) }\end{array}$ & $\begin{array}{c}\text { Tensile strength } \\
\text { (MPa) }\end{array}$ & $\begin{array}{c}\text { Failure strain } \\
(\%)\end{array}$ & Reference \\
\hline $\begin{array}{l}\text { Standard } \\
\text { and manual } \\
\text { extraction }\end{array}$ & $\begin{array}{l}\text { Gauge length: } 3 \mathrm{~mm} \text {, } \\
\text { strain rate: } 0.005 \mathrm{~s}^{-1}\end{array}$ & - & 1500-1800 & & [132] \\
\hline- & $\begin{array}{c}\text { NF T 25-704 } \\
\text { Gauge length : } 10 \mathrm{~mm} \text {, } \\
\text { speed : } 1 \mathrm{~mm} / \mathrm{min}\end{array}$ & $54.08 \pm 15.12$ & $1339 \pm 486$ & $3.27 \pm 0.84$ & {$[140,154]$} \\
\hline $\begin{array}{l}\text { Manual } \\
\text { extraction }\end{array}$ & $\begin{array}{c}\text { XP T 25-501-2 } \\
\text { Gauge length : } 10 \mathrm{~mm} \text {, } \\
\text { speed : } 1 \mathrm{~mm} / \mathrm{min}\end{array}$ & $\begin{array}{c}50.1 \pm 27.2 \text { to } 68.2 \\
\pm 35.8\end{array}$ & 854 to 1335 & 1.8 to 2.2 & [67] \\
\hline - & $\begin{array}{c}\text { NF T } 25-704 \\
\text { Gauge length: } 10 \mathrm{~mm} \text {, } \\
\text { speed : } 1 \mathrm{~mm} / \mathrm{min}\end{array}$ & $68.2 \pm 35.8$ & $1454 \pm 835$ & $2.3 \pm 0.6$ & [53] \\
\hline- & $\begin{array}{c}\text { NF T 25-704 } \\
\text { Gauge length: } 10 \mathrm{~mm} \text {, } \\
\text { speed : } 1 \mathrm{~mm} / \mathrm{min}\end{array}$ & $55.5 \pm 20.9$ & $899 \pm 461$ & $1.7 \pm 0.6$ & [228] \\
\hline $\begin{array}{l}\text { Manual } \\
\text { extraction }\end{array}$ & $\begin{array}{c}\text { NF T 25-704 } \\
\text { Gauge length: } 10 \mathrm{~mm} \text {, } \\
\text { speed : } 1 \mathrm{~mm} / \mathrm{min}\end{array}$ & 54.1 to 68.2 & 865 to 1454 & 1.8 to 3.3 & [13] \\
\hline $\begin{array}{l}\text { Manual } \\
\text { extraction }\end{array}$ & $\begin{array}{c}\text { NF T 25-501-3 } \\
\text { Gauge length: } 10 \mathrm{~mm} \text {, } \\
\text { speed: } 1 \mathrm{~mm} / \mathrm{min}\end{array}$ & $\begin{array}{c}46.9 \pm 15.7 \text { to } 51.2 \\
\pm 18.1\end{array}$ & $\begin{array}{c}850 \pm 359 \text { to } 991 \\
\pm 399\end{array}$ & $\begin{array}{c}2.14 \pm 0.82 \\
\text { to } 2.42 \pm \\
0.99\end{array}$ & [229] \\
\hline- & XP T 25-501-2 & $52.5 \pm 8.6$ & $945 \pm 200$ & $2.07 \pm 0.45$ & [163] \\
\hline
\end{tabular}




\begin{tabular}{|c|c|c|c|c|c|}
\hline & $\begin{array}{c}\text { Gauge length: } 10 \mathrm{~mm}, \\
\text { speed: } 1 \mathrm{~mm} / \mathrm{min}\end{array}$ & & & & \\
\hline- & NF T 25-704 & $51.28 \pm 12.02$ to & $1317 \pm 529$ to \\
& $\begin{array}{c}\text { Gauge length: } 10 \mathrm{~mm}, \\
\text { speed: } 1 \mathrm{~mm} / \mathrm{min}\end{array}$ & $\begin{array}{c}2.93 \pm 13.65 \\
\text { to } 3.34 \pm 0.74 \\
0.71\end{array}$ & {$[80]$} \\
\hline- & $\begin{array}{l}\text { XP T } 25-501-2 \\
\text { Gauge length: } 10 \mathrm{~mm}, \\
\text { speed: } 1 \mathrm{~mm} / \mathrm{min}\end{array}$ & $57.5 \pm 0.3$ & $1034 \pm 6$ & $2.0 \pm 0.1$ & {$[162]$} \\
& & & & \\
\hline
\end{tabular}


Table 6: Synthesis of models investigating plant fibres

\begin{tabular}{|c|c|c|c|c|c|c|}
\hline Authors & $\begin{array}{c}\text { Type of } \\
\text { fibres }\end{array}$ & Behaviour & $\begin{array}{c}\text { Type of } \\
\text { solution }\end{array}$ & Parameters & Geometry & Scale \\
\hline $\begin{array}{c}\text { Bergander } \\
\text { et al. [188] }\end{array}$ & Wood & Elastic & Analytical & $\begin{array}{c}\text { MFA and thickness } \\
\text { of walls }\end{array}$ & Laminated composite & Cell wall \\
\hline $\begin{array}{c}\text { Neagu et } \\
\text { al. [189] }\end{array}$ & Wood & $\begin{array}{c}\text { Elastic/ } \\
\text { failure } \\
\text { criterion }\end{array}$ & Analytical & RH & $\begin{array}{c}\text { Multilayer cylindrical } \\
\text { tube }\end{array}$ & Unitary fibre \\
\hline $\begin{array}{c}\text { Joffre et al. } \\
\text { [230] }\end{array}$ & Wood & Hygro-elastic & FEA & RH & $\begin{array}{c}\text { 3D reconstruction by X- } \\
\text { ray micro-tomography }\end{array}$ & Unitary fibre \\
\hline $\begin{array}{c}\text { Saavedra } \\
\text { Flores et } \\
\text { al. [191] }\end{array}$ & Wood & Elastic & FEA & $\begin{array}{c}\text { MFA, cellulose } \\
\text { content, cell wall } \\
\text { thickness and } \\
\text { porosity }\end{array}$ & $\begin{array}{c}\text { Homogeneised } \\
\text { cylindrical tube or } \\
\text { parallelepiped }\end{array}$ & $\begin{array}{c}\text { Multiscale } \\
\text { (microfibril to } \\
\text { bulk wood) }\end{array}$ \\
\hline $\begin{array}{c}\text { Gassan et } \\
\text { al. [192] }\end{array}$ & $\begin{array}{c}\text { Plant } \\
\text { fibres }\end{array}$ & Elastic & Analytical \\
and FEA & $\begin{array}{c}\text { MFA, cellulose } \\
\text { content, elliptical } \\
\text { geometry and } \\
\text { lumen }\end{array}$ & $\begin{array}{c}\text { Laminated structure or } \\
\text { thick elliptical tube }\end{array}$ & Unitary fibre \\
\hline $\begin{array}{c}\text { Placet et } \\
\text { al. [168] }\end{array}$ & Hemp & Elastic & Analytical & $\begin{array}{c}\text { Diameter, type of } \\
\text { rotation allowed }\end{array}$ & $\begin{array}{c}\text { Multilayer cylindrical } \\
\text { tube }\end{array}$ & Unitary fibre \\
\hline $\begin{array}{c}\text { Del Masto } \\
\text { et al. [193] }\end{array}$ & Hemp & Viscoelastic & FEA & $\begin{array}{c}\text { Degree of } \\
\text { ellipticity, MFA }\end{array}$ & $\begin{array}{c}\text { Monolayer elliptical } \\
\text { tube (outline from } \\
\text { microscopy images and } \\
\text { simplified geometry) }\end{array}$ & Unitary fibre \\
\hline
\end{tabular}




\begin{tabular}{|c|c|c|c|c|c|c|}
\hline $\begin{array}{l}\text { Del Masto } \\
\text { et al. [194] }\end{array}$ & $\begin{array}{l}\text { Hemp and } \\
\quad \text { flax }\end{array}$ & $\begin{array}{l}\text { Viscoelastic/ } \\
\text { failure } \\
\text { criterion }\end{array}$ & FEA & $\begin{array}{l}26 \text { parameters } \\
\text { (ultrastructural, } \\
\text { morphological...) }\end{array}$ & $\begin{array}{c}\text { Monolayer elliptical } \\
\text { tube }\end{array}$ & Unitary fibre \\
\hline $\begin{array}{l}\text { Thuault et } \\
\text { al. [195] }\end{array}$ & Flax & Elastic & FEA & $\begin{array}{l}\text { MFA, cell wall } \\
\text { width and } \\
\text { composition }\end{array}$ & $\begin{array}{l}\text { Multilayer cylindrical } \\
\text { tube (S2 with } 3 \\
\text { sublayers) }\end{array}$ & Unitary fibre \\
\hline $\begin{array}{l}\text { Beakou et } \\
\text { al. [197] }\end{array}$ & Flax & $\begin{array}{c}\text { Elastic } \\
\text { Bilinear } \\
\text { cohesive } \\
\text { zone model }\end{array}$ & FEA & $\begin{array}{l}\text { Middle lamella and } \\
\text { gauge length }\end{array}$ & $\begin{array}{l}\text { Hexagonal cross-section } \\
\text { of fibres without lumen, } \\
\text { staggered arrangement } \\
\text { of fibres into a bundle }\end{array}$ & Bundle \\
\hline $\begin{array}{l}\text { Sedhigi- } \\
\text { Gilani et al. } \\
{[198,199]}\end{array}$ & Wood & $\begin{array}{c}\text { Elasto-plastic } \\
\text { for } \\
\text { amorphous } \\
\text { polymers } \\
\text { Damage }\end{array}$ & Analytical & MFA & $\begin{array}{l}\text { Monolayer thick-walled } \\
\text { cylindrical tube }\end{array}$ & Unitary fibre \\
\hline $\begin{array}{l}\text { Beaugrand } \\
\text { et al. [111] }\end{array}$ & Hemp & $\begin{array}{l}\text { Linear elastic } \\
\text { model / } \\
\text { crack } \\
\text { propagation }\end{array}$ & FEA & Shape of the notch & $\begin{array}{l}\text { 3D reconstruction based } \\
\text { on optical microscopy } \\
\text { and tomography }\end{array}$ & $\begin{array}{c}\text { Unitary fibres } \\
\text { and bundles }\end{array}$ \\
\hline $\begin{array}{l}\text { Guessasma } \\
\text { et al. [110] }\end{array}$ & Hemp & Damage & FEA & $\begin{array}{l}\text { Shape of the notch } \\
\text { and stress criteria }\end{array}$ & $\begin{array}{l}3 \mathrm{D} \text { reconstruction by } \mathrm{X}- \\
\text { ray micro-tomography }\end{array}$ & $\begin{array}{l}\text { Unitary fibres } \\
\text { and bundles }\end{array}$ \\
\hline $\begin{array}{l}\text { Khodayari } \\
\text { et al. [200] }\end{array}$ & $\begin{array}{l}\text { Cellulose } \\
I_{\beta} \text { and } \\
\text { hemicellul } \\
\text { ose }\end{array}$ & $\begin{array}{l}\text { Elastic, } \\
\text { damage }\end{array}$ & $\begin{array}{l}\text { Molecular } \\
\text { dynamics }\end{array}$ & $\begin{array}{l}\text { Hemicellulose type, } \\
\text { water }\end{array}$ & $\begin{array}{l}6 \times 6 \text { cellulose chains, } \\
5 \text { hemicellulose types }\end{array}$ & $\begin{array}{l}\text { Cellulose and } \\
\text { hemicellulose }\end{array}$ \\
\hline
\end{tabular}


